\title{
Thyroid dysfunction and depression in the postpartum period : incidence, prevalence and course
}

Citation for published version (APA):

Pop, V. J. M. (1991). Thyroid dysfunction and depression in the postpartum period : incidence, prevalence and course. [Doctoral Thesis, Maastricht University]. Rijksuniversiteit Limburg. https://doi.org/10.26481/dis.19910913vp

Document status and date:

Published: 01/01/1991

DOI:

10.26481/dis.19910913vp

Document Version:

Publisher's PDF, also known as Version of record

\section{Please check the document version of this publication:}

- A submitted manuscript is the version of the article upon submission and before peer-review. There can be important differences between the submitted version and the official published version of record.

People interested in the research are advised to contact the author for the final version of the publication, or visit the DOI to the publisher's website.

- The final author version and the galley proof are versions of the publication after peer review.

- The final published version features the final layout of the paper including the volume, issue and page numbers.

Link to publication

\footnotetext{
General rights rights.

- You may freely distribute the URL identifying the publication in the public portal. please follow below link for the End User Agreement:

www.umlib.nl/taverne-license

Take down policy

If you believe that this document breaches copyright please contact us at:

repository@maastrichtuniversity.nl

providing details and we will investigate your claim.
}

Copyright and moral rights for the publications made accessible in the public portal are retained by the authors and/or other copyright owners and it is a condition of accessing publications that users recognise and abide by the legal requirements associated with these

- Users may download and print one copy of any publication from the public portal for the purpose of private study or research.

- You may not further distribute the material or use it for any profit-making activity or commercial gain

If the publication is distributed under the terms of Article $25 \mathrm{fa}$ of the Dutch Copyright Act, indicated by the "Taverne" license above, 
THYROID DYSFUNCTION AND DEPRESSION IN THE POSTPARTUM PERIOD 
ISBN 90-9004458-2

Omslag: zwangere vrouw in brons, Tjikkie Kreuger.

Bij de Egyptenarten bond een vrouw die over tijd was een rietje om haar hals: wanneer het rietje na enige weken knapte door een - voor de zwangerschap normale - vergroting van de schildklier, was zij zwanger.

fotografie: Amerens Hedwich

Opmaak en druk: Wibro dissertatiedrukkerij, Helmond

Dit proefschrift kwam mede tot stand dankzij de welwillende medewerking van Organon Nederland (hoofdsponsor), Weverij de Ploeg uit Bergeyk en Jan Louwers. Amersham International verleende medewerking door het ter beschikking stellen van de TSH kits. 


\section{THYROID DYSFUNCTION AND DEPRESSION IN}

\section{THE POSTPARTUM PERIOD}

\section{INCIDENCE, PREVALENCE AND COURSE}

\section{PROEFSCHRIFT}

ter verkrijging van de graad van doctor aan de Rijksuniversiteit Limburg te Maastricht, op gezag van de Rector Magnificus, Prof. Mr. M.J. Cohen, volgens het besluit van het College van Dekanen, in het openbaar te verdedigen op vrijdag, 13 september 1991 om 14.00 uur

door

Victor Jozef Marie Pop

geboren te Bandung in 1955 
Promotores

Co-Promotores
: Prof. Dr. C.A. de Geus Prof. Dr. G.G.M. Essed

: Prof. Dr. D. van der Heide Dr. M.J.M. van Son

Beoordelingscommissie : Prof. Dr. F. Sturmans (voorzitter) Prof. Dr. A.P.W.M. Appels Prof. Dr. J.L.H. Evers Prof. Dr. A.C. Nieuwenhuijzen Kruseman Prof. Dr. J.W. van Ree Dr. ir. H.L. Vader 
Wij verafschuwen alles wat ongeordend, ongelijksoortig, toevallig is en proberen ook in concrete zin - ons te beperken, onszelf grenzen te stellen en ons toe te leggen op mensen en dingen om ons heen. Wij zijn er van overtuigd dat een belangrijke onthulling alleen maar voort kan komen uit een hardnekkig bezig blijven met steeds dezelfde moeilijkheid. Wij hebben niets gemeen met reizigers, experimentators en avonturiers. We weten dat de zekerste - en de snelste - manier om verrast te worden het onverstoorbaar gadeslaan is van steeds dezelfde mensen en objecten. Op een gegeven ogenblik zal het ons voorkomen - wonderlijk genoeg - dat wij hen nog nooit gezien hebben.

vrij naar Cesare Pavese

'Dialoghi con Leucd', 1943. 


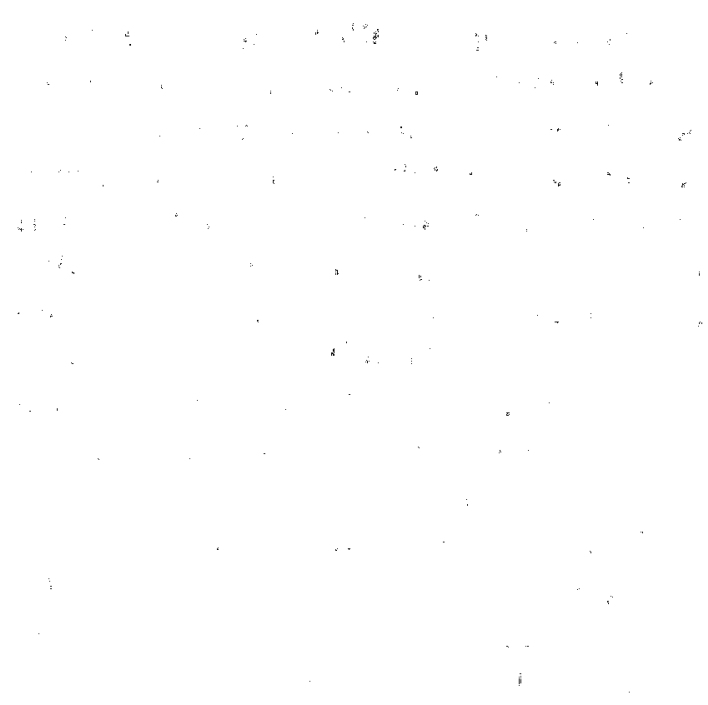




\section{Voorwoord}

Dit proefschrift was zonder de steun van mijn echtgenote Bernadette niet tot stand gekomen. Haar betrokkenheid legde een stevige basis voor het welslagen van dit onderzoek. Maar ook onze 'mannen' Emile, Philippe, Nicolas en Patrick, alias de "vier Daltons", waren een belangrijke steun in de rug: al lego spelend onder, op en achter mijn studeertafel, tekeningen makend op de blaadjes uit het manuscript die vervolgens vol trots werden getoond: het hield mij op de been tijdens het invoeren van de vele gegevens in de computer. En het gejoel van enthousiasme dat dagelijks opsteeg vanuit de keuken, als ik enigszins uitgeblust van eén van mijn visites thuis kwam, gaf nieuwe impulsen om 's avonds menige letter op papier te zetten. Samen met Bernadette ontstond er een teamgeest van: "promoveren, dat doen we toch even samen", wat niet wegneemt dat het volgende gezegde regelmatig van toepassing moet zijn geweest:

"Niets onmenselijks is de wetenschapper vreemd, want hoe groter geest hoe groter beest, dus moeders gaat voor uw kindjes staan, daar komt een promovendus aan ".

Dit onderzoek was eveneens niet mogelijk geweest zonder de stimulans die uitging van Monique Botden en Arnold Romeijnders, mijn collegaewaarnemers. Zij lieten er geen twijfel over bestaan dat - zelfs binnen de kleine waarneemgroep van twee - het welslagen van dit onderzoek een hoge prioriteit had.

Geachte professor de Geus, beste Cees, het geduld en het "luisterend oor", dat je vanaf het eerste moment dat wij elkaar ontmoetten voor mij had, waren gedurende het hele onderzoek van grote waarde. Steeds opnieuw gaf jij blijk van een integere betrokkenheid. Geachte professor Essed, beste Gerard, was het de ijskast onder jouw bureau die de herinnering aan het eerste gesprek dat ik met je had zo positief maakt? Het feit echter dat jij mij regelmatig met een andere voornaam aansprak, was wel een van de grootste drijfveren om tot een "wetenschappelijke prestatie" te komen.

Geachte dr. van Son, beste Maarten, jouw voortdurende rol als 'advokaat van de duivel' heeft mij geleerd op een zorgvuldige wijze te formuleren. Bovendien wees jij bij herhaling op het belang van onderzoek in de psychologie dat wordt gevoed vanuit de eerste-lijns-geneeskunde. 
Geachte professor van der Heide, beste Daan, de vanzelfsprekendheid waarmee jij energie in mijn onderzoek investeerde, bracht mij enerzijds in verlegenheid, anderzijds was het een prikkel om dit onderzoek tot een goed einde te brengen.

Maar wat jullie promotoren gemeenschappelijk hebben, is de manier waaróp jullie mij de afgelopen jaren hebben begeleid. Ik heb voortdurend het gewoel gehad dat de opbouwende kritiek die ik mocht ontvangen, plaatsvond in een sfeer van wederzijds respect..

Vooral voor dit laatste ben ik jullie zeer erkentelijk.

De leden van de beoordelingscommissie te Maastricht dank ik voor de tijd die zij hebben besteed om het manuscript op zijn wetenschappelijke waarde te toetsen.

Geachte dr. de Rooy, beste Hans, wie had ooit kunnen denken dat een telefonisch intercollegiaal consult in 1981 de eerste steen zou zijn van dit onderzoek? Het enthousiasme waarmee jij te allen tijde bereid was je kennis op het gebied van schildklierziekten aan mij over te dragen was een voorbeeld van ondersteuning vanuit de tweede lijn voor wetenschappelijk onderzoek in de eerste lijn.

Geachte dr. Vader, beste Huib, het ingetogen afgrijzen dat jij uitstraalde wanneer ik jou liet zien hoe goed mijn databestand in elkaar zat, was de uitgelezen manier om mij te leren zo"n bestand maar beter in én keer goed op te zetten. Zo resulteerden de "staccato" bezoekjes, die ik (soms bijna dagelijks) op je kamer aflegde, mede in dit proefschrift.

Geachte drs. Komproe, beste Ivan, waar jij het geduld vandaan haalde om mij te begeleiden in het opzetten van SPSS programma"s is mij nog steeds een raadsel; ik dank je bovendien voor de vriendschappelijke sfeer waarin onze gesprekken plaatsvonden.

Ik ben blij dat ik Ernst Loendersloot heb mogen ontmoeten. Zijn betrokkenheid - zelfs tot vlak voor zijn overlijden - met onderzoek naar postpartale depressie, was een bron van inspiratie.

Dear dr. Othman, I will always be very grateful for your kindness and the time you spent in introducing me to the field of postpartum thyroid dysfunction, saving me at least one year of orientation.

Dear Professor Cox, your enthusiasm and interest for my work were a great stimulation during the period of 'hardtime" in my study.

Dear Professor Hall, the time and interest you spent on that 'strange GP from Holland' and particulary the empathy in your attitude towards 
young researchers, deeply impressed me and motivated me to finish my study.

Ook al kun je als promovendus nog zo enthousiast zijn over je eigen onderwerp, het welslagen is uiteindelijk voor een groot deel afhankelijk van anderen. Zonder iemand tekort te willen doen, noem ik de verloskundigen uit Waalre, Hapert en Veldhoven die het veldwerk praktisch uitvoerbaar maakten. Vooral Hennie Wijnen en Monique van Montfort hebben er toe bijgedragen dat het aantal vrouwen dat deelnam in een bestek van enkele maanden helemaal uit de hand liep. De huisartsen uit Waalre, Hapert, Eersel en Veldhoven dank ik voor de medewerking die zij aan het onderzoek verleenden.

Het St. Joseph Ziekenhuis uit Veldhoven heeft een belangrijke rol vervuld bij het welslagen van dit onderzoek. Hierbij gaat mijn dank uit naar mensen die direkt betrokken waren bij mijn onderzoek, zoals de maatschap gynaecologie; Nelleke Maris die een belangrijke rol speelde tijdens de voorbereidingen van het veldwerk; de klinisch chemici, die menige theepauze 's middags door mijn aanwezigheid verstoord zagen; Gabrielle Ponjee die een welkom klankbord was om frustraties over niet geaccepteerde artikelen of geflopte lezingen te ventileren. Maar ook naar al die "onzichtbare" mensen die een extra steun in de rug waren: de mensen die mij studieruimte ter beschikking stelden, het personeel van de medische bibliotheek en natuurlijk het personeel van het klinisch laboratorium: geen tijd was hen te dol om weer een paar van die verrekte buisjes met bloedmonsters "af te draaien" (was het record niet half drie 's nachts?) en ze vervolgens zorgvuldig op te nemen in het databestand.

Maarten Keunen en Femke Zeijen dank ik voor de vanzelfsprekendheid waarmee zij mij te hulp schoten in de periode dat ik door een ongeval enigszins "gekreukeld" onderzoek moest verrichten. Jan-Kees Quak stond mij - sneller dan het licht - terzijde als (vaak) op cruciale momenten de soft- en hardware mij in de steek lieten.

De vrouwen die deelnamen wil ik bedanken voor hun inzet en betrokkenheid met het onderzoek.

Gay Wylie dank ik tenslotte voor de zorgvuldige wijze waarop zij mijn "engelse" versie van dit proefschrift corrigeerde.

Helaas heeft mijn schoonvader, fietsmaatje en raadsman Frans van Gent, het einde van dit proefschrift niet kunnen meemaken. Ik kon niet vermoeden dat zijn raadgeving welke weg in te slaan in de moeilijke periode die ik doormaakte vlak voor dit onderzoek, een van zijn laatste zou zijn. Ik 
ben dankbaar dat de stelling die ik hem vroeg te maken aan het begin van zijn ziekbed in dit proefschrift is opgenomen: het wachten op het kennis nemen ervan is een stimulans geweest om dit onderzoek tot een goed einde te brengen, de inhoud houdt op een gelouterde wijze de herinnering aan hem levend.

Met dit proefschrift sluit ik een periode van vier jaar af die voor mij een belangrijke betekenis had. En op zo'n moment bekruipt mij een gevoel van "terug naar de bron": mijn ouders, mijn naaste familie.

In mijn situatie ga je ook mijmeren hoe moeder Tilly of hoe mijn broer Marcu dit moment zouden beleven en dan besef je eens te meer dat hun niet-meer-zijn er altijd zal zijn.

Maar tegelijkertijd denk ik aan onderzoek uit de psychologie: de weerslag die het wegvallen van dierbare personen heeft op hen die achter blijven, wordt in belangrijke mate bepaald door het feit of anderen in staat zijn het geven van warmte en geborgenheid over te nemen.

En vader en moeder Virge zijn daar op een bijzondere wijze in geslaagd. Aan hen draag ik dit proefschrift op.

Pop, that's us.

Riethoven, september 1991 
ter nagedachtenis aan mammie en Marcu opgedragen aan vader en moeder Virge 


\section{Preface}

The incidence and prevalence of thyroid dysfunction and depression in the postpartum period has never yet been investigated in The Netherlands.

This thesis presents the results of a prospective study carried out between November 1988 and June 1990 into the prevalence of thyroid dysfunction and depression in the postpartum period.

Part I, the General Introduction, starts with a discussion of the general aspects of depression most relevant to the study (chapter I). In chapter II, l.c. some fundamentals of thyroidology and immunology are presented. In chapter III the most common mood disturbances in the postpartum period are described. Chapter IV contains an overview of the prospective studies on postpartum thyroid dysfunction described in the literature. Chapter V summarizes the most important findings on the relationship between thyroid dysfunction and depression. Chapter VI discusses the relevance of this study and the formulation of the questions in it. Moreover, a theoretical model of the study is presented.

Part II, Methods, contains two chapters describing the variables which were investigated in this study (chapter VII) and the sample of subjects, assessment procedure and demographic characteristics (chapter VIII).

In part III, Results, the results are summarized, beginning with the incidence and prevalence of postpartum thyroid dysfunction (chapter IX), thereafter the incidence and prevalence of postpartum depression (chapter $\mathrm{X}$ ), and the relationship between the two conditions (chapter XI). In chapter XII, the relationship between psycho-social factors and depression in the postpartum period is investigated.

In part IV, General Discussion and Conclusions, the questions posed in the general introduction are evaluated (chapter XIII). Moreover, it contains the general discussion and conclusions and a summary of the findings most relevant to general practice. 


\section{Contents}

\section{Part I. General introduction}

Chapter I : General aspects of depression

1.1 Introduction 3

1.2 Definition of depression 3

1.3 Epidemiology of depressive mood disorders 4

1.4 Assessment of depressive mood disorders 6

1.5 Different theories on depression 7

$\begin{array}{ll}\text { 1.5.1. Predisposition } & 7\end{array}$

1.5.2. Precipitating factors 8

1.5.3. Mechanism of precipitation $\quad 12$

1.6 Treatment of depression 16

Chapter II: The thyroid gland and autoimmune thyroid diseases

$\begin{array}{lll}2.1 & \text { The thyroid } & 19\end{array}$

$\begin{array}{ll}2.1 .1 & \text { Introduction } \\ 2.1 . & 19\end{array}$

2.1.2 Normal physiology of the thyroid gland 19

2.1.3 Assessment of thyroid function 23

2.1.4 Thyroid and pregnancy 24

2.2 The immune system 24

2.2.1 Introduction 25

2.2.2 Cells of the immune system 25

2.3 Autoimmunity and autoimmune thyroid diseases 26

2.4 The autoimmune thyroid diseases (AITD) 27

2.4.1 Hashimoto's thyroiditis 27

2.4.2 Graves" disease (GD) 28

Chapter III : Mood disorders in the postpartum period

3.1 Introduction $\quad 29$

$\begin{array}{ll}3.2 \text { Definitions } & 29\end{array}$

3.3 Onset, prevalence and course of postpartum depression 31 
3.4 Etiological aspects of postpartum depression 34

3.4.1 Predisposition 34

3.4.2 Precipitating factors 34

3.5 Treatment and prevention $\quad 42$

Chapter IV: Postpartum thyroid dysfunction

4.1 Introduction 45

4.2 Prevalence of postpartum thyroid dysfunction 45

4.3 Etiology of postpartum thyroid dysfunction 47

4.3.1 Postpartum thyroiditis $\quad 47$

4.3.2 Postpartum Graves' disease $\quad 48$

4.3.3 Environmental factors $\quad 48$

4.4 Clinical signs and symptoms 49

4.5 Diagnostic tests for postpartum thyroid dysfunction 50

4.6 Pathogenesis of postpartum thyroid dysfunction 51

4.7 Prognosis of postpartum thyroid diseases $\quad 54$

4.8 Management of postpartum thyroid disease 55

Chapter V: Thyroid dysfunction and mood disorders

5.1 Affective disturbances in thyroid disease $\quad 57$

5.2 Thyroid and affective disorders $\quad 58$

5.3 The effect of TRH and thyroid hormones on behaviour 59

5.4 Thyroid dysfunction and depression in the postpartum period

Chapter VI: Relevance of the study and presentation of the questions

6.1 Relevance of the study 61

6.1.1 Postpartum thyroid dysfunction 61

6.1.2 Postpartum depression 64

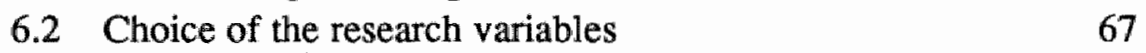

6.3 Presentation of a theoretical model for the study, choice of analysis and presentation of the questions from the study $\quad 69$

6.3.1. Presentation of a model 69

$\begin{array}{ll}\text { 6.3.2. Choice of analysis } & 71\end{array}$

6.3.3. Presentation of the questions from the study 72 


\section{Part II Methods}

Chapter VII: Variables and operationalization

7.1 The central variables

7.1.1 Thyroid dysfunction and parameters of thyroid function

7.1.2 Depression and depressed mood

7.2 Variables related to depression

7.2.1 Social support

7.2.2 Coping behaviour

7.2.3 Life events and depression

7.2.4 Past adversity

7.3 Variables especially related to postpartum depression

7.3.1 The infant temperament

7.3.2 Premenstrual syndrome

7.3.3 Blues

7.3.4 Obstetrical complications

7.3.5 Transition to parenthood

7.3.6 Breastfeeding

7.4 Statistical analysis and matching procedure

Chapter VIII: Description of subjects, assessment procedure, demographic characteristics, and study design

8.1 The sample

8.2 Assessment procedure

8.3 Demographic characteristics

8.4 Design of the study

\section{Part III: Results}

Chapter IX: Incidence, prevallence and course of postpartum thyroid dysfunction

9.1 Incidence and prevalence

9.2 Subclinical postpartum thyroid dysfunction

9.3 Signs and symptoms in women with thyroid dysfunction

9.4 Discussion 
Chapter X: Incidence, prevalence and course of postpartum depression

10.1 Incidence and prevalence of postpartum depression

10.2 The course of postpartum depression

10.3 Characteristics of depressed women according to RDC 10.3.1 Major depression

10.3.2 Minor depression

Chapter XI: The relationship between postpartum depression and postpartum thyroid dysfunction.

11.1 Incidence and prevalence of postpartum depression and thyroid dysfunction

11.2 Nature of depression in women with thyroid dysfunction

11.3 Depression in women with thyröd dysfunction versus euthyroid women

Chapter XII: The correlations between postpartum depression/depressive symptoms and other variables

12.1 Correlations between postpartum depression/depressive symptoms and other variables

12.1.1. Background features

12.1.2. Contributing factors

12.1.3. Predisposition

12.2 Discussion

12.2.1. Background features

12.2.2. Contributing factors

12.2.3. Predisposition 
Part IV: General discussion and conclusions.

Chapter XIII: Evaluation of the questions from the study, general discussion and conclusions

13.1 Evaluation of the questions from the study 143

13.2 General discussion and conclusions 145

$\begin{array}{ll}\text { Summary } & 151\end{array}$

$\begin{array}{ll}\text { References } & 155\end{array}$

$\begin{array}{ll}\text { Summary in Dutch } & 167\end{array}$

$\begin{array}{ll}\text { Appendix } & 171\end{array}$

$\begin{array}{ll}\text { Curriculum vitae } & 177\end{array}$

$\begin{array}{ll}\text { Publications } & 179\end{array}$ 
viii 


\section{Part I}

General Introduction 
2 


\section{Chapter I}

\section{General aspects of depression}

\subsection{Introduction}

Feelings of sadness, unhappiness, disappointment, and agitation, are part of the human condition, experienced by everyone at some point in their lives. It is not surprising that the depressive mood has been labelled the common cold of psychopathology (Gilbert, 1984). Although this comparison suggests a frequent but self-limiting complaint, there are some forms of depression that have rather detrimental effects on human beings. Depression is the cause of the majority of suicide deaths (Kerkhof, 1985). The social life of the depressed individual may also be affected as is shown by the incapability of maintaining satisfying relationships and by disturbed sexuality. Detrimental effects on the social environment of the depressed individual may also be attributable to depression; for instance, the consequences for the partner and the influence on up-growing children in family life. The clinical observation that depressive disorder in either parent is associated with mood disorder in the children has been confirmed by several studies. Moreover, recent studies have shown that the immune system of depressed persons undergoes alterations which increase susceptibility to various infectious diseases (Daruna and Morgan, 1990) and may reduce the life expectancy of patients with cancer (Calabrese et al., 1987, Camara and Danano, 1989).

\subsection{Definition of depression}

It is obvious that feelings of sadness and unhappiness are not identical to 'depression'. The above-mentioned feelings and the affective disorders, or mood disorders or mood disturbances, each refer to a particular state of mood. The expression 'mood' refers to an emotional key-note with a certain consistency - a "Leitmotif". This has to be distinguished from affection or emotion which refers more to a reaction or fits with momentary and short-lasting aspects (van den Hoofdakker et al., 1989a). Depressed mood can be regarded in two ways: depressed mood as a symptom of psychiatric or even physical diseases, and depressed mood as 
a syndrome with depressive or manic symptoms as the central features. When depressed mood is conceived as a syndrome, it concerns a syndrome which consists of a whole series of complaints or signs, not only with emotional aspects but also with cognitive, behavioural and somatic aspects. These aspects refer to complaints or behaviour which constitute the symptoms of a mood disorder.

It is generally accepted that the central features of a depressive mood disorder are feelings of sadness, desperation, and hopelessness and pessimistic thinking. But also lack of enjoyment, loss of concentration, reduced energy, slowness and decreased appetite for, or satisfaction in, undertaking all kinds of activities, are part of depressive mood disorder. Feelings of low self-esteem or feelings of guilt may also be characteristic of depressive mood disorder. These characteristics fluctuate during the period of the depressive disorder. When the mood disorder only consists of depressive symptoms, it is commonly called a unipolar disorder (UP). When depressive episodes are alternated with manic episodes, the disorder is called bipolar (BP). Psychiatric disorders are mainly classified on the basis of symptoms. There are several methods of classification. In our study, we used the criteria for depression according to the Research Diagnostic Criteria (RDC, Spitzer et al. 1975, 1978). According to these criteria two categories can be distinguished in depression: major and minor depression (the latter is called dysthymic disorder in the DSM-III). The RDC criteria represent a multi-axial classification system with inclusive and exclusive criteria and were the basis for the development of the Diagnostic and Statistical Manual (DSM). The DSM, in its third revised version (DSM-III-R), is nowadays a worldwide classification system.

\subsection{Epidemiology of depressive mood disorders}

It is difficult to determine the prevalence of depressive disorder, because different investigators have used different diagnostic definitions. Many studies in the United States were not concerned with the syndrome of depression, but with depressive symptoms. Depressive symptoms are common, as shown by reported point-prevalences of between 13 and 20 percent of the population (Boyd and Weisman, 1982). They are more frequent among women, among the lower socio-economic groups and among the divorced or separated (Weissman 1987).

The use of standardized diagnostic schedules has led to more accurate information about the prevalence of depressive syndromes. The pointprevalence in industrialized countries for major depressive disorders was investigated among 18,571 persons in the Epidemiologic Catchment Area 
Program (Regier et al. 1988). In this study the researchers found an overall point-prevalence (one-month prevalence) for mood disorders of $5.4 \%$ (mania episodes not included). The point-prevalence for bipolar disorders was $0.4 \%$, for major depressive disorder $2.2 \%$ and for the dysthymic mood disorder $3.3 \%$. The lifetime prevalence, the percentage of people of 18 years and older who have had a major depressive disorder, is about $0.8 \%$ for bipolar disorder, $5.8 \%$ for major depressive disorder and $3.3 \%$ for dysthymic mood disorder. In The Netherlands, Hodiamont et al. (1987) found a one-month prevalence of $4.5 \%$ among persons of between 18 and 65 years. The incidence rate, the amount of newly detected cases of depression during a certain period of time, has almost never been investigated (van den Hoofdakker et al. 1989a). Goldberg and Huxley (1980) introduced a model based on aspects of a depressive disorder that reflect its morbidity. They distinguished five levels. Each level reflects the intensity of care given by the health professional (e.g., general practitioner) to the depressive disorder. The first level reflects depressive symptoms in a general population for which consultation of a health professional does not occur. The second level refers to those people who present with depressive symptoms when they consult their general practitioner. The third level reflects the cases which are recognized by the general practitioner as depression and are treated within the 'first line' of health service. The fourth and fifth levels reflect the cases which are referred to the 'second line' of health service, on an extramural and an intramural basis, respectively. The situation for The Netherlands is summarized in Table 1.1 (Ormel et al. 1984).

table 1.1 Different levels of recognition of depression and one-year prevalence among people of 18 years and older

\begin{tabular}{clc}
\hline & level & one-year prevalence (\%) \\
\hline 1. & General population & 6.7 \\
2. & General practice, totally & 5.4 \\
3. & General practice, detected & 2.6 \\
4. & Ambulant health services & 0.44 \\
5. & Intramural health services & 0.15 \\
\hline
\end{tabular}

The incidence and prevalence rates of unipolar depressive disorder among women are much higher than those for men. It is generally agreed that for depression the ratio women:men lies between 1.3:1 and 2:1. There is no clear explanation for this finding. Bipolar disorders begin on average in the mid-twenties, unipolar disorders in the late thirties. In dysthymic disorder one can distinguish an 'early onset' group around the 
twenties and a "late onset' group in middle age. Bipolar disorders are more frequent in the upper sociall classes, unipolar disorders have not been found to be especially linked to any social class (Gelder et al. 1989). There is an association between marital state and depressive mood disorder: divorced and separated people are more frequently depressed.

\subsection{Assessment of depressive mood disorders}

In this section, standardized and validated instruments which are available in psychology and psychiatry will be summarized. It is beyond the scope of this thesis to describe them in more detail. The psychometric characteristics of the instruments used in this study will be described in part II.

Broadly speaking, we may divide these instruments into two main groups: instruments to evaluate whether a person is depressed or not (diagnostic instruments) and instruments to obtain information about the severity of depression and/or the depressive symptoms (rating scales).

Diagnostic instruments are (semi-)structured interviews. A set of questions is available to the interviewer. The interview covers a large area of psychopathology, such as mood disorders or psychosis. Examples of such instruments are the Present State Examination (PSE, Wing et al. 1974) and the Diagnostic Interview Schedule (DIS, Robins et al. 1981).

The rating scales are instruments to evaluate the severity of depression. The observation scales are interviews during which an interviewer has to evaluate (numeric) which statements (items) apply to the patient. The evaluation is partly based on the patient's answers during the interview, partly on the behaviour of the patient during the interview. Sometimes hetero-anamnestic data are also used. Two specific interviews for depression are commonly used in The Netherlands: the Hamilton Rating Scale for Depression (Hamilton, 1967, 1986 HRS) and the MontgommeryÀsberg Depression Rating Scale (MADRS, Montgommery and Åsberg 1979).

Self-rating scales are instruments with which the patient has to decide and to rate to what degree the items apply to himself. The answers are structured in such a way that the patient is forced to make a choice out of a few possibilities ranging from "absolutely not" to "very much". Each answer corresponds to a score. The sum of the scores reflects the severity of depressive symptoms.

Multidimensional scales measure all kinds of psychopathology. The most commonly used are the Minnesota Multiphasic Personality Inventory (MMPI) and the Symptom Check List (SCL-90, Derogatis et al. 1973). The Scl-90 was used in our study and will be described in more detail in part II. There are many uni-dimensional depression scales which are devel- 
oped to measure depressive symptoms as a syndrome. One of the most widely used is the Beck Depression Inventory (BDI, Beck et al. 1961, 1972, 1988). It was also used in this thesis. The Self-rating Depression Scale of Zung (SDS, Zung 1965) is another widely used scale and was also used in this study. In contrast to the above-mentioned scales, there are others which measure just one of the aspects of depression, such as mood, behaviour and cognition. We will mention here Lubin's Depressive Adjective Check List (DACL) because it was used in our study. The DACL was validated for The Netherlands by Van Rooijen and Arrindell $(1979,1985)$ in a abbreviated version (VROPSOM).

\subsection{Different theories on depression}

Many different theories on depression have been developed. This indicates that its etiology is multifactorial. In this section we will use the model as it is presented by Gelder et al. (1989).

It is generally accepted that the predisposition for developing mania and severe depressive disorders has genetic determinants. There is no convincing evidence that this inherited predisposition is modified significantly by specific childhood experiences of the kind postulated by the psychodynamic theorists. Nevertheless, adverse early experience may play a part in shaping features of personality which, in turn, determine whether, in adult life, certain events are experienced in such a way that they trigger depression. Precipitating causes are stressful life events and certain physical illnesses.

Both the effect of predisposition and precipitating factors may be modified by a number of background factors which make a person more or less vulnerable; for example, "having someone to confide in" - social support - and personality characteristics of the patient.

Several mechanisms have been proposed to explain how precipitating events lead to the phenomena observed in depressive disorders. In our study, we used a model based on two mechanisms: one psychological and one biological.

\subsubsection{Predisposition}

a. Genetic features

Genetic studies for mood disorders have recently been reviewed by Mcguffin and Katz (1989). In family studies it was shown that the lifetime risks in first-degree relatives for UP and BP proband is 3 to 10 times higher than the average risk in the general population. In twin studies a three-times higher rate of depression was shown to occur in monozygous twins compared with dizygous twins for UP and BP 
disorders. In adoption studies, it was shown that an affective illness occurred twice as often in the biological parents compared with the adoptive parents (Mcguffin, 1988a).

What is inherited in severe affective illness is not the certainty of becoming ill but rather a liability to develop the disorder. Liability may be contributed to by genes, environment, or both. The most feasible way is to speculate that there is a major gene locus (or a number of different major loci) which shows its effect against a polygenic or multifactorial background (multiple additive effects of the environment). Although there have been many publications on this issue, there are no conclusive data available so far (Mcguffin and Katz 1988a). For less severe depression it is more difficult to find inherited factors. Environmental factors are thought to play a more prominent role in these milder conditions. Certain forms of adversity, such as life events that carry a severe or moderately severe threat, have a strong association with onset of depression (Brown and Harris, 1978). However, studies examining the role or relationship between environmental stress and familial/genetic factors in the same population (Bebbington et al. 1988) have shown that both depression and threatening life events tend to cluster in families. It is possible that a liability to develop depressive illness and a propensity to experience unpleasant life events are different manifestations of the same familial diathesis (Mcguffin et al, 1988b, 1988c).

\section{b. Psychoanalytic explanations}

Many psychoanalytic or psychodynamic theories have been developed. One major hypothesis implies that childhood deprivation or maternal separation or loss predisposes towards depressive disorders in adult life. Another important issue refers to the kind of relationship between the depressed patient and his parents. Parents who were less caring or overprotective of their children may have predisposed them towards depression in adult life. Epidemiologists have attempted to discover what proportion of adults with depressive disorder has experienced parental separation or loss in childhood. The results are conflicting. At present, this association is uncertain and supposedly weak and non-specific (Gelder et al. 1989).

\subsubsection{Precipitating factors}

a. Stressful life events

There is no doubt that environmentally induced stress can lead to adverse mental health. Research on the stressors of daily life, however, has failed to lead to a consensus on the strength and the interpretation of associations observed between events and psychopathology (Ferguson and Horwood, 1987, Schrout et al., 1989). Moreover, there is much less evidence 
that there are particular kinds of events more likely to provoke depressive disorder. Because depressive symptoms are part of the normal response to bereavement, it has been suggested that loss by separation or death might be particularly important. However, not all people with a depressive disorder report loss, and not all people who have experienced loss events, develop a depressive disorder (Paykel 1978, 1989a).

Some investigators reported strong effects of life events on health and well-being (Brown and Harris, 1978), while others concluded that only a weak association exists (Tennant et al. 1981). Even in the case of strong associations, the interpretation has been questioned, for example: events may be the consequence of psychopathology (Bebbington et al. 1988, Mcguffin et al. 1988b), events and symptoms may both be the consequence of a common third factor, or association may be a function of reporting bias. As summarized by Sanderman (1989), research into life events and depression mainly investigated three important questions:

- is there a possible causal relationship between the prevalence of stressful events and the occurrence of depression?

- are some people with specific personality traits and cognitive styles in general more prone to develop depression than others?

- are some people with specific personality traits and cognitive styles more prone to depression than others when a stressful event happens to them?

Three models investigating these questions can be distinguished (Sanderman 1989): (a) the vulnerability-stress model, an interaction model in which life events are thought to interfere with psychological wellbeing; (b) the main-effect model, an additive model in which life events are thought to interfere directly with psychological well-being without interaction with personality and cognitive styles; (c) the synergetic model in which both effects are thought to occur.

Controlled studies showed that depressed patients experienced more stress before the onset of depression compared to healthy controls and reported more events of loss. Cross-sectional studies showed conflicting data (Sanderman 1989), mainly because it is unclear in how far depressive symptoms interfere with causes or consequences of events. Prospective studies (Lewinsohn et al. 1988, Brown et al. 1986, 1987, 1989) showed weak predictive values. These studies in particular pointed out that many individuals report stressful events without developing depression. One major conclusion is that stressful events have etiological implications for depression (depressed people often report stressful events), but poor predictive value (many people report stressful events, only a small percentage develops depression).

\section{b. Social support}

Almost complementary to the theory of stressful life events as 
precipitating factors for depression, the buffer theory of social support has been developed. This theory postulates that social support moderates the power of psychosocial adversity to precipitate episodes of depression. Clinical and laboratory studies have shown the contribution of social relationships to psychological well-being (Cohen and Wills, 1985), and epidemiological studies have shown social support to be a significant protective factor for health outcome (Broadhead et al. 1983).

A major theme in social support research is the assumption that social support interacts directly and indirectly with a wide range of stressful events. This interaction mainly consists of beneficial effects that facilitate or increase psychological and environmental processes that the individual must set in motion to overcome the objective problem that is taxing his or her resources, or to decrease the magnitude of aversive emotions that are generated by the problem (Lazarus and Folkman, 1984). As pointed out by Thoits (1982) and Cohen and Wills (1985), the association between social support and well-being is mainly thought to be attributable to an overall beneficial effect of support (main- or direct-effect) or to a process of support protecting persons from potentially adverse effects of stressful events (buffering or indirect-effect).

The main effect may be found when the measure of support is determined by a person's degree of integration in a large social network. In this model, the beneficial effect of social support occurs because large social networks provide persons with regular positive experiences and a set of stable, socially rewarding roles in the community. Evidence for a buffering effect consists of the assumption that social support may prevent potential stressful events from being appraised as threatening and/or that social support may interfere with the way events, once appraised as stressful, cause alterations in psychological and physiological processes, resulting in illness or illness behaviour (Cohen and wills 1985). These two effects are not mutually exclusive. However, the results from studies in this area are controversial and equivocal. Poor definition of social support and lack of generally accepted measures of social support are the main causes for these conflicting data (Alloway and Bebbington 1987).

Recently, these concepts of the way in which social support interacts with stressful events have been re-evaluated by several authors (Jacobson 1986, Cutrona 1990, Sarason and Sarason 1990, Rook 1990, Schulz 1990, Newcomb 1990, Coyne 1990). The conclusions can be summarized as follows:

Firstly, what seems to be important in the buffering effect of social support is not the availability of actual support but rather the extent to which social support is perceived to be available (Sarason et al. 1990). Two 
types of cognition are important in perceiving social support: the sense of support, the belief that support will be provided by others regardless of the sacrifice, and the sense of acceptance, whereby the belief that one is accepted by others regardlless of the way in which one behaves, is a major issue.

Secondly, in the process of perceiving social support, not only interpersonal aspects are important but also intrapersonal aspects. As summarized by Newcomb (1990), factors such as personality, self-esteem and self-confidence, psychopathology, behaviour, physical health, and personal competence are all important intra-individual features that may influence the way social support is perceived.

Thirdly, Cutrona (1990) argues that objective characteristics of stressful situations alone may be insufficient determinants of the type of social support that will be maximally beneficial: different stressful events pose different coping requirements. Cutrona and Russel (1990) propose a set of five basic support dimensions - emotional support, social integration or network support, esteem support, tangible aid, informational support which matches social support in an adequate way with four dimensions of stressful events- desirability, controllability, life domain affected by stress, duration of consequences. After reviewing many studies with the aid of this model, Cutrona and Russel (1990) concluded that, for some events (financial crisis), specific components of social support can be identified which facilitate optimal adjustment, but that for other events (bereavement, unemployment) a broad range of social support components is required for recovery.

Finally, Coyne (1990) emphasizes, on the contrary, the fact that the effect of perceiving social support in some circumstances (partner relationship) may have detrimental consequences for the individual. He argues that, for example in a good partner relationship, the positive influence that is thought to occur is due to the absence of the detrimental effects of a poor relationship. Coyne suggests that support interactions will be most effective when they occur but are not perceived, which suggests that the impact of a given behaviour may be more positive when it does not activate conscious attributional behaviour (Coyne 1990).

\section{c. Coping behaviour}

Life events that occur in everyday interactions with the environment affect the psychological, physical and social well-being of an individual. The person and his environment are seen in a transactional way: there is an ongoing relationship of reciprocal action, each affecting and in turn being affected by the other (Lazarus and Folkman, 1984). This relationship is mediated by two processes. 
Appraisal is a cognitive process through which an event is evaluated with respect to what is at stake (primary appraisal) and what coping resources and options are available (secondary appraisal). There are three major types of stressful appraisals: harm or loss, referring to damage that has already occurred; threat, referring to harm or loss that has not yet occurred but is anticipated; challenge, referring to an anticipated opportunity for mastery or gain (Folkman and Lazarus 1980).

Coping is defined as the cognitive and behavioural efforts with the intention of mastering, tolerating or reducing external and internal demands and conflicts among them. The degree to which a person experiences psychological stress, that is "feels harmed, threatened or challenged", is the result of appraisal and coping. Coping implies two aspects: (a) efforts to deal with the sources of stress by changing the person-environment relationship, and (b) efforts aimed at reducing emotional distress. Most stressful situations elicit both coping functions (Coyne and Aldwin 1981). Coping efforts are made in response to stress as well as to appraisalls and both continuously influence each other, as appraisal provokes coping-style which in turn provokes reappraisal.

\section{d. Physical diseases}

Associations between physical illness and depressive disorders are well described in the literature. Some conditions in particular appear to be followed by depression: influenza, glandular fever, and certain endocrine disorders (Cushing). Moreover, it is likely that many physical illnesses (surgeries) can act as non-specific stressors in provoking depressive disorders, but that only a few have specific effects.

\subsubsection{Mechanism of precipitation}

Two sets of theories have been proposed to explain how precipitating events can lead to the phenomena observed in depressive disorders, psychological and biological theories.

\section{a. Psychological theories}

Stress can cause strain, which in turn can lead to depression. Factors which may have adverse effects on an individual are called stressors. They include a large number of physical, psychological and social factors.

The most important goal of psychodynamic theories was to conceive mental pathology as the interplay of psychological processes on physiological ones in order to understand the role of inherited psychobiological predispositions (Gilbert 1984). However, there are no clear data underlining the etiological role of disturbed personality 
development in depression. It is believed that a disturbed personality development in childhood does influence the way in which life events are experienced later on (Gelder et al. 1989).

In learning theories of depression, the interplay between individual and environment is the major issue. Moreover, according to behaviourists, there are only quantitative differences between normal and abnormal behaviour, and no qualitative differences (Hoevenaars and van Son ${ }_{n} 1989$ ). The experiments of Skinner (1953) on animals led him to define depression as lowered frequency of normal behaviour. This lower frequency is a consequence of decreased positive reinforcement of behaviour. Lewinsohn (1979) emphasizes the inadequate social interaction as a source of too little reinforcement and as a major contributing factor to depression. In his model, there is a low rate of positive reinforcement and a high rate of aversive experiences. Costello (1972) slightly modified Lewinsohn's theory by arguing that it is not the number of reinforcers that can lead to depression but a reduced effectiveness of the reinforcers. Empirical data supported this theory: depressed people do indeed mention a reduced positive experience of otherwise pleasant events, not a decreased number of experienced pleasant events (Hoevenaars and van Son, 1989).

In the cognitive approach to depression (Beck 1973), the central issue is that cognitive processes translate external events into meaningful internal representations. These 'internal representations' and not the events themselves, are the pathogenic agents. The major theme of the depressed person's cognitive appraisal system is centred around the appraisal of loss. For the depressed person, the appraisal of loss pervades evaluations concerning the self, the world, and the future ('negative triad'). Beck postulates that this negative triad already exists in the depression-prone adult, but in a latent state. The basis for this predisposition is laid in early life when sensitizing experiences produce negative views leading to latent negative cognitive schemata. Under certain conditions of stress, these schemata become invoked again as organizing cognitive systems (Albersnagel 1989). One of the major problems of cognitive theories is that so far there has been a lack of evidence that these mechanisms are present in people before the onset of depressive disorder, or that they are more frequent in people who subsequently develop depressive disorders than in those who do not (Gelder et al. 1989). However, as pointed out by Paykel (1989b), cognitive behavioural therapy as part of the therapy for depression is becoming more and more important with a high percentage of good results and a low percentage of rellapses. 


\section{b. Biological theories}

Studies in biological psychiatry are faced with several problems. The living human brain is not accessible to detailed biochemical study and the alternatives developed so far - postmortem studies, studies on animals, and studies of cerebrospinal fluid, blood and urine - do not necessarily represent changes in the (central) brain. Moreover, if an effective drug blocks a particular transmitter system, it cannot be concluded that the disease is caused by an excess of that transmitter (Gelder et al.1989). Recently, advances have been made with new non-invasive techniques for studying the living brain, such as single photon emission computerized tomography (SPECT), and positron emission tomography (PET). Reduction of global cortical blood flow at rest has been reported in major depressives compared to normal controls (Sackeim et al. 1990). These techniques show that it is important to pay more attention to studies on disturbances in the neuroanatomy of primary and secondary affective disorders (Jeste et al. 1988).

Biological factors can, broadly speaking, be seen as trait markers and as state markers, both confined to qualitative aspects of the biological factor. A trait marker is a measurable indicator of a disease which is quite stable irrespective of the actual situation of the diseased person. A state marker is a measurable indicator which reflects the actual situation of the affected person.

\section{Neurotransmitter hypothesis}

Important transmitters for research into depression are the monoamines: serotonin, noradrenaline, and dopamine. From studies on animall behaviour, it is known that monoamines are involved in pleasure-giving mechanism. Dopamine is believed to be released when an approach or "go-system", guiding the individual to locations where a reward might be expected becomes operative. Noradrenaline is believed to be active when success is achieved and the behaviour becomes reinforced. Serotonin may act to oppose these actions and hold the approach and reward system in check (Donovan 1988). The monoamine hypothesis supposes that depressive disorder is due to an abnormality in a monoamine neurotransmitter system at one or more sites in the brain. It is believed that serotonin (5-hydroxytryptamine 5-HT) function and noradrenergic function in the brain are decreased in depressive disorders, although the evidence for this hypothesis is fragmentary and contradictory (Meltzer, 1987, 1989). There is little evidence of an abnormality of dopaminergic function in depressive disorder (George and Sandler 1988). 


\section{Neurohormonal hypothesis}

Abnormalities of neuroendocrine factors are of importance in the aetiology of depressive disorder (Gelder et al 1989, George and Sandler 1988). Some disorders of endocrine function are followed by depressive disorders. Moreover, endocrine abnormalities found in depressive disorder suggest dysfunction of the hypothalamic centres. Finally, hypothalamic mechanisms are partly controlled by monoamine systems, and therefore endocrine changes might reflect abnormalities in monoamine systems. In the last few years many studies have been carried out on biological changes during behavioural and physiological reactions to stress. The hypothalamic-pituitary-adrenocortical axis (HPA-axis) is a model which has been investigated intensively. It is believed that, in some depressed individuals, plasma cortisol is elevated. Several mechanisms have been proposed to explain this finding, such as a persistently increased corticotrophin-releasing hormone (CRH) secondary to hypothalamic or higher (limbic, cortical?) overdrive to the neurosecretory cell (Stokes and Sikes, 1988), a hyper-responsivity of the adrenal gland to ACTH stimulation, or decreased sensitivity of pituitary glucocorticoid receptors to dexamethasone (Kathol et al. 1989). Because clinical signs of cortisol overproduction are absent, it can be assumed that the number and binding affinity of cortisol receptors are altered. However, the specificity of the disturbances is uncertain: other psychiatric syndromes show the same disturbances and a large number of depressed people do not present with these disturbances (Kathol et al. 1989).

Recently, a new class of neurotransmitters was described, such as the neuropeptides (endorphins, enkephalines), and hormones like thyrotropin-RH and somatostatin. Their possible role in depressive disorder still remains to be established. The role of thyroid hormone and thyrotropin will be discussed in chapter V.

\section{Circadian Rhythm hypothesis}

There is an increasing interest in research into the possible role of neurophysiological variables in depression. One major topic is the circadian rhythm of several 'Zeitgebers' (light-dark, sleep-wakefeeding). As summarized by Gold et al. (1988a), a phase advance of a "strong" internal oscillator for the REM sleep is suggested in some forms of depressive disorders.

A comparable mechanism is suggested for the so-called seasonal affective disorders. Patients have been described with depression only in winter and not in summer. This phenomenon might be an equivalent of the hibernation encountered in animals, which can be manipulated by increasing daylight hours. Moreover, phototherapy in winter could 
ameliorate the depressed state of mood in some patients. The chronobiological disturbances in depressed patients may be explained as disorders caused by, or partly belonging to, non-specific disturbed reaction to stress (Gold et al.. 1988b).

\subsection{Treatment of depression}

When a patient recovers after treatment with antidepressive drugs, we should realize that this may have been spontaneous. The high prevalence and episode rate of mild depression in the community make it clear that many people with this disorder go into remission without it ever being recognized or treated. Other processes are also at work, such as social effects of ventilation, support, hospital admission in itself and the effect of receiving an inert placebo. In placebo-controlled trials in depression, as a rule only $20-30 \%$ more recoveries occur on active treatment than on placebo (Paykel 1989b).

\section{Biological therapies}

\section{a. Antidepressive drugs}

These drugs include the tricyclic antidepressive drugs, the 'second generation' antidepressive drugs, lithium and the monoamine-oxidase inhibitors (MAOI). The first two groups are most commonly used. They have relatively few side effects, are easily administered (one single dose per day), and even on the long-term are not harmful to the body. As Paykel pointed out (1989b), they are broad spectrum antidepressants, effective across a wide range of depressions and in anxiety disorders. They are the first choice when medication is to be used: the presence of an established depressive syndrome of all but a very mild severity. One major problem is their toxic character when an overdose is taken (tentamen suicide).

b. Electroconvulsion therapy

In psychiatry, electroconvulsion therapy (ECT) still plays an important role in the treatment of depression, especially in the severe forms which do not react to drug therapy (Gelder et al. 1989, Paykel 1989b). However, ECT is not very popular in The Netherlands compared with other countries, mainly on political grounds (van den Hoofdakker 1989b).

\section{Psychological therapies}

The main purpose of psychodynamic therapy is to investigate which experiences in childhood made a patient react to his environment in such a way that depression occurs. Dynamic psychotherapy is usually appropriate for handling psychodynamic and interpersonal problems in combination with antidepressants. From clinical studies, it seems to be unproductive to use psychoanalytic psychotherapy for the more severely 
ill until symptom remission, due to drugs or ECT, makes it possible (Paykel 1989b). In behavioural therapy the operant treatment is mainly based on the work of Lewinsohn. The therapist assesses the level of positive reinforcement. When low levels are predominantly found, it is important to detect the nature (social, physical, material) and to find out what the reason might be for the lack of reinforcement. The therapy reflects the possible causes: social skills training, forcing the patient to undertake all kinds of activities and teaching a patient to increase the frequency of undertaking pleasant activities (Albersnagel et al. 1989).

In cognitive behavioural therapy, the therapist tries to detect the dysfunctional cognitions and make them clear to the patient. The patient has to become aware of his negative cognitive schemata (about self, the world and the future) and of his 'automatic negative thoughts' (Albersnagel et al. 1989).

The efficacy of behavioural and cognitive therapies seems to be about the same as that of antidepressive drugs. One striking difference from drug treatment is the much lower level of relapse occurring with behavioural and cognitive therapy compared to drug treatment (Paykel 1989b). 


\section{Chapter II}

\section{The thyroid gland and autoimmune thyroid diseases}

In this chapter, the fundamentals of thyroidology and immunology are summarized. As references for the thyroid, we used Werner's textbook 'The Thyroid',1986 edition, the fourth edition of 'Fundamentals of Clinical Endocrinology', edited by Hall and Besser 1989, and 'Schildklierziekten', edited by Wiersinga and Krenning 1988.

As references for immunology, we used the last edition of Roitt's 'Essential Immunology' 1990, the sixth edition of 'Basic \& Clinical Immunology', edited by Stites et al. 1987, and 'Advanced Immunology' edited by Male et al. 1987 .

\subsection{The thyroid}

\subsubsection{Introduction}

The thyroid gland consists of multiple spherical follicles with a diameter of between 50 and 500 microns. The follicles are bound together in groups of about forty to form lobules, each supplied by an end artery. The follicle is surrounded by a single layer of epithelial cells and filled with a substance known as colloid, almost entirely composed of the iodinated glycoprotein, thyroglobulin. From the apices of the thyroid epithelial cells, there are microvilli projecting into the colloid, the epithelial cells resting on a basement membrane which separates them from the adjacent capillaries.

\subsubsection{Normal physiology of the thyroid gland}

\section{Synthesis and secretion of thyroid hormones}

Synthesis of thyroid hormones by the gland involves several processes which are summarized in fig 2.1 .

Uptake of iodine from the blood by an active transport against a steep iodide concentration-gradient (a). Thyroglobulin is synthesized by follicular cells. The protein is transported to the apical membrane where it makes contact with an enzyme system, peroxidase (b), which is 


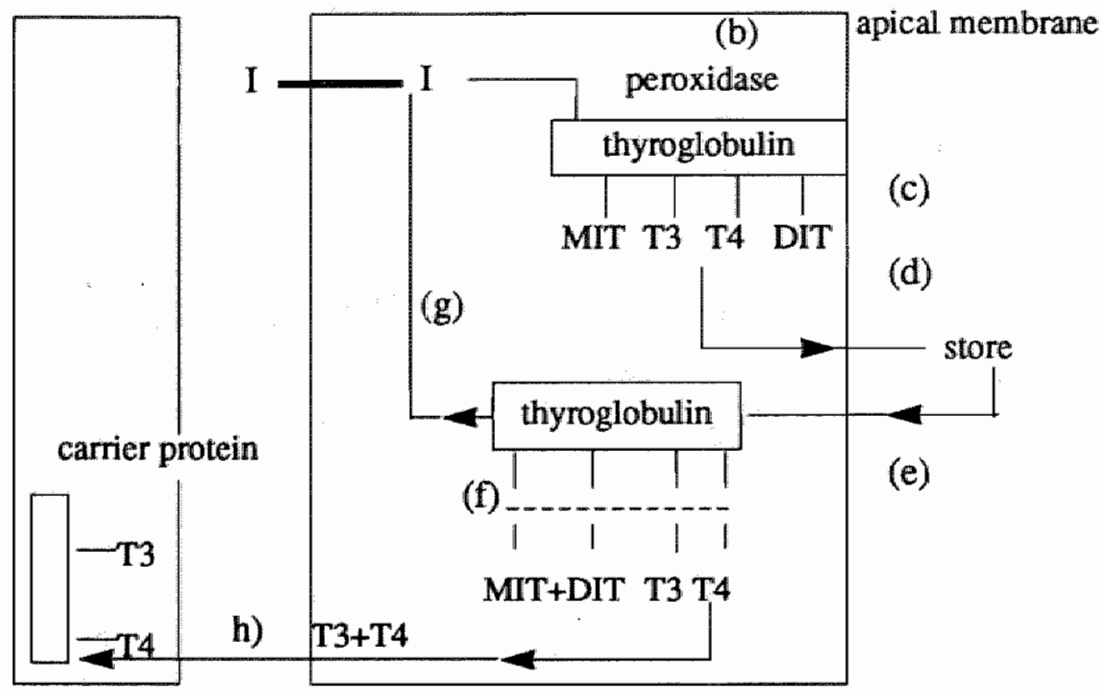

fig 2.1 synthesis and secretion of thyroid hormone

responsible for iodination of the thyroglobulin. Monoiodotyrosine (MIT) and diiodotyrosine (DIT) are formed by incorporating one or two iodine atoms into the thyrosine molecule. Within the thyroglobulin, the thyronines are synthesized by a coupling reaction of MIT and DIT mediated also by peroxidase and leading to tetraiodothyronine (T4) and triiodothyronine (T3) (c). The thyronines, as part of the thyroglobulin molecule, are stored in the colloid of the lumen of the thyroid follicle (d). In order to release thyroid hormones from the colloid, the glycoprotein must be taken back into the thyroid cell where lysosomal enzymes can release the iodothyronines for secretion into the circulation. Resorption of the glycoprotein from the colloid stores (e) occurs by protrusion of microvilli from the thyroid cell membrane into the colloid to form a colloid droplet (endocytosis). Fusion of these droplets with the lysosomes of the cell activates proteolytic enzymes within the lysosomes. These proteolytic enzymes degrade the thyroglobulin molecule, releasing iodo- and other aminoacids and sugars ( $\mathrm{f}$ ). The mono- and diiodotyrosine molecules (MIT and DIT) are deiodinated and the iodine is recycled back into the cell $(\mathrm{g})$. The iodothyronine hormones ( $\mathrm{T} 4$ and $\mathrm{T} 3$ ) pass across the cell membrane to gain access to the serum, in which they are bound to carrier-proteins (h). 


\section{Circulating thyroid hormones and their metabolism}

In serum, both the iodothyronine hormones (T3 and T4) are strongly bound to serum proteins (iodothyronine binding proteins and albumin); only small fractions of T3 and T4 are not bound. Most of the T4 is peripherally (kidney, brain, liver and anterior pituitary) converted to T3 or reverse T3 (rT3). This mechanism of T4 deiodination provides the body either with the biologically active metabolite (T3) or one that is biologically inactive (rT3), thereby having the opportunity to change its regulatory activity acutely in different circumstances (i.e., energy consumption). In normal conditions the half-life of $\mathrm{T} 4$ in the plasma is about 6-7 days, that of T3 24-36 hours and that of rT3 12-20 minutes.

\section{Action of thyroid hormones}

Thyroid hormones maintain the level of tissue metabolism by their ability to stimulate oxygen consumption. They are essential in normal physical and mental development during the fetal period and maturation in children and play an important role in the metabolism of proteins, carbohydrates and fats. The principal, and probably primary, site of action is in the cell nucleus, where receptors for T3 have been identified. In normal conditions and depending on the site in the body, between 15 and $85 \%$ of these receptors are occupied by T3 (and partly by T4). After binding of $\mathrm{T} 3$ to the gene receptor, transscription is influenced by fluctuation of the transcription rate of specific mRNAs in the nucleus, resulting in protein synthesis induction (e.g., growth hormone, different enzymes in liver, muscle cells, catecholamine receptors). An example of down regulation of $\mathrm{T} 3$ is the inhibition of thyroid stimulating hormone (TSH) synthesis in the pituitary.

\section{Regulation of the thyroid}

The activity of the thyroid gland is controlled by thyrotropin - or thyroid stimulating hormone (TSH) - from the anterior pituitary gland; the secretion of this is, in turn, positively controlled by thyrotropin releasing hormone (TRH) and negatively controlled by somatostatin, both released from the hypothalamus (fig 2.2).

TSH is a glycoprotein produced in the thyrotroph cells of the anterior pituitary. There is a circadian rhythm of TSH secretion, with a peak at night and a nadir at about 1100 hours. The biosynthesis of TSH is regulated by thyroid hormones, TRH, dopamine, somatostatin and cathecholamines. The net result of TSH action is to increase the release of the thyroid hormones as well as to augment the synthesis of fresh thyroid hormone stores. The thyrotropin releasing hormone (TRH) from the hypothalamus represents the most important positive control system of TSH secretion. It is synthesized as an inactive pro-hormone (Pro- 


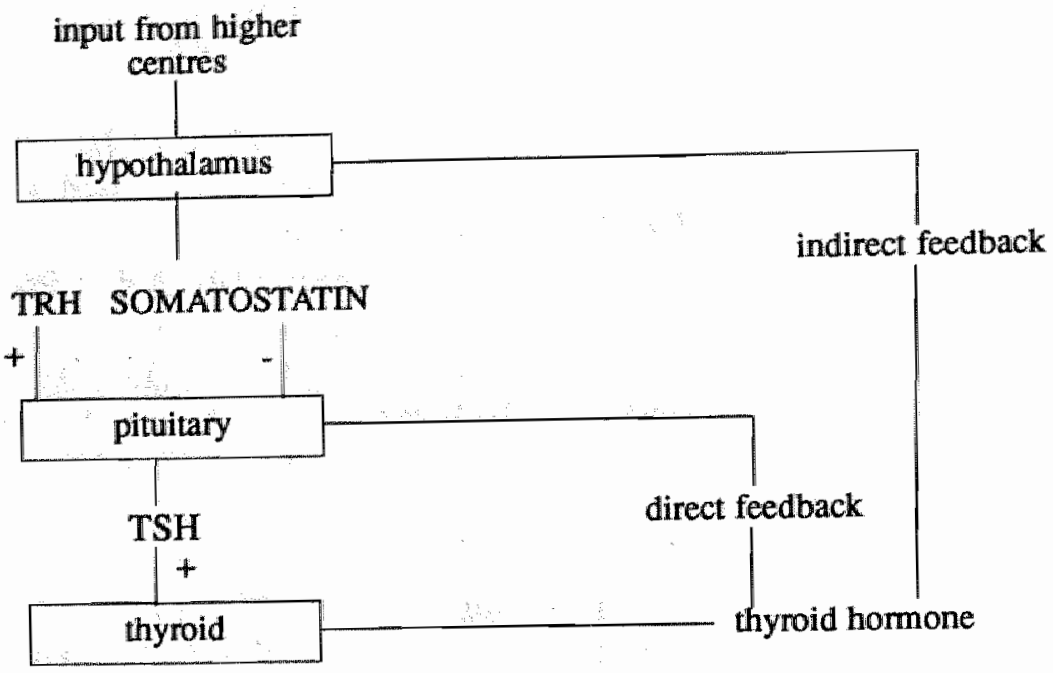

fig 2.2 regulation of the thyroid

TRH) in the paraventricular nuclei of the hypothalamus, packed in vesicles and transported by axons until it is released in the portal vessels of the pituitary stalk. Beside this action on the pituitary, TRH has multiple other effects such as those on thermoregulation, and on the cardiovascular, respiratory and digestive systems. It can also directly affect the electrical activity of nerve cells, in this way acting as a neurotransmitter.

\section{Iodine and thyroid function}

The amount of iodine incorporated into the thyroglobulin is directly related to the concentration of iodide reaching the thyroid gland from the circulation. The main source of iodine in the circulation is dietary iodide. It was calculated that the appropriate daily iodide intake should be at least 140 micrograms. The iodide in the total body-iodide-pool is cleared by the kidney $(66 \%)$ and the thyroid $(33 \%)$. In many areas of the world iodine deficiency is still a major problem. The thyroid has several mechanisms to compensate for low dietary iodine intake, including increased clearing of iodide from the total body iodide-pool and, preferentially, secretion of $\mathrm{T} 3$ (which is biologically much more active). The increased TSH concentration induces thyroid enlargement: goitre. A goitre prevalence of more than $10 \%$ of the population indicates an endemic area. 


\subsubsection{Assessment of thyroid function}

Measuring total circulating levels of thyroid hormones (T4 and T3) has been replaced by measuring free thyroid hormones (fT 4 and $\mathrm{fT} 3$ ), mainly because of the erroneous results when binding proteins were altered. The direct assessment of circulating levels of fT 3 and fT 4 is a widely used assay in clinical practice. The main advantage is the fact that the outcome is not affected by the amount of circulating thyroid hormone binding globulin (TBG, such as by the use of oral contraceptives) or a variety of other drugs. Limitations are the disturbed outcome in severe non-thyroidal illness, with the presence of abnormal binding proteins, the presence of circulating T4 binding antibodies, and the disturbed concentration or structure of circulating albumin.

Tests for hypothalamic-pituitary function started with the development of thyrotropin radioimmunoassay (TSH-RIA). This test discriminated well between hypothyroidism (the upper level of normal and abnormal TSH) and euthyroidism/hyperthyroidism. When the TSH-RIA test was used together with the TRH test - intravenous injection of a single bolus of TRH produces a change in the TSH level which reflects thyroid function - it was possible to distinguish hyperthyroidism from euthyroidism. With the development of sensitive TSH assays, such as the immunoradiometric (IRMA) methods, it became possible to distinguish between hypo-, hyper- and euthyroidism. The TSH-IRMA tests are nowadays the screening instrument of first choice for thyroid function (Caldwell et al., 1985, Klee and Hay, 1987, Hay and Klee, 1988). Since the introduction of the TSH-IRMA tests, the clinical relevance of the TRH test has become less genuine. Its major application is found to be the investigation of hypothalamic/pituitary disorders. Moreover, as will be discussed later on in this thesis, there is a subgroup of patients with major depression which shows a blunted response to the TRH test - with normal basal TSH level - suggesting the presence of subclinical thyroid dysfunction.

There are several well-described antibodies, such as thyroglobulin antibodies $(\mathrm{TgAb})$, microsomal antibodies (Ms $\mathrm{Ab}$ ), and thyrotropin receptor antibodies (TRAb). In postpartum thyroid dysfunction microsomal antibodies are mainly involved. The nature of these antibodies has recently been shown to be an antibody against thyroid peroxidase (TPO-Ab) (Czarnocka et al. 1986, Marioti et al. 1987, Hamada ct al. 1987). This has led to a change of name: microsomal antibodies (MsAb) and thyroid peroxidase antibodies (TPO-Ab) are the same. As explained before, this enzyme is important for the iodination of thyroglobulin. Ruf 
et al. (1988) developed a new technique to detect the TPO-antibodies and there is evidence, so far, that this method is more sensitive for detecting elevated titres than the commonly used hemagglutination techniques (Glinoer et al. 1990).

\subsubsection{Thyroid and pregnancy}

Pregnancy is associated with two major series of alterations in the endocrine system. On the one hand, hormonal changes necessary for the maintenance of pregnancy must occur and, on the other hand, pregnancy itself influences the function of the endocrine glands.

\section{Endocrinology of pregnancy}

The placenta serves several important functions to ensure the survival of the fetus. Moreover, it is an organ with a hormonal secretory capacity partly in collaboration with the fetus. Some aspects of these hormonal changes are: elevation of steroid hormones such as progesterone and oestriol mainly produced by the placenta and the fetus, the production of protein hormones by the trophoblast such as human chorionic gonadotrophin (hCG), human chorionic thyrotropin (hCT) and human placental lactogen (hPL), and a 10-fold increase in prolactin levels in the serum between four and 38 weeks of pregnancy.

\section{Influence of pregnancy on the thyroid}

The renal clearance of iodide rises early in pregnancy, remains high throughout, and returns to normal by six weeks after delivery. As a consequence, plasma inorganic iodide is significantly lowered from the 16 th week of pregnancy. The thyroid gland therefore increases its bloodflow to maintain the iodine supply during pregnancy. The thyroid enlarges during pregnancy, strongly depending on geographical aspects such as iodine intake. If a partial deficiency of iodine exists in the diet, this may result - in addition to the already reduced circulating iodine pool during pregnancy - in thyroid gland enlargement, in order to maintain sufficient synthesis of thyroid hormones.

Thyroid function in pregnancy is influenced further by an oestrogeninduced increased synthesis of thyroxine binding globulin (TBG). Since TBG is the main thyroid hormone binding protein, this rise in levels has a profound impact on the circulating levels of thyroidal hormones in their bound form. On the other hand, human chorionic gonadotrophin (HCG) and human chorionic thyrotropin (HCT), both of which are protein hormones derived from the trophoblast, show a weak thyroid stimulating effect early in pregnancy. As a consequence, the serum levels of free T3 and $\mathrm{T} 4$ show a small rise early in pregnancy and then fall throughout the pregnancy. The serum levels of TSH rise slightly during normal pregnancy, also within the physiological range. 


\subsection{The immune system}

\subsubsection{Introduction}

The immune system has evolved to protect the body from the numerous potential pathogens which are present in the environment. The basis of immunity is the ability to recognize foreign molecules (antigens) and react to them, while at the same time tolerating molecules of the body's own tissues. The immune system consists of a variety of molecules and cells. The most important cells are leucocytes which fall into various broad categories. Firstly, there are the phagocytes - including neutrophil polymorphs, monocytes and macrophages - producing substances such as lysozymes, complement factors, and acute phase proteins such as interferon. Secondly, the lymphocytes produce substances such as lymphokines and antibodies. The cells do not act in isolation; antibodies produced by lymphocytes help phagocytes to recognize their targets, and lymphokines stimulate phagocytes to destroy their infectious agents more effectively.

\subsubsection{Cells of the immune system}

There are three different kinds of $1 y m p h o c y t e: ~ T$ cells, $B$ cells and natural killer cells.

T cells are lymphocytes which develop and differentiate in the thymus. Three major subsets of T-lymphocytes can be distinguished.

Firstly, T-helper (T-h) cells confer their immunological effect by helping macrophages and other B and T lymphocytes. The T-h cells produce lymphokines which promote differentiation of B cells into plasma cells (which in turn enhances antibody secretion), and other lymphokines which assist in the development of cytotoxic $\mathrm{T}$ and suppressor $\mathrm{T}$ cells. Secondly, T-suppressor (T-s) cells can be distinguished which block the differentiation of B cells into plasma cells (and hence antibody production). Finally, cytotoxic (T-c) cells play an important role in antiviral, antitumour protection and in the mediation of the transplant rejection phenomena.

The B cells are classically defined by the presence of endogenously produced immunoglobulins: antibodies. Antibody molecules only bind to one molecule on the micro-organism surface. Molecules to which antibodies bind are called antigens. The part of the antigen to which the antibody binds is called an epitope. When the B cell encounters a foreign antigen, it will bind to it with its specific antigen receptor and differentiate into a plasma cell that produces the antibody.

A third class of cells is the large granular lymphocytes, natural killer cells (NK-cell). They bind to the host cells and destroy them 
(cytotoxicity). Soluble factors which are activated during infection are acute phase proteins such as complement, C-reactive protein, interferon and lysozymes.

There are two different types of phagocytic cell.

The phagocytic tissue macrophages form a network - the reticuloendothelial system (RES) which is found in many organs. These cells neutrophil polymorphs and monocytes - engulf particles, internalize them and destroy them.

Another type of cell is the antigen-presenting cell (APC). These cells are a heterogeneous population of leucocytes. They are important for the recognition of antigen by T-cells: without an APC cell, T-helper cells cannot recognize antigens.

There are several control mechanisms of the immune response. Firstly, the Major Histocompatibility Complex (MHC) - the human leucocyte antigen (HLA) gene cluster on chromosome 6 in humans - is the region where proteins that play an important role in many aspects of immunological recognition are encoded. Secondly, there is another group of genes linked to the structure of the immunoglobulins ( $\mathrm{Ig}$ ) and therefore relevant to immune regulation. The Ig molecule consists of a constant region - isotype - which determines the class of the Ig molecules, and a variable region - idiotype - which represents the antigen recognition site. Finally, immune regulation is carried out by a T-cell population. This consists of a cascade of T-lymphocytes with different immunological functions, namely helper (T-h), suppressor (T-s) and contra-suppressor (T-cs) lymphocytes. This network of $T$ cells provides a distinct regulatory system in the normal immune response and in control of the autoimmune response.

With the discovery of auto-antibodies in a number of diseases, it was realized that the immune system is also potentially capable of recognizing (self)antigens. This mechanism is reflected in the idiotypic network hypothesis of Jerne (1974) which might partly explain the presence of circulating antibodies in the normal population, without the presence of an autoimmune disease.

\subsection{Autoimmunity and autoimmune thyroid diseases}

Immunological tolerance is the acquisition of non-reactivity towards particular antigens and it is the converse of immunity. The central dogma of immunology has been that, in normal conditions, the immune system does not react to the body's own constituents. Accordingly, autoimmunity defines a state in which the natural unresponsiveness or tolerance to selfcomponents terminates. As a result, antibodies or cells react with the body's own constituents, thereby causing disease. This definition implies 
that responses against self-components do not normally occur and that if they do occur the outcome is harmful to the body. However, it has recently become apparent that autoimmune responses are not all harmfull. In contrast, it has become clear that certain forms of autoimmune responses are essential for the diversification and normal functioning of the intact immune system. Therefore, one has to distinguish between harmful and normal or positive autoimmune response.

Clinically, the wide spectrum of autoimmune diseases has been divided into 'organ-specific' diseases and systemic or 'non-organ-specific' ones. At one end of the spectrum, organ specific autoimmune diseases are found, such as Hashimoto's thyroiditis, Graves' disease, pernicious anaemia, Addison's disease and Diabetes Mellitus Type-I. At the other end, non-organ-specific autoimmune diseases are found, such as rheumatoid arthritis, scleroderma, systemic lupus erythematosus. In Hashimoto's thyroiditis, situated at one pole of the spectrum, the antibodies are directed at antigens specific for just one organ in the body. At the other end of the spectrum, Systemic Lupus Erythematosus (SLE), the antibodies are directed at antigens which are widespread throughout the body. The most common target organs in organ-specific disease include the thyroid, adrenals, stomach and pancreas, where the nonorgan-specific diseases (rheumatic diseases) involve the skin, kidney, joints and muscles.

\subsection{The autoimmune thyroid diseases (AITD)}

Autoimmune thyroid disease (AITD) defines a group of conditions characterized by the presence of circulating thyroid antibodies and immunologically competent cells, capable of reaction with certain thyroid constituents. This does not imply that these antibodies always have a causal relationship with the thyroid disorder.

The autoimmune thyroid diseases consist of Hashimoto"s thyroiditis (including myxoedema), silent (painless) thyroiditis, post-partum thyroiditis and Graves' disease. Hashimoto's thyroiditis and Graves' disease are the best known representatives. These will now be discussed in more detail. Postpartum thyroiditis (silent painless thyroiditis in the postpartum) will be discussed in chapter IV.

\subsubsection{Hashimoto's thyroiditis}

The prevalence of Hashimoto's thyroiditis (HT) is of the order of $2-5 \%$ and is 10 to 15 times more common in women than in men. It is particularly common in the 30 to 50 year age group. The patient may complain of thyroid enlargement, and hypothyroidism can occur at any time. In the subacute variety, pain and tenderness of the gland may be 
prominent, but this is uncommon. Histologically the thyroid gland shows a spectrum of the juvenile mild form with little infiltration, the oxyphil variant with diffuse lymphocytic infiltration and lymphoid follicles, many plasma cells and disruption of thyroid follicles with disruption of the basement membrane, and the fibrous variant where the normal structure of the thyroid cell is lost. Some epithelial cells are enlarged and show a characteristic oxyphilic change in the cytoplasm (Askanazy cells), while others are hyperplastic. According to the stages mentioned, the clinical picture can be divided into: goitre without thyroid dysfunction, goitre with subclinical hypothyroidism, and goitre with clinically manifest hypothyroidism. HT has a familial aggregation. It may occur in families in conjunction with other organ-specific autoimmune diseases (Diabetes Mellitus Type I, Addison disease, iron deficiency anaemia). More than $90 \%$ of patients has elevated titres of microsomal antibodies - predominantly in the early stage of the disease - and thyroglobulin antibodies, the latter especially in the final stage of the disease, reflecting the cellular destruction. The cytotoxic effect of MsAb on the target cells appears to correlate significantly with the MsAb titres in the sera. TSH receptor antibodies (presumably of TSH receptor blocking activity) are found in up to $15 \%$ of HT.

\subsubsection{Graves' disease (GD)}

Hyperthyroidism is thought to occur in $1-3 \%$ of the general population, Graves'disease being the cause in at least $70 \%$ of cases. It occurs eight times more frequently in women than in men, usually in the third to fifth decades. The clinical picture varies from diffuse hyperplastic goitre and extrathyroidal manifestations - exophthalmos and pretibial myxoedema to isolated hyperthyroidism without thyroid enlargement or secondary signs. Although GD shows a familial tendency, less than half the patients have a positive family history. GD is strongly associated with the HLAB8 and HLA-DR3 region in Caucasians. It is now generally agreed that hyperthyroidism and goitre in GD result from the action of thyroid stimulating antibodies which mimic the effect of TSH. There is now conclusive evidence that these immunoglobulins are antibodies to the TSH receptor of the thyroid membrane. These antibodies are actually a heterogenous population of stimulatory and inhibitory IgG proteins. When patients are hyperthyroid (as in GD), the stimulatory antibodies predominate, whereas TSH-receptor blocking antibodies may predominate in some cases of hypothyroidism. 


\section{Chapter III}

\section{Mood disorders in the postpartum period}

\subsection{Introduction}

Interest in postpartum mental disorders has a long history. In his book 'Maladies Mentales', from 1845, Esquirol devoted a chapter to puerperal psychosis. In 1858, Marcé described psychiatric complications following labour in 31 patients. More recently, there have been several studies either relying on global judgments regarding the presence or severity of depression, or focusing on emotional distress in general rather than on depression. Gordon and Gordon $(1959,1965)$ studied postpartum women whose mood state was rated on a five-point scale by an obstetrician and public health nurses. However, it was not until 1968 that Pitt carried out a prospective study of postpartum depression with the aid of well-defined diagnostic criteria. Prospective studies which could meet the criteria test of proper methodology in research were not performed until the early eighties.

\subsection{Definitions}

Postpartum mental disorders are generally classified as follows: postpartum psychosis, postpartum depression and postpartum blues.

Postpartum psychosis is a rare disorder characterized by severe mental decompensation, requiring acute hospitalization and treatment. It is characterized by a schizophrenic or affective mood disturbance starting within one month of delivery (Kendell et al. 1987, Brockington et all 1982, Paffenbarger 1982, Hamilton 1982, Koerselman 1983, Brockington and Cox 1988. Klompenhouwer et all, 1988). The variability of the symptoms is typical of the disorder: highly fluctuating and frequent changes in the disorder which occur from one moment to another: kaleidoscopic picture(Kortmann 1983). Primiparity, Caesarian section, perinatal death and poor relationship with the partner appear to be risk factors, as well as previous psychosis and a family history of psychiatric disease. Postpartum psychosis occurs in $0.1 \%$ of women who deliver a baby. The prognosis is good if the disorder is recognized in time and treated adequately (Kendell et al., 1985, 1987, Cox et al. 1982). However, further childbirth may intensify and detoriate the disorder (Davidson and Robertson, 1985). 
Postpartum blues are mild mood disturbances marked by emotional instability (crying spells without any cause, insomnia, exaggerated cheerfulness, anxious tension, headache, irritability, etc.). In most cases the complaints develop within the first week after labour, continue for several hours to a maximum of ten days and then disappear spontaneously (Stein, 1982 Kennerly and Gath, 1986, 1989a). Because of its frequent occurrence (30-70\% after delivery), there are authors who consider it a normal physiological event. It is assumed that the biological changes in the first week postpartum are responsible, in view of the timing and course of the symptoms. Ehlert et al. (1990) reported blues symptoms to be related to elevated morning levels of salivary cortisol. Other authors (Smith et al., 1990) found that women who reported blues showed greater falls in their plasma beta-endorphins concentrations after delivery than women without blues. There are studies reporting a similar period of dysphoric mood postoperatively (Levy, 1987). However, recently it was demonstrated that complaints relating to blues are specific to the puerperium and are essentially different from non-specific mood fluctuations on physical and emotional stress, e.g., postoperatively or post-traumatic (Kennerly and Gath 1989a, lles et al. 1989). O'Hara et al. (1990a) showed in their prospective controlled study that childbearing women show a four-fold higher rate of mild dysphoria in the first week after delivery compared with non-childbearing women. The main factors positively associated with maternity blues are: poor social adjustment, poor marital relationship, previous history of severe or moderate premenstrual tension, high neuroticism, fear of labour and anxious and depressed mood during pregnancy (Kennerly and Gath 1989b, Smith et al. 1990). Generally, there are no associations found between the blues and demographic and social factors, life events and obstetric factors (Kennerly and Gath 1989b, O'Hara et al. 1990a). It is not clear to what extent severe "blues", which last for more than ten days, are predictive of postpartum depression (Kendell et al. 1981, Handley et al. 1980, Kennerly and Gath 1989b).

Postpartum depression - as pointed out by Koerselman (1982, 1983) often also incorrectly called postnatal depression - will be further discussed below. There are authors who argue that the name "postpartum depression" is in some way a confusing term: one assumes that the events occurring during pregnancy (hormonal changes) or birth are somehow contributory factors. However, evidence today, as will be explained further on, suggests that factors which are associated more with motherhood circumstances (e.g., availability of social support, changes in life style) than with pregnancy and birth may be major contributing factors to this kind of depression. The expression "maternal depression" 
or 'motherhood depression' reflects more accurately a depression related primarily to the motherhood role (Chalmers and Chalmers 1987). Moreover, in the first chapter it was already mentioned that, in the DSM-III-R, there is no separate description of postpartum depression: it is generally accepted that the depressive mood disorders in the postpartum period are not nosologically different from depressions outside this period.

The boundaries between these three mental disorders, blues, psychosis and depression in the postpartum period, are not clearly defined, as pointed out by O'Hara and Zekoski (1988). It is believed that they can be set on a continuum ranging from psychosis $(0.1 \%)$ to positive mood which existed during and before pregnancy (20-30\%). Between these two extremes lies depression which is so severe that treatment is required (3$7 \%$ ), less severe a depression which however lasts for more than one week and leads to dysfunction of the mother (8-20\%), and dysphoric mood which persists for a period of several hours to one week and does not cause functional impairment.

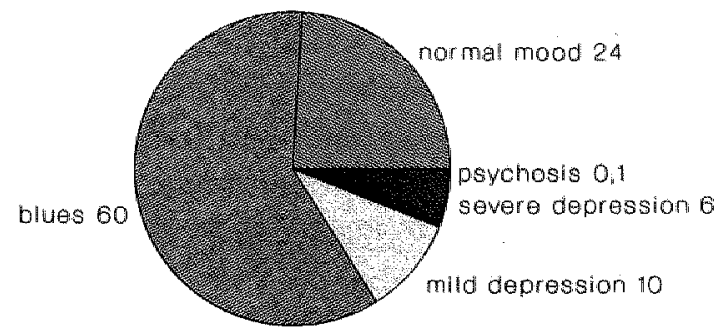

fig 3.1 postpartum mood state prevalence in percentage

\subsection{Onset, prevalence and course of postpartum depression}

Studies into the incidence of postpartum depression show rather divergent results. Moreover, many studies do not specifically investigate depression, but rather consider any emotional symptom that is detected (O'Hara and Zekoski 1988). The research design is sometimes retrospective, sometimes prospective, and there are differences in the criteria for depression, the size of the patient population, the kind of assessment and the observation period. With regard to the latter issue, there has been considerable debate as to what constitutes the limit of the postpartum period. For postpartum psychosis, it is generally accepted that onset within the first month is essential (Brockington 1982, Kendell 1987). There is, by contrast, no agreement regarding the limit for the onset of postpartum depression. A major problem in determining a time limit is the continuing lack of knowledge of the specific etiological or risk factors 
for postpartum depression which are associated with childbirth (O'Hara and Zekoski, 1988). If hormonal disturbance was thought to be a prime etiological factor, then the return to normal hormonal levels had to be seen as the ultimate limit for the beginning of what is called a postpartum depression. Moreover, a study of the natural history of depressions during the puerperium might elucidate on the most suitable time for assessment. Again, there are rather conflicting data regarding an increased risk. Most of the studies carried out so far give evidence of the depression occurring a few weeks to months postpartum with a 'peak' around the fourth month (Kendell et al. 1987, Watson et al. 1984, Kumar and Robson 1984, O'Hara and Zekoski 1988, O'Hara and al. 1990), although Nott (1982) describes the highest prevalence occurring at nine months'postpartum.

As will be explained later on in this thesis, one of the major explanations for is discrepancy in the outcome of several studies is the assumption that it depends on the time of assessment in the postpartum period as to whether or not a significant relationship between some variables and postpartum depression is found.

The results of the most important prospective studies in which depression was carefully diagnosed with the aid of self-assessment scales or a semistructured psychiatric interview are summarized in table 3.1.

table 3.1 prevalence of postpartum depression

\begin{tabular}{lcl}
\hline study & prevalence $\%$ & assessment postpartum \\
\hline Pitt (1968) & $10.8-19.7$ & $6-8$ weeks \\
Cox et al. (1982) & 13 & 4 months \\
Cox (1983) & 10 & 3 months \\
Cutrona (1983) & 8.2 & 2 and 8 weeks \\
Kumar and Robson (1984) & $4.6-14.9$ & $3,6,12$ months \\
O'Hara et al. (1984) & $10-12.0$ & 9 weeks \\
Watson et al. (1984) & $7.8-12.0$ & 6 weeks \\
Cooper et al. (1988) & $5.2-8.7$ & 3 , 6, 12 months \\
Whiffen (1988a) & 16.5 & $6-8$ weeks \\
Troutman \& Cutrona (1990) & $20-26$ & 6 weeks, 12 months \\
O'Hara et al.(1990a) & 10.4 & 9 weeks \\
\hline
\end{tabular}

If a prevalence rate of $10 \%$ is assumed and this percentage is applied to the situation in The Netherlands, this would mean that approximately 20,000 women per year would be depressed postpartum (in 1989, there were 189,000 women who delivered a baby in The Netherlands). In the study of Troutman and Cutrona (1990), a very high prevalence rate was found $(26 \%)$. However, this study was carried out in adolescent mothers 
(14 to 18 years old, only $20 \%$ of them being married) who are believed to present a group at particular risk for depression in general.

In spite of the fact that mothers in the puerperium are still receiving extra medical attention, it is believed that most depressed mothers do not actually receive help, although the majority is thought to need it (Cox 1988). If not recognized, or not well treated, the depression can last for more than a year after childbearing. The detrimental effects on family life, especially for the child, are well described: poor weight gain, behavioural problems, poor growth, accidents, and affective illness (Zuckerman and Beardslee 1987, Uddenberg and Englesson 1975, 1978. Davidson and Robertson, 1985, Cogill et al. 1986, Murray and Stein 1989).

It is still frequently debated as to whether or not depression in the postpartum period occurs more frequently compared to other periods in a woman's life. Some studies which adequately compared prevalence rates of depression during pregnancy $(4.2 \%)$ with the postpartum period $(14.9 \%)$, found a three-fold increase (Kumar and Robson 1984). Other studies found the same prevalence rate for depression during and after pregnancy (Cooper et al. 1988). Comparing prevalence rates for depression in studies of postpartum depression with prevalence rates in other epidemiological studies on depression, proved to be problematic (O'Hara and Zekoski 1988). Different criteria for depression are used across studies and the periods under study are quite different - period versus point prevalence - and finally the characteristics of the populations involved seem to be quite different. Several authors compared their prevalence rates with those of studies carried out in the same area among other populations by other authors and found no differences (Watson et al. 1984, Paykel 1980, Cooper et al. 1988), or a much higher frequency postpartum (O'Hara et al. 1984).

The best way to investigate a possible difference between postpartum women and non-postpartum women is to use a control group which is screened in the same way: the same instruments, same period of assessment, same frequency of assessment, same characteristics. There are only two studies published so far which were performed in this way. O'Hara et al. (1990a) and Troutman and Cutrona (1990) reported no differences in the prevalence rate of depression between a postpartum group and a control group of non-childbearing subjects. However, depressive mood symptoms did occur more often in the postpartum group, suggesting that the early puerperium constitutes a time of increased psychological distress for women.

Finally, as pointed out by Lewinsohn (1988), in a large study concerning possible risk factors for depression, it was found that three factors strongly predict depression in a general population: a previous episode of 
depression, being a woman and being young (mean age 35 years). It is obvious that the latter two factors are always present in a study of postpartum depression, so we could argue that in screening for postpartum depression, a certain kind of bias might occur.

\subsection{Etiological aspects of postpartum depression}

As mentioned in the first chapter, the etiology of a depressive mood disorder is multifactorial. For the sake of clarity, the model presented in chapter I will be used to describe the results of research concerning risk factors for postpartum depression.

\subsubsection{Predisposition}

The predisposition (genetic and psychological characteristics) to postpartum depression has only occasionally been investigated. The few studies that have been carried out resulted in conflicting data: $\mathrm{O}^{\prime} \mathrm{Hara}$ (1986) and Watson et al. (1984) found an increased risk in women with a first-degree relative who had had episodes of depression to develop depression in the postpartum period; however, Kumar and Robson (1984) reported no association between the diagnosis of postpartum depression and family psychiatric care. Neuroticism does not seem to be related to an increased risk of postpartum depression. Several studies have shown that women who report high anxiety levels during pregnancy were obviously more depressed after delivery (Watson et all. 1984, O' Hara et al. 1990b). Most of the studies found that women who had experienced a psychiatric disorder in the past were at increased risk for developing postpartum depression (O'Hara et al 1983, O'Hara 1986, O'Hara et al 1990b, Paykel et al. 1980, Watson et al. 1984, Uddenberg 1974).

\subsubsection{Precipitating factors}

There are many studies concerning the precipitating factors for postpartum depression. The most important factors are stressful life events, lack of social support, marital and parental relationships, obstetrical and gynaecological factors, and finally the child's temperament as a stressor for the mother.

Pregnancy and birth are generally considered to be stressful life events, which as such can provoke depression. Furthermore, it is believed that additional stressful life events occurring during pregnancy and immediately postpartum lead to an increased risk of postpartum depression (Cox 1988). As pointed out in chapter I, one major problem is how to discriminate between a direct predictive aspect of a stressful life event on the outcome of postpartum depression and the etiological importance of stressful life events (Sanderman 1989). Several studies have shown a distinct relationship between the occurrence of stressful life 
events and the outcome of postpartum depression (Watson et al. 1984, O'Hara et al 1983, O'Hara 1986, Whiffen 1988a, Arizmendi and Affonso, 1987). O'Hara et al.(1984, 1990b) proposed a vulnerability-stress model based on interactions of vulnerability-life events. A central feature of this model is vulnerability. Vulnerability is defined as any characteristic of a person, or an environment, which increases the risk of strains occurring, however, only in the presence of provoking agents (Brown 1989). One of the aspects of strain is depression or depressive symptoms. Depression or depressive symptoms are thought to occur when an individual perceives the stimulus from the environment to exceed his own competence to cope with it.

Paykel et al. (1980) regarded the stress of pregnancy and childbearing as being important only as an additional stress in tenuous situations, rather than as a major cause. Recently, O'Hara et al. (1990b), in their controlled study, demonstrated that in the childbearing group as well as in the nonchildbearing group, the vulnerability-stress interactions are strong predictors of depression. There are other studies (Hopkins et al. 1987, Kumar and Robson 1984) which did not find an association between stressful life events and postpartum depression.

There are several studies which investigated the role of social support as a buffer against postpartum depression. They have been summarized by O'Hara and Zekoski (1988). Most of the studies found a negative correlation between the emotional and instrumental support perceived from the partner, on the one hand, and the occurrence of postpartum depression in the woman on the other. Interestingly, O'Hara et al. (1982, $1984,1986)$ and Cutrona (1986) demonstrated that this relationship could only be found in the postpartum period and not during gestation: women who were depressed during gestation did not report less adequate support from their partners than did non-depressed women. Another important finding was the fact that, in one study, social support was not a buffer against depression at two weeks'postpartum, whereas it was later on in the puerperium at eight weeks'postpartum (Cutrona 1984). This means that, during the postpartum period, at different assessment points different etiological factors may be responsible for the onset of depression.

Cutrona $(1983,1984)$ published data in which she demonstrated the different dimensions of social support that play an important role in buffering against postpartum depression. The dimensions of emotional support, tangible support and network support proved to be negatively correlated with postpartum depression. However, one important finding was the fact that social support showed a buffering effect only in minor depression and not in major depression, suggesting that coping behaviour can be influenced positively by social support only to a certain degree 
(Cutrona 1984). In a recent study, Whiffen (1988a) emphasized the relationship between marital adjustment in pregnancy and the occurrence of postpartum depression. Women with good marital adjustment - which suggests that they perceive adequate social support from the spouse during gestation, less frequently reported depressive symptoms in the postpartum. In the study of O'Hara et al. (1990b), the role of social support was investigated in a social and cognitive vulnerability model. While other variables, such as a previous history of depression and life stress, proved to be highly significant in the prediction of postpartum symptomatology, the social and cognitive variables only accounted for $1 \%$ of the variance in postpartum symptomatology, suggesting a minor association between social support and depression.

Almost all the studies investigating marital relationship and postpartum depression outcome found a strong correlation between poor relationship with the partner and the likelihood of developing postpartum depression (O'Hara and Zekoski, 1988).

The woman's relationship with her parents can play an important part in two aspects. In the first place, the transition to motherhood (especially in primiparae) may be the reason to actualize a disturbed relationship with her parents (the mother in particular). Secondly, parents are often very supportive to a women who has just given birth (O'Hara and Zekoski 1988). If there is lack of support from the parents depression might occur more frequently. Several studies found an association between poor parental relationship and the occurrence of postpartum depression (Uddenberg 1974, Kumar and Robson 1984), which could not be confirmed however by Paykel et al. (1980).

The loss of parents, in particular of the mother, at a young age has been identified as a risk factor for depression (Brown and Harris 1978, Brown et al. 1986, 1989, Harris et al 1986, 1987), although the data are not conclusive (Brown 1989). The quality of replacement of parental care after such a loss is reported to be more important than the loss of the parent itself: inadequate replacement of care proved to be correlated with increased risk of depression (Brown 1989). Only a few studies reported a relationship between parental loss and postpartum depression (O'Hara and Zekoski, 1988). Watson et al. (1984) and Paykel et al. (1980) could not find any relationship.

Many studies have investigated to what extent obstetrical complications of pregnancy and/or labour play a part in the development of postpartum depression. The data are conflicting, but the general conclusion is that the influence, if it exists, will be very weak. The extent to which parity is involved is not clear (O'Hara and Zekoski, 1988, O'Hara et al. 1990b). 
The extent to which menstruation problems are important has only briefly been investigated (Gitlin and Pasnau, 1989). As summarized by O'Brien (1987), the premenstrual syndrome (pms) can be defined as a disorder with non-specific somatic, psychological or behavioural characteristics regularly recurring in the premenstrual (luteal) phase of the menstrual cycle. Symptoms must resolve completely by the end of the menstruation, leaving a symptom-free week. The psychological key symptoms are irritability, aggression, tension and anxiety. The most prominent somatic complaints are abdominal bloatedness, weight gain, headache, abdominal pain and breast symptoms. These symptoms should be of important severity to disrupt any aspect of social, family or occupational life. There is still no consensus about the way in which pms should be diagnosed in an appropriate way. The prevalence rate ranges from 5-97\% in the literature ( $O^{\prime} B$ rien 1987). Indeed, most of the discrepancies between these prevallence rates can be explained by the use of different definitions of pms, and moreover differences in the characteristics of the investigated samples and a retrospective versus a prospective manner of assessment are responsible for the divergence of the results. A diversity of etiological theories exists ranging from purely hormonal theories - such as imbalance in the renin-angiotensin system, imbalance of oestrogen/progesterone or decreased levels of endorphins - to purely psychological theories. A possible relationship between pms and blues and between pms and postpartum depression has been reported in several studies (Pitt 1968, Uddenberg 1974).

A factor that has received little attention is the temperament of the infant as part of the factors contributing to the severity of the stress experienced by the mother who has recently delivered (Cutrona and Troutman 1986). It is only recently that studies have been carried out which have investigated the existence of an interaction. They all found an important association between the occurrence of maternal depression and the extent to which the child was experienced as stressful by the mother (Atkinson and Rickel 1984, Cutrona and Troutman 1986, Hopkins et al. 1987, Whiffen 1988a, Whiffen and Gotlib 1989, O'Hara et al. 1990b).

Infant temperament exerts both indirect and direct effects on depression. The indirect influence probably interacts at two different levels. At the behavioural level, women with little confidence in their parenting ability behave in a way that does not elicit positive reactions from their child. According to behavioural theories (Lewinsohn, chapter I), a lack of positive reaction may lead to depression. At the attributional level, low self-efficacy leads to a predominance of self-blaming causal explanations for negative events. The efforts, even of highly skilled parents, will not 
succeed in quietening the cries of an unhappy baby and so the selfblaming explanations may lead to depression.

The direct relationship between infant temperament and maternal depression may be explained in a number of ways. The sound of infant crying is highly aversive to adults. Prolonged exposure to such an aversive stimulus, without control over its termination, may lead to a dysphoric affect. Moreover, a baby which is difficult to handle may disrupt many aspects of a woman's life and may place strain on the marital relationship (Cutrona and Troutman 1986).

Several background features have been investigated that might make a person more vulnerable to postpartum depression. These include demographic factors such as social class, marital status, age and resigning from a job. Only the latter was shown to be associated with increased risk of postpartum depression (Watson et al 1984, O'Hara et al. 1984, Kumar and Robson 1984). In one study, poor marital relationships were found to be correlated to the outcome of postpartum depression (Fegetter and Gath 1981).

It is only recently that medical anthropologists have begun to pay attention to the impact of cultural factors on the occurrence of postpartum depression. Stern and Kruckman (1983) put forward the challenging hypothesis that it is the absence of postpartum behavioural constraints in Western society that is important in the causation of postpartum depression. The often young and inexperienced parents cannot rely on a fixed or established behavioural pattern. Other anthropologists argue that the absence of rituals to celebrate the transition to parenthood could play a causative role. The change of status from that of a childless woman to that of a mother is a major change of role which should be marked by a public change in social status, and the carrying out of an appropriate "rite de passage" (Seel 1986). However, as shown by Cox (1983) and Mampunza et al. (1984), postpartum mood disorders also occur in non-Western societies. Moreover, it was shown that mood disorders in the puerperium formed a clearly defined psychiatric disease long before Western psychiatric terminology was introduced (Cox 1988). The mechanism of precipitation may, as in chapter I, be divided into a psychological and a biological part.

Psychological studies on predictive factors for the occurrence of postpartum depression include attributional style, self-control attitude, and cognitive-behavioural characteristics. Some authors favour a strong relationship between these psychological characteristics and the occurrence of postpartum depression ( $O^{x}$ Hara et al. 1982, Cutrona 1983, Atkinson and Rickel 1984), while others could not find such association (O'Hara et al. 1984) in a later study. 
There were many studies concerning the buffering-hypothesis of social support on postpartum depression. Most of them found a direct relationship between social support perceived by the mother (from partner, relatives and friends) and the occurrence of postpartum depression (Paykel et al. 1980, O'Hara et al. 1983, O'Hara et al. 1986, Cutronal 1984, Dimitrovsky et al. 1987, Whiffen 1988a). As pointed out by Cutrona (1984), one of the strongest predictors of the level of postpartum depressive symptoms is the non-availability of companionship and the absence of feelings of belonging to a group of similar persons. There are authors who could not find this association (Hopkins et al. 1987). However, as pointed out in chapter II, one of the major problems in research into social support is the difference in methods used to measure social support.

Biological studies on the etiology of postpartum depression can be regarded from two basic perspectives. 'Non-specific' biological factors reflect characteristics fundamental to depressions also occurring at other times. These include biological factors such as cortisol, neurotransmitters, peptides, hormones, etc. The second perspective is more concerned with the special features of postpartum mood disorders and potential hormonal dysfunction. These "specific-biological' factors are particular hormonal changes during and after pregnancy, e.g., of oestrogens, progestagens and prolactin (O'Hara and Zekoski 1988).

Studies on these biological factors have recently been reviewed by O'Hara and Zekoski (1988) and George and Sandler (1988). As far as these studies concern the postpartum period, they will be briefly summarized here.

Most of the studies concerning the role of non-specific biological factors in relationship to mood disturbances in the postpartum are carried out within the first week postpartum, considering a relation to "blues" disorders. Studies into a possible relationship with postpartum depression are rare. Handly et al. (1980) reported a link between low levels of circulating tryptophan and postpartum depression which could not be confirmed by Gard et al. (1986). The latter study, however, claimed to find a positive association between the level of non-esterified fatty acids (which compete with tryptophan for albumin binding) at three days' postpartum and the occurrence of postpartum depression. Plasma cortisol levels were not shown to be different in depressed and non-depressed postpartum women (Handly 1980, Kuevi et al., 1983). Ehlert et al. (1990) showed that women who reported blues had elevated morning levels of cortisol in saliva on those days on which the symptoms of blues occurred, in contrast to those days without symptoms as well as in contrast to those 
women who did not experience postpartum blues. Recently O'Hara et al. (1990b) could not find any difference in total cortisol and urinary cortisol levels between postpartum depressed women and non-depressed women. Dexamethasone suppression (DST) in postpartum depression was evaluated by Greenwood and Parker (1984). Although a very high percentage of subjects had an abnormal DST response in the first week postpartum, there was no relationship between DST-response and depression symptom level at six weeks' postpartum. Similar findings were reported by O'Hara et al. (1990b). However, there is evidence that the DST test cannot adequately be interpreted in the immediate postpartum period (George and Sandler 1988). The possible role of thyroid hormones in mood disorders in the postpartum will be discussed in chapter $\mathrm{V}$.

The hypothesis that specific-biological factors (hormones) play a role in the etiology of postpartum depression mainly relies on three phenomena. Firstly, hormones such as oestradiol and progesterone show dramatic changes in concentration over a very short period of time around delivery. Secondly, these hormones also show marked shifts at other times when many women experience mood disturbances (premenstrual disorders, menopause). Thirdly, 'artificially' induced abrupt changes of the same hormones (ovariectomy, oral contraceptives) are often accompanied by fluctuating mood disorders (O'Hara and Zekoski 1988. Halbreich 1987, Glick et al., 1987). Before discussing the data obtained from research so far in more detail, some theoretical reflections are worth mentioning.

Until recently, the outcome of most biochemical tests in neuroendocrinology was mainly interpreted in one way: the tests reflect abnormal changes of a particular kind in a neuro-hormonal axis system (Halbreich 1987). For example, the review of articles discussing HPA axisabnormalities in depression shows no conclusive data. There are several explanations for these findings.

The first assumption, that one single factor (e.g., cortisol) is responsible for one syndrome (e.g., depression) and that changes in peripheral plasma levels represent changes in central nervous activity, is too simplistic. Changes in the final peripheral stage of the HPA system can be at least partially dissociated from changes in other stages: altered receptor sensitivity, circadian rhythm disturbances, involvement of control mechanism for ACTH production by other hormone axis systems. The latter two factors have already been shown to occur. Instead of a vertical 'within systems', a horizontal 'across systems' has to be postulated (Halbreich 1987).

Secondly, not the change in the absolute levels of a hormone but rather 
the rate in change-over time may be an important feature. Empirical data underlining this hypothesis are the observation that acute withdrawal of psychopharmaca is often accompanied by mood disturbances, which do not occur if drugs are reduced at a slow pace. Moreover, from stress research, the existence of two distinct receptor mechanisms involved in mediating slow "activation" - coordinating actions of glucocorticoids and rapid "adaptation" response of the brain has been postulated, As shown in fig. 3.2 these theoretical reflections can be applied to the postpartum period as well (Halbreich 1987).

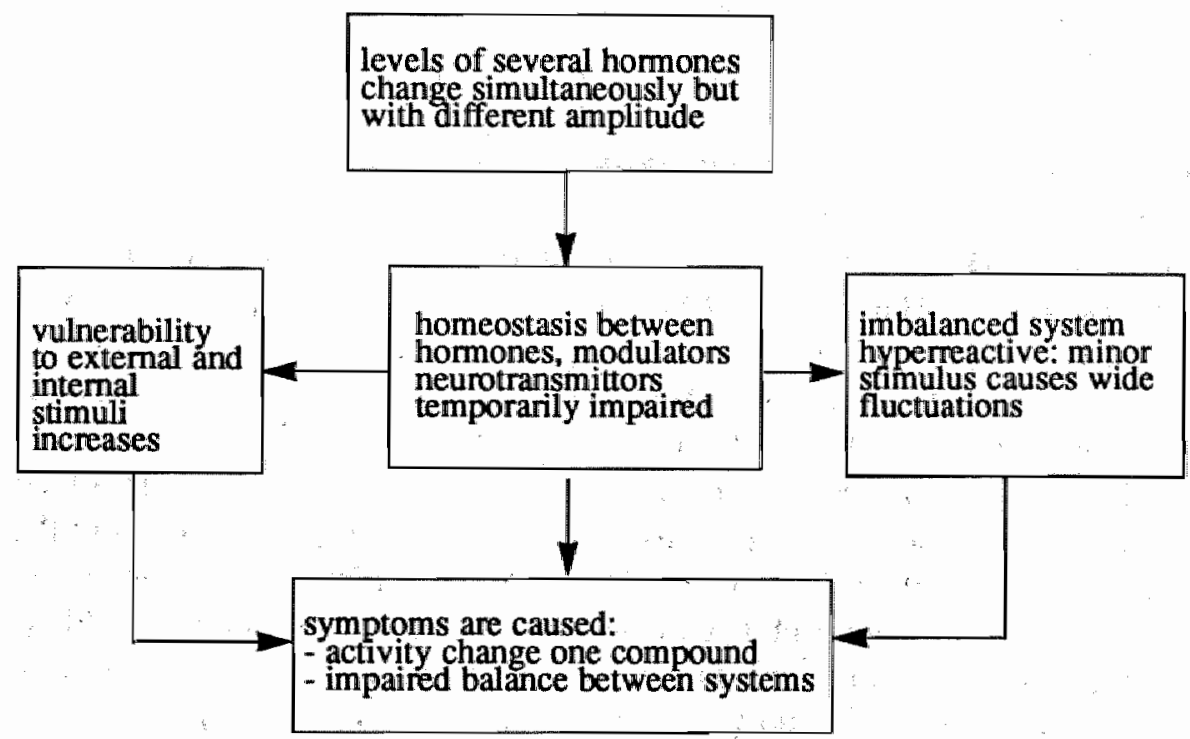

fig 3.2 rate-change of hormonal concentrations (postpartum, premenstrual, menopausal)

Finally, as summarized by George and Sandler (1988), several methodological aspects have to be mentioned which sometimes make interpretation of results hazardous:

- the total and protein-bound concentrations of the various

substances are frequently measured and not the levels of the free, biologically active, hormone;

- the basic conditions in which blood-sampling takes place are not standardized, although this is required in view of the fluctuation in concentrations which often exists in the hormones under study (diurnal rhythm, breast feeding, menstruation cycle);

- the methods of analyzing the samples differ, so that it is difficult to compare the results of different studies; 
- the study populations are often small and rarelly include a control group;

- the fact that stress as such often causes fluctuations in hormone levels is often not taken into account.

Some authors reported that low oestradiol and progesterone levels increase the risk of postpartum depression (Harris et al. 1989), others found no relationship between the hormone levels and depression (Gard et all. 1986). Although there are some authors who claimed successful treatment of postpartum depression with high doses of progesterone (Dalton 1980), others failed to find a relationship (Kuevi et al. 1983, O'Hara et al. 1990b). So far, no double-blind controlled cross-over study has been undertaken to investigate the possible benefits of progesterone administration in the postpartum period. Studies into the possible role of prolactin in the puerperium have shown no conclusive data. Alder et al. (1986) did not find any association, Harris et al. (1989) suggested that low levels of prolactin enhanced the risk of postpartum depression, which could not be confirmed by O'Hara et al. (1990b). However, changes in prolactin levels are difficult to interpret in the puerperium, not only because of the influence of possible breastfeeding but also because of normal physiological fluctuations (George and Sandler 1988).

As far as we know, except for microsomal antibodies which are involved in postpartum thyroid dysfunction, no data have been published about the interaction which might exist between postpartum depressive mood disorders and immunological changes during and after pregnancy. This is all the more surprising as it has been shown that the immune system in women presents important alterations during and immediately after pregnancy.

\subsection{Treatment and prevention}

Apart from the general treatment of depression (chapter I), a specific treatment for postpartum depression has been developed. As mentioned before, although some authors claimed successful treatment with pyridoxine and progesterone, others could not confirm these results (O'Hara and Zekoski 1988, George and Sandler 1988).

Intervention programmes are used in an attempt to train future parents during pregnancy to cope better with risk factors (poor marital relationship, giving up work, additional stressful life events). The results of these studies are not conclusive (O'Hara 1988).

Another method is to screen all women for depressive symptoms at set times during pregnancy and after delivery. Nordström et al. (1988) showed that women with high scores on the antenatal "Health 
Questionnaire" more frequently presented with depression and depressive symptoms in the postpartum than women with low scores. Due to the fact that several authors have pointed out that existing self-rating scales appeared to be less valid in the postpartum period (Cox et al., 1987, Whiffen, 1988b, Harris et al., 1989), the Edinburgh Postnatal Depression Scale was developed (Cox et al., 1987, Harris et al., 1989), and this has been adapted for women in the postpartum period. Intervention or further screening is advisable for women with a high score. Holden et al. (1989) reported a significant difference in recovery from postpartum depression between a group women in whom intervention by health visitors had taken place compared with a control group without intervention. Oakley et al. (1990) showed that women with social support intervention during pregnancy were significantly healthier in the early postpartum than mothers who had had no intervention during pregnancy. 
44 


\section{Chapter IV}

\section{Postpartum thyroid dysfunction}

\subsection{Introduction}

In 1948, Roberton described the occurrence of hypothyroidism in the postpartum period in an endemic goitre area. In the Seventies, it was shown that the severity of autoimmune diseases of the thyroid (Graves' disease and Hashimoto's thyroiditis) decreased during pregnancy and exacerbated in the postpartum period. In 1974, Nelson and Palmer described the remission of goitrous hypothyroidism during pregnancy, followed by a recurrence in the postpartum period. It was Amino et al. $(1976,1977)$ who postulated for the first time on a relationship between transient hypothyroidism, pregnancy and postpartum. Ginsberg and Walfish (1977) published their data on the occurrence of transient hyperthyroidism after pregnancy, which was thereafter confirmed by many case reports. Prospective epidemiological studies from different parts of the world demonstrated the universal occurrence of postpartum thyroid dysfunction (Amino et al. 1982a, Walfish and Farid 1982, Jansson et al. 1984, Walfish and Chan 1985, Freeman et al. 1986, Nikolai et al. 1987, Lervang et al. 1987, Fung et al. 1988, Vargas et al. 1988, Hayslip et al. 1988a). It was generally concluded from these studies that postpartum thyroid dysfunction is an autoimmune syndrome which is also influenced by genetic and environmental factors.

\subsection{Prevalence of postpartum thyroid dysfunction}

The prevalence of postpartum thyroid dysfunction has been investigated in several prospective studies which are summarized in table 4.1 . It can be concluded from these data that the prevalence rate varies from $1.9 \%$ to $21 \%$. There are several factors which might explain this broad range. Firstly genetic, geographical (iodine intake) and racial factors should be mentioned (Jansson et al. 1986, Hayslip et al. 1988a). Secondly, the design of the study plays an important role: how many times were the women screened, when did the screening start and for how long were they screened? As will be shown, most women with biochemical thyroid dysfunction are symptom free, the dysfunction is transient and can occur from one month after delivery until one year postpartum. It is reasonable to assume that many 
table 4.1 prevalence of postpartum thyroid dysfunction

\begin{tabular}{lcl}
\hline \multicolumn{1}{c}{ study area } & prevalence \% & $\begin{array}{c}\text { assessment } \\
\text { in months }\end{array}$ \\
\cline { 2 - 3 } Amino et all.(Japan, 1982) & 5.5 & 3 \\
Jansson et al. (Sweden, 1984) & 6.5 & $2+5$ \\
Walfish \& Chan (Canada, 1985) & 7.1 & +6 \\
Freeman et ail. (USA, 1986) & 1.9 & $1+2$ \\
Nikolai et al. (USA, 1987) & 6.7 & $1+3$ \\
Lervang et al. (Denmark, 1987) & 3.9 & 3 \\
Fung et all. (UK, 1988) & 16.7 & $0-12 *$ \\
Hayslip et al. (USA, 1988a) & 3.3 & $0-6 *$ \\
Vargas et al. (Canada, 1988) & 21.0 & $3+6+12$ \\
\hline
\end{tabular}

* assessment monthly

cases were not diagnosed when the sampling occurred only once or twice (Amino et al. 1982a, Jansson et al. 1984, Nikolai et al. 1987, Lervang et al. 1987). Thirdly, it is important to differentiate between an unselected population (Amino et al 1982a, Jansson et al 1984, and Lervang et al.1987) and a selected group, based on the presence of microsomal antibodies (Fung et al. 1988, Hayslip et al. 1988a). Finally, one important feature which may strongly influence the prevalence rate is the definition of thyroid dysfunction. Most of the studies used a biochemical definition. However, Nikolai et al. (1987) also included thyroid enlargement in their definition of thyroid dysfunction. Fung et al. (1988) made their own definition based on reference ranges for fT3, fT4 and TSH in normal microsomal antibody negative pregnant women and normal postpartum women, who remained microsomal antibody negative. If $\mathrm{fT} 3$, fT 4 or TSH concentrations were outside the mean of the corresponding group plus or minus $2 \times \mathrm{SD}$, they were classified as having thyroid dysfunction. The results of the study of Freeman et al. (1986) are influenced by the fact that only $25 \%$ of all women, who were initially screened at one month after delivery, were followed up at 8 to 12 weeks' postpartum.

Recently, a review of the literature on prospective studies on the epidemiology of postpartum thyroid dysfunction was published by Gerstein (1990). He concluded that only three studies (Amino et al. 1982a, Jansson et al. 1984, Lervang et al. 1987) met four methodological criteria: unbiased sampling, high ascertainment rate, distinct definition of thyroid dysfunction, and a homogenous racial population sample. Gerstein concluded that, in an open population, the prevalence rate for postpartum thyroid dysfunction is between 3.7 and $5.9 \%$. 


\subsection{Etiology of postpartum thyroid dysfunction}

The etiology of postpartum thyroid dysfunction can, generally speaking, be divided into two main categories (Walfish and Chan 1985, Goldman 1986) which include more than $95 \%$ of all women with postpartum thyroid dysfunction: postpartum thyroiditis (70-80\%) and postpartum Graves' disease (10-15\%). These will be discussed in more detail below. Other causes occurring in less than 5\% (further description is beyond the scope of this thesis) are de Quervain thyroiditis, toxic nodular goitre, iodine-induced hyperthyroidism and thyrotoxicosis factitia (Walfish and Chan 1985).

\subsubsection{Postpartum thyroiditis}

In 1975, Papapetrou and Jackson described an unusual form of thyroid dysfunction: 'silent' thyroiditis, also known as 'painless thyroiditis with transient toxicosis" or "lymphocytic thyroiditis with spontaneously resolving hyperthyroidism' (Nikolai et al., 1980, 1981, Woolf 1980, Amidi and Berghuis 1983, Dahlberg et al., 1983, Vitug and Goldman 1985, Jansson et al. 1988, Walfish and Chan 1985). Its frequent occurrence in the postpartum period was initially mentioned by Amino et al. (1976, 1977), Ginsberg and Walfish (1977) and Fein and Goldman (1980).

In its "classical" form, the biochemical disturbances in postpartum thyroiditis show a biphasic pattern (fig 4.1) which is caused by the infiltration of lymphocytes, resulting in thyroid cell destruction. As a consequence, the serum levels of thyroid hormones increase initially resulting in an (often transient) period of hyperthyroidism.

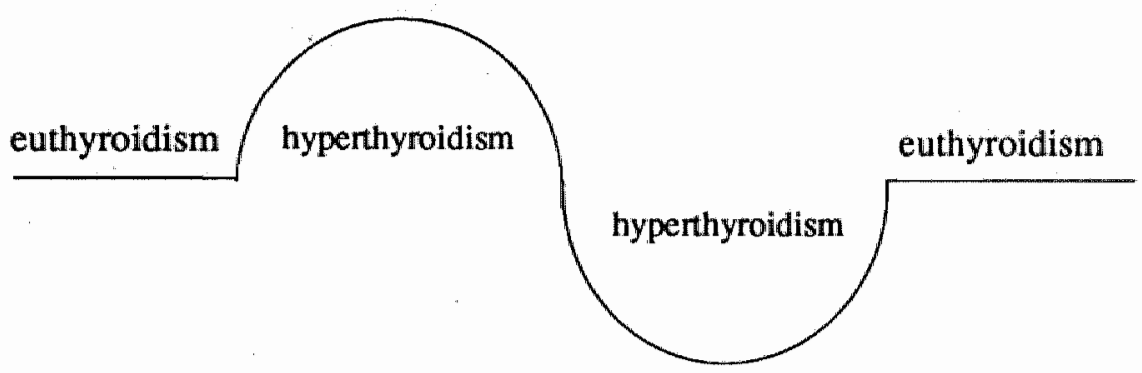

fig. 4.1 classical biphasic pattern of postpartumthyroiditis

Normally, this phase only lasts for a few weeks and is followed by a period of hypothyroidism that usually lasts longer, due to a depletion of the thyroid hormone stores in the colloid. Thereafter, thyroid function spontaneously becomes normal again. In only $40 \%$ of all cases will this biphasic pattern be seen. Most patients, however, only show a hyperthyroid phase or a hypothyroid phase and the prevalence of these separated 
dysfunctions varies geographically. Hyperthyroidism alone is common in some parts of the USA (Nikolai et al., 1987), in Japan (Amino et all, 1982a), and in Walles (Fung et al., 1988). Hypothyroidism alone is more common in Sweden (Jansson et al., 1984), and Denmark (Lervang et al.. 1987). Therefore, in most of the prospective studies carried out so far, women with thyroid dysfunction are usually divided into three subgroups: hyperthyroidism followed by hypothyroidism, hyperthyroidism alone, and hypothyroidism alone (hypothyroidism followed by hyperthyroidism being very rare). There is no clear explanation why mainly hyperthyroid phases are mostly found in some areas, whille in other areas hypothyroid phases are usually reported. Some authors (Jansson et al., 1988) suggest iodine intake to be an important factor.

Microsomal antibodies are frequently observed in postpartum thyroid dysfunction. The target for the microsomal antibodies is the enzyme thyroid peroxidase (TPO). After destruction of the thyroid cell by lymphocytic infiltration, it is believed that the microsomal antibodies disturb the synthesis of iodoproteins, which may result in thyroid hormone deficiency, TSH stimulation and enlargement of the thyroid. A low iodine intake in the postpartum period may further aggravate the hypothyroid phase.

\subsubsection{Postpartum Graves' disease}

Graves' thyrotoxicosis is frequently observed in the postpartum period (Amino et al. 1982b, 1987a, Jansson et al. 1988, Walfish and Chan 1985). This thyrotoxicosis can reflect an exacerbation of Graves' disease which already existed before pregnancy, or it can reflect the first acute phase of Graves' disease in women who were already prone to this autoimmune disorder, but in whom further derangement of the immune response was enhanced by the immune alterations in pregnancy and postpartum. The relative risk of the development of clinically important Graves' thyrotoxicosis in these women increases 6.5 times in the postpartum period (Jansson et al., 1985).

Autoimmune thyroiditis and Graves' disease may co-exist in the same individual. As reported by Amino et al. (1982b) who followed 41 pregnancies in 35 patients with Graves" disease, in almost one third of the pregnancies postpartum thyrotoxicosis was due to the occurrence of postpartum thyroiditis.

\subsubsection{Environmental factors}

It is generally accepted that immune regulatory malfunction in autoimmune thyroid disease - which is usually secondary to a genetic predisposition can be influenced by number of environmental factors. These factors were recently summarized by Safran et al. (1988) and include dietary iodine intake, medicaments (amiodarone, lithium), infectious agents 
(Yersinia enterocolitica) and some pollutants. It is thought that these factors may play an important role, in genetically predisposed persons, in triggering pathogenetic mechanisms that lead to autoimmune thyroid disease. For example, there are several reports of painless thyroiditis which might result from patients having eaten ground beef contaminated with bovine thyroid gland (Kinney et al. 1988, Jansson et al. 1988, Salvi and How 1987) or secondary viral infection (de Bruin et al. 1990). However, Prentice et al. (1990) found no difference in the development of subclinical autoimmune thyroid disease in seven towns in England and Wales, suggesting that iodine intake does not play a major role in the development of subclinical autoimmune thyroïd disease.

\subsection{Clinical signs and symptoms}

It is obvious that the clinical signs and symptoms of women with thyroid dysfunction may reflect that particular dysfunction: hyperthyroidism when the thyroid hormones are elevated hypothyroidism due to low concentrations of thyroid hormone. However, because of the transient nature of hyper- and hypothyroidism, the dysfunction usually goes unrecognized both by the mother and the health professional: vague complaints of tiredness, headache, dizziness, weight loss, sweating. These complaints often are thought to be normal for the postpartum period and are attributed to the delivery itself, feeding at night or breastfeeding. Thyroid tenderness is usually absent, as postpartum thyroid dysfunction is not different from the painless thyroiditis also occurring in the general population. Some authors reported an increased frequency of fatigue, weight gain and loss of initiative to occur more frequently in hypothyroidism compared with euthyroid postpartum women (Dahlberg and Jansson 1983, Hayslip et al. 1988a). There are several authors who suggested a possible relationship between postpartum thyroid dysfunction and the occurrence of "mental disturbances" in the postpartum period (Amino et al., 1982 a, Jansson et al., 1984, Hayslip et al,, 1988a). However, most of these studies only mentioned case reports of women with postpartum depression and severe thyroid dysfunction.

On clinical examination, the thyroid is usually only enlarged in half the patients. Most studies did not show any difference in complaint pattern between women with thyroid dysfunction and normal postpartum controls. Amino et al. (1982a) mentioned a significantly greater prevalence of fatigue and palpitations in the thyroid dysfunction group. As Fung et al. (1988) pointed out, clinical signs and symptoms do not provide a reliable guide to normal functioning or dysfunctioning of the thyroid. Hayslip et al. (1988a) found women with postpartum thyroid dysfunction to have more complaints when compared with a normal control group. 


\subsection{Diagnostic tests for postpartum thyroid dysfunction}

Thyroid hormone levels in postpartum thyroiditis depend on the hyper- or hypofunction phase of the disease: elevated fT 4 and IT 3 with low TSH, or decreased fT4 and fT3 with elevated TSH. As shown in table 6.2, the fluctuations of thyroid dysfunction in a classical biphasic thyroiditis patient can change very quickly. Isolated increase of TSH with normal fT3 and fT4 has also been described.

Immunological parameters include the presence of different types of antibodies. In postpartum thyroiditis, mainly microsomal antibodies are found (MsAb, or recently: anti-TPO). The clinical implications of elevated titres of microsomal antibodies will be discussed here in more detail.

There are several reports on the significance of circulating antibodies in pregnancy (Amino et al., 1978, 1982a, Jansson et al., 1984, 1987, Fung et al., 1988, Vargas et al., 1988, Hayslip et al., 1988a) and in the normal population (Tunbridge et al., 1977, 1981, Amino et al., 1980, Hawkins et al., 1980, Pinchera et al., 1985). The predictive value of the presence of circulating antibodies in pregnancy or immediately after delivery on the occurrence of thyroid dysfunction in the postpartum period varies between studies: Jansson et al. (1984) found 85\% of women with elevated antibody titres to develop thyroid dysfunction, Fung et al. (1988) and Hayslip et al. (1988a), respectively, 65\% and 67\%. In a study of 261 mothers, Vargas et al. (1988) found $15 \%$ with positive microsomal antibodies at delivery, $21 \%$ at 2-4 months, $26 \%$ at 5-7 months, gradually decreasing to $23 \%$ at one year postpartum. Of the antibodypositive women, almost $70 \%$ developed thyroid dysfunction. However, Amino et al. (1982a) could not demonstrate elevated titres in $15 \%$ of women with histologically proved postpartum thyroiditis. Finally, it should be mentioned that Tunbridge et al. $(1977,1981)$ showed that elevated microsomal antibodies occur in $15 \%$ of the normal female population up to the age of 60 years. It is known from follow-up studies that the progression of antibody-positive women with raised TSH to overt hypothyroidism is 5\% per year (Bilous and Tunbridge, 1988). Amino et al. (1980) found microsomal antibodies in $10.2 \%$ of adult females and $6.0 \%$ of adult males; in all cases this was only associated with elevated TSH levels in $9.1 \%$. However, when the subjects with positive microsomal antibodies were separated into two groups according to age, subjects of less than 50 years showed a prevalence of $2.2 \%$ of increased TSH level, compared with $16.2 \%$ in the group older than 50 years. Therefore an age effect should be considered when assessing the predictive value of microsomal antibodies for a raised serum TSH (Amino et al. 1978, 1980, 1988).

Amino and Miyai (1983, 1987b) and Jansson et al. (1984) showed a close relationship between the level of antibody titres in pregnancy and the 
occurrence of postpartum thyroid dysfunction. The higher the level in the first trimester of pregnancy, the more likely the women are to develop thyroid dysfunction in the postpartum period. When the TSH level was taken into account, it was demonstrated that a high level of TSH in pregnancy correlated well with highly elevated titres of antibodies in the postpartum period. In several studies (Amino et al.,1978, Jansson et al., 1984, Lervang et al., 1987, Fung et al., 1988) it was shown that microsomal antibodies were detectable in almost $95 \%$ of women with postpartum hypothyroidism. The development of hypothyroidism generally occurred 4 to 8 months' postpartum and coincided with the peak of microsomal antibodies. Subsequently, antibody titre decrease was usually accompanied by normalization of thyroid function (Jansson et al. 1988). Therefore, several authors stress the importance of screening for microsomal antibodies during pregnancy or immediately after birth in order to predict thyroid dysfunction.

Microsomal antibody titres can also be demonstrated in postpartum Graves' disease, but less commonly with fluctuations (Walfish and Chan 1985). As mentioned before, antibodies against the TSH receptor are very common in postpartum Graves' disease, but are rarely seen in postpartum thyroiditis. One of the most typical signs of postpartum thyroiditis is found on radioactive thyroid scans. In postpartum thyroiditis there is almost no uptake of radioactive iodine in the thyroid after intravenous administration. In Graves' disease, the uptake is usually elevated.

Gutekunst et al. (1989) showed that ultrasonography of the thyroid may accurately diagnose lymphocytic thyroiditis.

Anatomopathological features, as found by thyroid biopsy, are described by Inada et al. $(1979,1981)$ and Yoshida et al. (1978). In the hyperthyroid phase, there is an infiltration of lymphocytes into the thyroid cells. Most of the follicles have collapsed and the follicle cells have degenerated. In the hypothyroid phase, there is a hyperplastic pattern of thyroid cells with expanded cuboid epithelial cells in the follicle, which have usually been regenerated, and only a small amount of local infiltration of lymphocytes. In the euthyroid phase, all the follicles have a normal appearance and lymphocytic infiltration has almost disappeared. As mentioned before, these histological pictures are identical to the histology of painless lymphocytic thyroiditis. However, they do differ from the pattern seen in chronic lymphocytic thyroiditis in Hashimoto's disease in which the typical Askanazy cell are described.

\subsection{Pathogenesis of postpartum thyroid dysfunction}

It is generally accepted that postpartum thyroid dysfunction reflects alterations in the immune system during pregnancy and the postpartum 
period, which result in autoimmune disease (Amino et all, 1988, Walfish and Farid 1985, Dussault and Rousseau 1987, Jansson et al., 1987, 1988, Farid and Balazs 1988, Vargas et all. 1988, Davies et al. 1988, Volpe 1988). Evidence for this hypothesis can be summarized as follows.

Thyroid dysfunction in relation to pregnancy and postpartum is thought to be partly a consequence of the changes in the immune system normally occurring during and after pregnancy. The concept of normal pregnancy implies the protection of the fetus as an allograft. Although it is demonstrably untrue that a general state of immunosuppression exists during pregnancy, there are observations that autoimmune diseases show a tendency to become less active during pregnancy and to exacerbate in the postpartum period (Jansson et al.,1984, Fung et al., 1988). It was shown that women with circulating microsomal antibodies had high titre levels early in pregnancy which decreased later on during gestation. In the postpartum period, a marked elevation of the titres was found, even in some women without thyroid dysfunction. The altered immune response is reflected in fig. 4.2.

It is believed that some alterations in the maternal immune response are

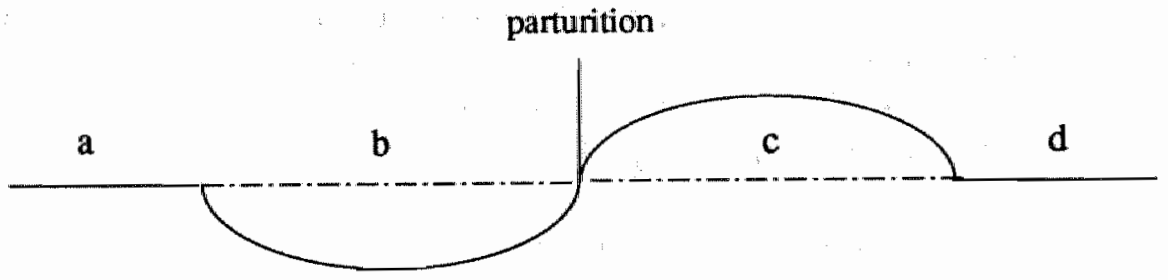

fig 4.2 graphical picture of normal immune response in non-pregnant women (a), during gestation (b), and after parturition (c)

(a) normal immune response

(b) suppression of immune response

(c) rebound of immune response

engendered by agents coming from the conceptus (Klopper 1989, Faulk and McIntyre 1988, Sargent and Redman 1989, Loke 1989). Retroplacental serum has a suppressive effect on the mixed culture lymphocyte reaction, and this suppressive effect increases during gestation. It is concluded that the trophoblast produces immunosuppressive substances. These substances are thought to reflect the maternal recognition of pregnancy which is, in part, immunological. This response is not a normal immunological one, otherwise the conceptus would be rejected. Therefore, an abnormal 
response of the mother has been postulated (Klopper 1989). The most attractive suggestion concerning the privileged immune status of the trophoblast lies in the hypothesis that the antibodies (blocking factors) raised against it, particularly in early pregnancy, are protective rather than being agents of immunological destruction (Klopper 1989, Faulk and McIntyre 1988, Sargent and Redman 1989, Loke 1989).

One major problem still remaining is the fact that these blocking agents, which supposedly have an immunosuppressive effect, have to act within the uterus while no evidence of the systemic unresponsiveness of the mother towards paternal alloantigens exists.

However, autoimmune diseases such as Hashimoto's thyroiditis, Graves' disease, myasthenia gravis, rheumatoid arthritis e.g., show a tendency to improve during pregnancy and are aggravated after delivery (Amino et al. 1985, Jansson et al. 1988). This immunological rebound phenomenon may also explain postpartum abnormalities in thyroid function in otherwise healthy women with a genetic predisposition towards autoimmune thyroid diseases (fig. 4.2).

The humoral activity of the immune system is shown to submit alterations in the postpartum period, resulting in elevated titres of circulating antibodies (mainly of microsomal origin). These alterations were described in the previous sections.

The cellular activity of the immune system has also been described to show alterations in the postpartum period in general and more specifically in postpartum thyroid dysfunction. The natural killer cells (NK), which show cytotoxicity against target cells without prior sensitization by antibodies, are thought to be decreased in pregnancy (Sridama et al. 1982). It has been shown that NK activity during pregnancy is depressed from 16 weeks to term, returning to control levels between 9 and 40 weeks after delivery. There is a decrease in NK cell numbers and those cells which remain have less lytic capacity (Hayslip et al. 1988b). It is presumed that a decrease in their lytic capacity to destroy trophoblasts during pregnancy is essential for the survival of the placental graft.

Hayslip et al. (1988b) showed that the activity of the NK cells was significantly reduced in the postpartum period compared to non-postpartum women. Although microsomal antibodies do not act on intact thyroid cells in vitro, it was shown that killer $(K)$ lymphocytes have a potential for killing antibody-coated target cells in vitro, reflecting the antibodydependent cell-mediated cytotoxicity (Amino 1988). This cytotoxic effect is correlated with microsomal antibody titres. It was postulated by Amino et al. (1982b) that a higher number of K cells increased the cytotoxic activity, leading to reduced thyroid function in autoimmune thyroid disease. Hayslip 
et al. (1988b) reported no difference in natural killer activity (NK) between postpartum thyroiditis and normal postpartum. However, Amino (1988) found an increased activity of NK cells in postpartum thyroid disease. The role of T-lymphocytes in autoimmune thyroid disease has been reviewed recently (Volpe et al., 1985, Ahmann and Burman 1987). There are authors who reported an increased activity of T-lymphocytes and a reduced ratio of Tsuppressor and contra-suppressor cells both in women with transient postpartum hyperthyroidism and Hashimoto's disease. Jitaka et al. (1988) reported a relative defect of antigen-specific suppressor T-lymphocyte function in suppressor/cytotoxic cells in patients with autoimmune thyroid disease, which may result in the presence of autoantibody-secreting cells. As summarized by Farid (1987) and Farid and Balazs (1988), it is postulated that the initial event leading to activation of these kinds of lymphocytes is a result of reduced suppressor activity by suppressor cells. The T-lymphocytes home onto the thyroid cells; where they expand and secrete lymphokines which influence the progression of auto-aggression.

Finally, genetic studies on the association between HLA-antigens and postpartum thyroiditis have provided varying results, possibly caused by racial differences (Lervang et al., 1987, Jansson et al., 1985, Fein et al., 1985, Vargas et al., 1988 and Tachi et al., 1988).

\subsection{Prognosis of postpartum thyroid diseases}

Although postpartum thyroiditis has only recently been investigated in prospective studies, there are already some reports of follow-up studies. Nikolai et al. (1987) found at three years' follow-up that $48 \%$ of women with postpartum thyroiditis still had thyroid dysfunction. Jansson et al. (1988) found that $31 \%$ of women who initially had postpartum thyroid dysfunction still had hypothyroidism at five years", and Tachi et al. (1988) found, at an average of 8.7 years' follow-up, that $31 \%$ of women still had hypothyroidism. Othman et al. (1990) found biochemical hypothyroidism in $23 \%$ of women with postpartum thyroid dysfunction, at 3 to 5 years' (TSH elevated with low normal thyroid hormones), most of them being without clinical signs and symptoms. The amount of women with overt hypothyroidism varied between these studies. In Sweden and Japan, almost all women with long-term thyroid dysfunction had clinically overt hypothyroidism, while in Wales (UK) only $10 \%$ of women had clinical hypothyroidism.

In all the above-mentioned follow-up studies, it was shown that microsomal antibody activity predicted the outcome of hypothyroidism: the higher the level of microsomal antibodies during pregnancy or in the postpartum period, the more likely the women were to become hypothyroid at long- 
term follow-up. The mechanism which could possibly explain this association remains unclear. One hypothesis might be that these women contracted euthyroid Hashimoto's autoimmune thyroiditis which proceeded to hypothyroidism due to pregnancy. There are no conclusive data on other predicting factors for long-term hypothyroidism. Othman et al. (1990) found an increased risk in multigravida for hypothyroidism that could not be confirmed by Jansson et al. (1988). It is estimated that $30-60 \%$ of woman with postpartum thyroid dysfunction will have a second occurrence of postpartum thyroid disease after a later pregnancy (Walfish and Chan 1985).

\subsection{Management of postpartum thyroid disease}

Postpartum thyroid dysfunction actually reflects transient autoimmune disease. An expectant attitude towards thyroid dysfunction in the postpartum period is generally advised because of the transient nature of thyroid dysfunction. A protocol, as summarized by De Rooy and Pop (1989), is presented in table 4.2

table 4.2 management of postpartum thyroid dysfunction

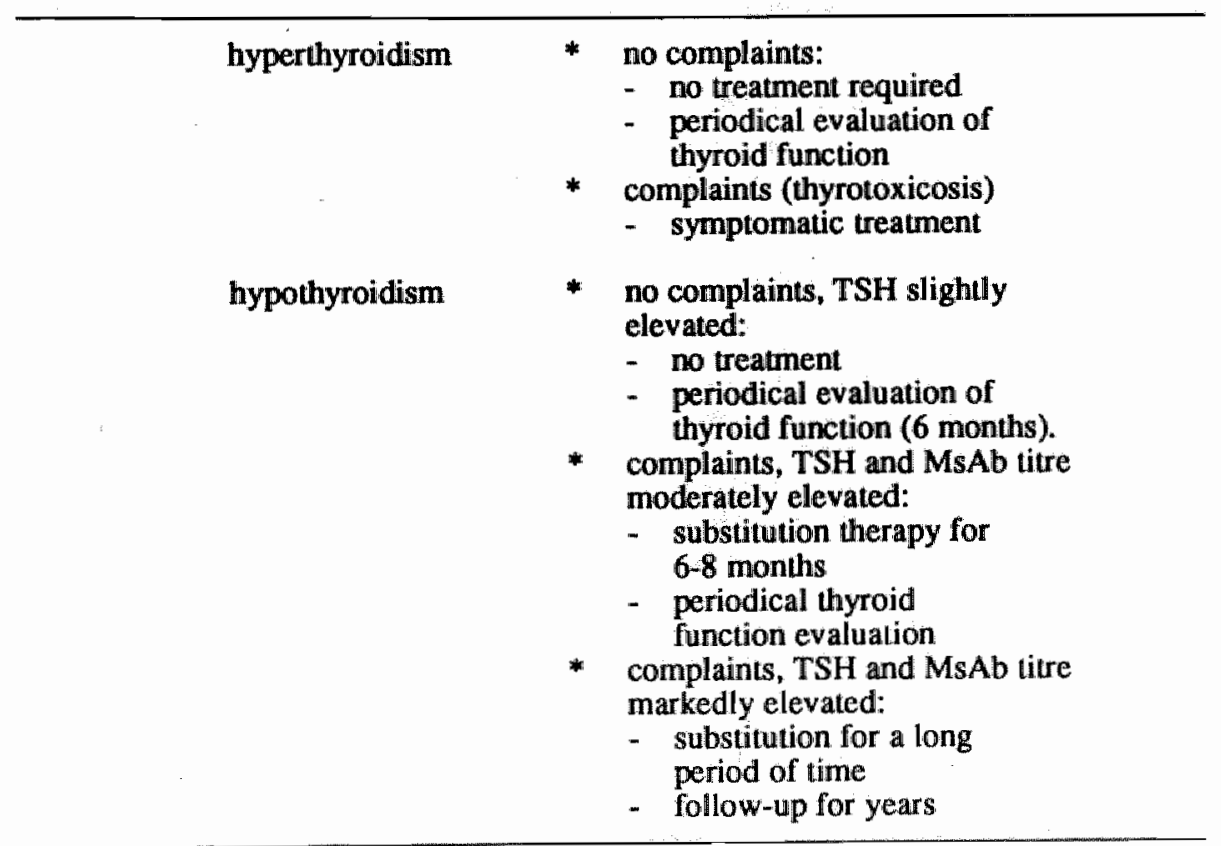

Severe hypothyroidism soon after pregnancy, without thyroid enlargement, has often been shown to develop into permanent hypothyroidism. Late onset of hypothyroidism after delivery is usually transient (Jansson et al., 1988). However, women with hypothyroidism in the postpartum period 
should be followed up for a long period of time, because of the probability of developing overt permanent hypothyroidism.

There are several authors who have tried to prevent new episodes of postpartum thyroid dysfunction after later pregnancy by administration of corticosteroids soon after delivery. The data are not conclusive. Kampe et al. (1990) tried to influence the course of postpartum thyroiditis by the administration of thyroxine or iodide to women who were at risk (high titre of microsomal antibodies in early pregnancy). They could prevent the occurrence of hypothyroid symptoms, but there was no difference between the treated and non-treated groups as far as the elevation of microsomal antibodies titre was concerned. 


\section{Chapter V}

\section{Thyroid dysfunction and mood disorders}

A possible relationship between thyroid dysfunction and the occurrence of depression has been suggested in many studies in the past. These were recently summarized by Loosen (1987) and Jadresic (1990).

\subsection{Affective disturbances in thyroid disease}

In both hyper- and hypothyroidism, cognition, mood and behaviour may be disturbed in varying degrees. There seems to be no specific behavioural syndrome associated with either of the two conditions. Hyperthyroidism is often accompanied by mental symptoms, such as irritability, fatigue, anxiety, tension and emotional instability. There is evidence which suggests an association between hyperthyroidism and other anxiety-related disorders (Jadresic,1990).

In contrast, in hypothyroidism symptoms such as depressive mood, pronounced loss of interest, generalized slowing of activity, memory loss and apathy, are most prominent although Jadresic (1990) stressed the fact that depression is much more common in hyperthyroidism than has been generally acknowledged. As Sachar (1975) pointed out, depression occurs in more than forty percent of hypothyroid patients. On the other hand depressed patients as a group clearly are clearly not hypothyroid.

Studies involving hyperthyroid and hypothyroid patients in a general population showed that, when hyperthyroid patients were compared with hypothyroid patients, hyperthyroid patients were found to be significantly less depressed, with less psychomotor retardation than hypothyroid patients, but they showed more motor tension. Cognitive dysfunction was observed in both conditions, but it was less pronounced in hyperthyroidism. It was found that cognitive function returned to normal when euthyroidism was established after hyperthyroidism had occurred. However, in long-standing hypothyroidism, there was evidence to suggest that cognitive disturbances may persist after replacement therapy with thyroid hormones (Loosen 1987). 


\subsection{Thyroid and affective disorders}

\section{a. Thyroid hormone levels}

In general, in an in-clinic psychiatric population, there is evidence of a higher incidence of thyroid dysfunction compared with the general population. In most cases, however, this dysfunction is of a transient nature: most of the patients with disturbed thyroid hormone levels on admission showed normal levels when thyroid function was re-evaluated several months later (Loosen, 1987).

In depression, there are no conclusive data about the relationship with thyroid hormone levels. There are authors who found hormone levels in the upper normal range in depressed people compared with normal controls. Gold et al. (1983) reported a lowered thyroid function in depressed patients. Of nine patients with mild to overt hypothyroidism, four were successfully treated and discharged by thyroid replacement alone. However, there are several reports of normal thyroid function in depressed patients (Loosen 1987).

\section{b. The TRH test}

The principles of this test have already been discussed in chapter II. It is now generally accepted that TRH-induced TSH response is blunted in about $25 \%$ of depressed patients. This finding is not specific for depression: in alcoholism and borderline personality disorders, TSH blunting also occurs. Some authors reported the TRH test to be a state marker for depression, while others found it to be a trait marker for depression: two of six phenotypically normal first-degree relatives of a proband with affective mood disturbances showed blunting of the TRH test, suggesting a high vulnerability for depression (Loosen 1987). Levy and Stern (1987) reported that both the TRH test and the DST test discriminate between non-endogenous depression and endogenous depression. Endocrinologically, it seems unlikely that TSH blunting in depression is the result of increased serum thyroid hormones levels. Most depressed patients with TSH blunting are euthyroid (Loosen and Prange, 1982). Moreover, some depressed patients with TSH blunting have low thyroid hormone levels, suggesting a disturbance in feedback inhibition. No clear association between cortisol hypersecretion and TSH blunting has been found in depressed patients (Caroll, 1981, Barry and Dinan, 1990). However, Haggerty et al.(1987), in a psychiatric inpatient unit, found that patients with a blunted DST response were more likely to have thyroid abnormalities - such as elevated TSH levels - than patients with a normal DST, suggesting an interaction between the hypothalamic-pituitarythyroid axis and the hypothalamic-pituitary-adrenal axis. Gewirtz et al. 
(1988) demonstrated an elevated TSH level or a low metabolic rate in $40 \%$ of depressed outpatients not responding to antidepressant pharmacological management. Moreover, the depressions of those women responded to medication with thyroid hormones.

\subsection{The effect of TRH and thyroid hormones on behaviour}

It was shown by Prange et al. (1969) that, in normal subjects, the administration of TRH increases their sense of well-being, motivation and coping capacity. Moreover, several studies have shown a rapid, although brief and partial, improvement of depression after a bolus injection of TRH in depressed patients, although this change in mood state is not specific for depression and also occurs in other psychiatric disorders (alcoholism). Pretreatment with a single dose of thyroid hormone abolishes the behavioural changes after TRH injection. TRH is also a potent stimulus for the release of prolactin from the anterior pituitary. Roy and Pickar (1988), however, found no difference in prolactin response between unipolar depressed patients and matched controls, nor any difference in prolactin response between patients with or without a blunted TSH response. Studies investigating TRH as an efficient remedy for depression could not demonstrate any benefit: longterm administration of TRH showed no improvement of depression.

Thyroid hormone administration, as an adjunct to tricyclic antidepressant (TCA) therapy showed two main phenomena. Firstly, the antidepressant effect of TCA occurred much faster when T3 was administrated in low doses to a number of depressed patients. Secondly, about $50 \%$ of depressed patients who did not respond to an adequate trial of TCA, did respond when T3 was administered simultaneously in a (sub)replacement dose (Extein and Gold, 1988). The exact mechanism is not well understood, but two major hypotheses have been proposed. Firstly, thyroid hormone may facilitate the functioning of the central nervous beta-adrenergic receptor. Normal thyroid hormone levels are essential for optimal central noradrenergic functioning. The second hypothesis suggests that thyroid hormones potentiate TCA by restoring normal thyroid function in depressed patients with some degree of hypothyroidism.

\subsection{Thyroid dysfunction and depression in the postpartum period}

As reported by George and Sandler (1988), interest in a possible relationship between postpartum mood disturbances and postpartum thyroid dysfunction was already present in the Fifties. Later on, Hamilton (1977) showed that postpartum psychiatric syndromes in the early 
puerperium were not related to thyroid dysfunction. After Amino et al. (1976) first described the occurrence of transient hypothyroidism in the postpartum period, several prospective studies on the prevalence of postpartum thyroid dysfunction followed in which it was found that some women with postpartum depression suffered from postpartum thyroid dysfunction (Amino et al. 1982a, Jansson et all, 1984). Recently, Stewart et al. (1988) were unable to find any difference in thyroid dysfunction between hospitalized postpartum psychotic women compared with matched postpartum control subjects. Stein et al. (1989) could not demonstrate any association between panic disorder and autoimmune thyroiditis in $\mathbf{3 8}$ patients (men and women) who met the DSM-III-R criteria for panic disorder and who were matched with healthy controls: the patients with panic disorder did not have microsomal antibodies any more often than the control group. Harris et al. (1989) found a relationship between depression and the presence of microsomal antibodies in the postpartum period but failed to demonstrate a relationship between depression and thyroid dysfunction. However, they only investigated a possible relationship at 4 to 6 weeks' postpartum.

As pointed out by George and Sandler (1988), no studies have been published which thoroughly investigated the relationship between thyroid dysfunction and postpartum depression up to 3 months or more after parturition. 


\section{Chapter VI}

\section{Relevance of the study and presentation of the questions}

\subsection{Relevance of the study}

\subsubsection{Postpartum thyroid dysfunction}

Postpartum thyroid dysfunction has been observed quite frequently, the main cause being postpartum thyroiditis. Although racial, geographical and genetic factors are thought to influence its occurrence, it is generally agreed that the etiology of postpartum thyroid dysfunction has an autoimmune origin. The literature concerning the incidence of postpartum thyroid dysfunction shows rather conflicting data. These differences may only partially be explained by racial and environmental factors.

Most of the differences are attributable to differences in methodology; one important issue is the definition of thyroid dysfunction. Most of the studies involved a biochemical definition of thyroid dysfunction. However, there are also authors who used other criteria in their definition, such as thyroid enlargement, radioactive scans and anatomopathological features (Nikolai et al., 1987). The clinical relevance of thyroid palpation as a useful tool in discriminating between normal and abnormal thyroid function in pregnancy and the postpartum period, is hazardous. Although there is an international consensus on the classification system that should be used in describing thyroid enlargement (Delange et al., 1986), in most of the studies published on postpartum thyroid dysfunction, the women were investigated by different researchers, which makes it difficult to exclude inter-assessor variation in the estimation of thyroid size. Moreover, as explained in chapter II, thyroid size in pregnancy may increase to compensate for a relative deficiency in iodine. Several prospective studies carried out on postpartum thyroid dysfunction (Amino 1982a et al., Jansson et al., 1984, Fung et al., 1988) found no relationship between enlargement of the thyroid and the occurrence of thyroid dysfunction.

Microsomal antibodies were also included in the definition of thyroid dysfunction by some researchers, frequently in combination with thyroid 
enlargement (Jansson et al. 1984, Nikolai et al. 1987). However, as demonstrated in many studies, in the postpartum period there are women - up to $30 \%$ with elevated microsomal antibody titres without postpartum thyroid dysfunction (Amino et al., 1984, Jansson 1986, Lervang et al., 1987, Fung et al., 1988). Moreover, Tunbridge et al. (1981), Hawkins et al. (1980), and Amino et al. (1980) have already demonstrated the occurrence - in up to $15 \%$ of the general population -of microsomal antibodies in non-pregnant healthy women.

Radioactive scans and biopsy of the thyroid are not feasible in screening a large population, especially not during the postpartum period because of breastfeeding women.

The biochemical definition of thyroid dysfunction is the most commonly used method of defining thyroid dysfunction in screening programmes in general and in the postpartum period in particular. The most specific and sensitive instrument is the TSH-IRMA test, which was discussed in chapter II. However, there has been frequent debate on the significance of an abnormal TSH value with a normal $\mathrm{fT} 3$ and/or $\mathrm{fT} 4$ value. Most studies defined postpartum thyroid dysfunction as occurring when there were abnormal fT 3 and fT 4 values, or when TSH was elevated with normal fT3 and fT4 values. The clinical relevance of an abnormal TSH with fT3 and fT4 values within normal limits is seriously in doubt. Signs and symptoms of hyper- or hypothyroidism are not thought to be a consequence of abnormal TSH values, but of abnormal fT 3 and/or fT 4 values. However, regarding the screening of thyroid dysfunction, there are several authors who argue that highly elevated TSH levels - twice the upper limit of normal TSH values - with normal fT3 and/or fT4 levels, should be interpreted as abnormal thyroid function, and more specifically, as hypothyroidism (Jansson et al., 1984, Lervang et al., 1987, Hayslip et al., 1988a, Vargas et al., 1988). In some studies elevated TSH levels were included in the definition of thyroid dysfunction when microsomal antibodies titres were elevated as well (Jansson et al., 1984, 1986). It is obvious that including abnormal TSH values with normal fT 3 and fT4 in the definition of thyroid dysfunction will augment the incidence rate.

Another important issue which has only occasionally been investigated is the question of whether a pattern of clinical signs and symptoms of postpartum thyroid dysfunction exists. Most studies were interested in the nature of thyroid dysfunction, and women with biochemical thyroid dysfunction were referred to hospital. As a consequence, when assessing the clinical signs and symptoms of thyroid dysfunction - whether thyroid dysfunction was related to a typical pattern of clinical signs and symptoms or not - the observer and the woman may both have been 
biased by knowing the results of the biochemical tests. The classical symptoms of hyperthyroidism and hypothyroidism are well described. However, hyper- and hypothyroidism do not usually occur in their classical form. In practice, only some of the typical signs are present and these are often accompanied by other signs and symptoms not specific to thyroid dysfunction. Moreover, in the postpartum period, there are many symptoms which could be attributed to thyroid dysfunction but are mostly thought to be typical of the postpartum period and are attributed to changes in hormones, such as oestradiol, progesterone and prolactin, or to factors such as feeding at night and complications during delivery. Excessive sweating, tiredness, palpitations, weight loss, concentration problems and irritation are all very common symptoms during the early postpartum period, but also occur in thyroid dysfunction. As mentioned in chapter IV, there are very few studies into the relationship between clinical signs and symptoms and postpartum thyroid dysfunction. Amino et al.(1982a), who screened 507 Japanese women once at 3 months' postpartum, reported a significant difference in frequency of fatigue and of reported palpitations between women with thyrotoxicosis and normal controls. Other studies which screened only once or twice did not find any differences. Hayslip et al. (1988a) followed 33 women with microsomal antibodies every 4 to 8 weeks up to 6 months' postpartum. They found a statistically significant difference in the total number of complaints between women with and without thyroid dysfunction. However, it is difficult to standardize the number of complaints in every day practice in order to discriminate between women with and without thyroid dysfunction. Moreover, their sample is not representative of a general population because only microsomal-antibody-positive women participated.

The clinical relevance of detecting postpartum thyroid dysfunction has two aspects. Firstly, there are consequences for the postpartum period itself: many postpartum women suffer complaints and most of the time these are accepted as being normal for this period or are treated in a symptomatic way without investigating the cause. The knowledge that some complaints and clinical signs - during certain postpartum periods are related to thyroid dysfunction, may prevent inadequate treatment with medicaments (antidepressants, tranquillizers) and when needed, makes it possible to treat complaints and clinical signs found to be related to hyper- or hypothyroidism in a suitable way. Secondly, there are long-term consequences revealed by (until now up to 8 years) follow-up of women with postpartum thyroid dysfunction. About $30 \%$ of these women still have (transient) thyroid dysfunction, and several of them have overt 
hypothyroidism. Women with postpartum thyroid dysfunction are at risk for other transient or even permanent thyroid dysfunction, irrespective of a new pregnancy (Othman et al. 1990, Jansson et al. 1988).

Postpartum thyroid dysfunction has been investigated in different areas of the world with different methods of research.

As pointed out before, most of the prospective studies on postpartum thyroid dysfunction have failed to meet four important methodological criteria: high ascertainment rate, distinct definition of thyroid dysfunction, unbiased sample, and a population sample without important racial differences (Gerstein 1990). However, the three studies meeting these methodological criteria assessed thyroid dysfunction only once or twice during the postpartum period (Amino et al. 1982a, Jansson et al. 1984, Lervang et al. 1987). Because thyroid dysfunction in the postpartum period is usually of a transient nature, many cases will not be recognized. Moreover, the assessment period should be of at least 6 months because most thyroid dysfunction is found between 2 and 6 months' postpartum or even later. Studies that screened women frequently for many months' postpartum, did not use a randomized sample. In summarizing these data, it can be argued that no study has been carried out which investigates the incidence prevalence and course of postpartum thyroid dysfunction in a randomized sample with frequent assessments (up to 6 months or more) of thyroid function in the postpartum.

Moreover, no studies have been carried out on the clinical signs and symptoms which might be specifically related to postpartum thyroid dysfunction. Studies investigating signs and symptoms possibly related to thyroid dysfunction did not use an unselected population, or have a study design in which both the woman and the researcher were informed about possible biochemical dysfunctioning of the thyroid which, as a consequence, made it difficult to screen in an unbiased way. Finally, no studies have been carried out in The Netherlands to investigate the incidence and course of postpartum thyroid dysfunction.

\subsubsection{Postpartum depression}

Postpartum depression has frequently been observed, although prevalence rates of postpartum depression in the literature are rather conflicting, the incidence only occasionally being investigated. Again, these differences are mostly attributable to methodological differences in these studies: definition of depression or depressive symptoms, time and frequency of assessment in the postpartum period and during which period the screening took place. The most important differences in methodology in studies carried out in the past have recently been summarized by O'Hara and Zekoski (1988). Factors thought to be 
responsible for most of the variations in prevalence rates include: use of criteria not related to any established diagnostic system, studies on prevalence rates which include other disorders in addition to depression (e.g., anxiety), small sample size and excessive dropout. Another important issue that may influence the prevalence rates is the frequency of assessment and the period in the postpartum during which assessment was carried out. In most of the studies, assessment was carried out only once or twice. Studies in which an assessment was made several times during the postpartum period showed that, at 3 to 4 months' postpartum, the prevalence rate was higher compared to other assessments in the postpartum period.

It is generally accepted that the etiology of postpartum depression is multifactorial. However, the studies carried out have resulted in inconclusive data. Factors, such as social support, blues, parity, stressful events and premenstrual syndrome, which are thought to play an important role in the etiology of postpartum depression, proved to be more or less strong predictors of postpartum depression in various studies, while in other studies no relationship with depression was found. Although differences in methodology are thought to be responsible for much of the variance between studies, another explanation might be that assessments at different moments during the postpartum period reveal different relationships between depression and other variables.

There is still much debate about the specificity of postpartum depression. The question of whether depression in the postpartum period has a higher prevalence rate than in the general (female) population has only been investigated in two prospective studies, with the aid of a control group of non-childbearing women (O'Hara et al.1990a, Troutman and Cutrona 1990). In neither study was a difference found in the prevalence rate of depression between the two groups. Depressive symptoms, however, occurred significantly more often in the childbearing group. We were interested to find out whether there are variables specifically related to postpartum depression. For that purpose women were followed for a long period of time and were assessed frequently. If there are factors especially related to pregnancy and delivery, it is reasonable to suggest that a relationship between these factors and postpartum depression would fluctuate during the postpartum period, with significance most probably being found early in the puerperium and declining later on in the postpartum period. Another suggestion is that factors which correlate significantly with postpartum depression in a relatively stable way during pregnancy and the postpartum period are not specifically related to this period and actually reflect factors possibly related to depression in general. 
The clinical relevance of detecting postpartum depression has short- and long-term aspects. The short-term detrimental effects of postpartum depression mainly consist of inadequate functioning of the mother in the family, which may result in problems in child development, such as poor weight gain or retarded senso-motorical development. The long-term negative effects have already been extensively described: inadequate development of child behaviour (chapter III).

An important aspect of research into the factors possibly related to postpartum depression is the fact that intervening in depressed women does not necessarily constitute the need for more professional assistance. Most, if not all, women who deliver a baby contact health professionals which means that screening for postpartum depression and possible intervention does not imply that another group of health professionals has to be integrated into the care of the women. It is the health professionals who actually meet women during pregnancy and the postpartum period (gynaecologist, general practitioner, midwife and health nurse), who possess more adequate tools to detect and eventually treat postpartum mood disturbances.

There are no studies investigating the course of postpartum depression. Most of the studies started arbitrarily within 4 to 6 weeks of parturition and consisted of only one or two assessments. In order to detect the natural course of depression in the postpartum period, screening should start soon after delivery and continue for several months. It is possible that, at different moments during the postpartum period, different women are depressed and that these women do not necessarily share the same characteristics or risk factors for depression. This might explain why some authors found correlations between depression and certain factors, while other did not.

As pointed out by George and Sandler (1988), there are no follow-up studies investigating whether or not postpartum thyroid dysfunction is related to postpartum depression.

There are several case reports of women with severe depression in the postpartum period - treated with antidepressant drugs - who afterwards proved to have suffered from severe thyroid dysfunction. Once thyroid dysfunction normalized, the depression also disappeared. Moreover, both thyroid dysfunction and postpartum depression are reported to occur between 2 and 6 months' postpartum, which also suggests a relationship between the two syndromes (Amino et al., 1982a, Jansson et al., 1988).

In summarizing these findings, it can be argued that follow-up studies into factors possibly related to postpartum depression with four or more assessments have not been published. The course of postpartum 
depression has only occasionally been investigated. Moreover, there are no follow-up studies investigating the relationship between postpartum thyroid dysfunction and postpartum depression.

Finally, the incidence, prevalence and course of postpartum depression in The Netherlands is not known.

\subsection{Choice of research variables}

In this section, the variables used in our study will be presented.

6.2.1. Two important variables in this study are: thyroid dysfunction and postpartum depression and depressive symptoms. We are interested in their incidence, prevalence and course in The Netherlands, and in the possible relationship between them, as explained in the previous section. We feel that the choice of these two variables has been sufficiently elucidated on in the previous chapters.

\subsubsection{A survey of the literature into factors which are related to} postpartum depression revealed two classes of variables: variables which are hypothesized to be related specifically to the postpartum period, and variables which are known to play a role in the etiology of depression in general. A further differentiation was made in the first group: variables which are known in the literature to be related to postpartum depression/depressive symptoms in a very conclusive way, and variables in which the relationship to depression/depressive symptoms is questioned. The variables are categorized according to the system of Gelder et al. (1988), as described in chapters I and III of this thesis.

(a) variables relating to depression in general

As mentioned before, a previous episode of depression seems to be strongly related to depression in the future (Lewinsohn et al. 1988, Brown et al. 1989).

Stressful life events are shown to be related to depression in general. However, Sanderman (1988) emphasized that most studies could not even demonstrate that these events are strongly related to depression. The delivery, as such, may be considered a stressful life event, as is the transition to parenthood.

Past adversity refers to events which occurred in the past and which are found to increase the risk for depression to occur when provoking agents and other risk factors are present in the current environment (Harris et al., 1987, Brown et al., 1989). In chapter III, we summarized studies which investigated a possible relationship with depression in general.

Social support moderates the possible effects of psychosocial adversity 
in precipitating episodes of depression. As explained in chapter I, a major theme in social support research is the assumption that social support interacts directly and indirectly with the effects of a wide range of stressful events. The effect of social support is closely related to coping behaviour, which was defined (Chapter I) as being cognitive and behavioural efforts to master, tolerate or reduce external and internal demands.

All these variables are studied in research as to the way certain factors are related to depression in general, and are discussed in chapter I. These variables were also part of studies into the way in which certain factors are related to postpartum depression, and are summarized in chapter III. We are interested in the extent to which these variables are related to depression and depressive symptoms in our population sample. According to the model of Gelder, a previous episode of depression in the woman herself and past adversity can both be regarded as general predisposing factors for; or predictors of depression, social support and coping behaviour as background features, and stressful life events and demographic features as general contributing factors to depression.

(b) variables relating to postpartum depression

Depression in pregnancy has frequently been investigated as to its relationship with postpartum depression and this relationship has been shown to be very strong. However, we believe that depression in pregnancy, as a distinct variable, is an 'artificial factor' and does not differ significantly from the factor 'previous episode of depression' in a nonchildbearing population.

In some studies, parity (primiparity-multiparity) has been shown to be related to postpartum depression, while other studies could not find such a relationship. There is no clear explanation for the fact that these data are inconclusive (chapter III).

Blues are shown in several studies to be rellated to postpartum depression, but again the data are not conclusive (chapter III). However, we believe that one explanation for these findings could be that a relationship between blues and postpartum depression depends on the time of assessment of depression in the postpartum period. A significant relationship is likely to exist early in the puerperium (chapter III), while later on in the postpartum period there is no obvious reason to expect a relationship between blues and depression/depressive symptoms:

Premenstrual syndrome has almost never been investigated as a factor possibly related to postpartum depression. As shown in chapter III, abrupt hormonal changes have been suggested to be a possible cause of the occurrence of mood disturbances. Therefore, it was suggested that 
women who are susceptible to mood disturbances as a consequence of hormonal fluctuations, as reflected in pms, are more likely to suffer from blues and postpartum depression early in the puerperium when most hormonal fluctuations occur.

The relationship between breastfeeding and postpartum depression has not frequently been investigated. This might be explained by the fact that it is difficult to interpret (because of diurnal fluctuations) the biological hallmark of breastfeeding - the hormone prolactin - and to relate it to mood changes in the puerperium. However, we were interested in finding out whether there were differences in the occurrence of depressive mood disturbances in women who were breastfeeding and women who were not.

Obstetrical complications are often thought to be related to postpartum depression, mainly based on the assumption that the more complicated the parturition, the more stressfully it will be received.

Child temperament and its relationship to postpartum depression has only recently been investigated. Its relationship has been shown to be very strong.

The relationship between the transition to parenthood and postpartum depression has seldom been investigated. In this study, we decided to include two variables on the definition of the transition: parity and resigning from working, or continuing to work, outside the home. From research into depression in general, it is known that losing or resigning from a job is a major stressful life event which may contribute to the occurrence of depression. We hypothesized that, in women who resigned from working outside the home, depressive symptoms and depression may occur more often than in women who continued to work outside the home.

In the literature, depression in pregnancy, pms, blues and obstetrical complications are hypothesized to be specific predisposing factors for postpartum depression; child temperament, parity and the transition to parenthood as contributing factors specific to the postpartum period. Therefore, we can expect a significant relationship between these factors and depression/depressive symptoms.

6.3 Presentation of a theoretical model for the study, choice of analysis and presentation of the questions from the study

\subsubsection{Presentation of a model}

The model, according to Gelder et al. (1988), as discussed in part I of this thesis, is shown in fig 6.1. 


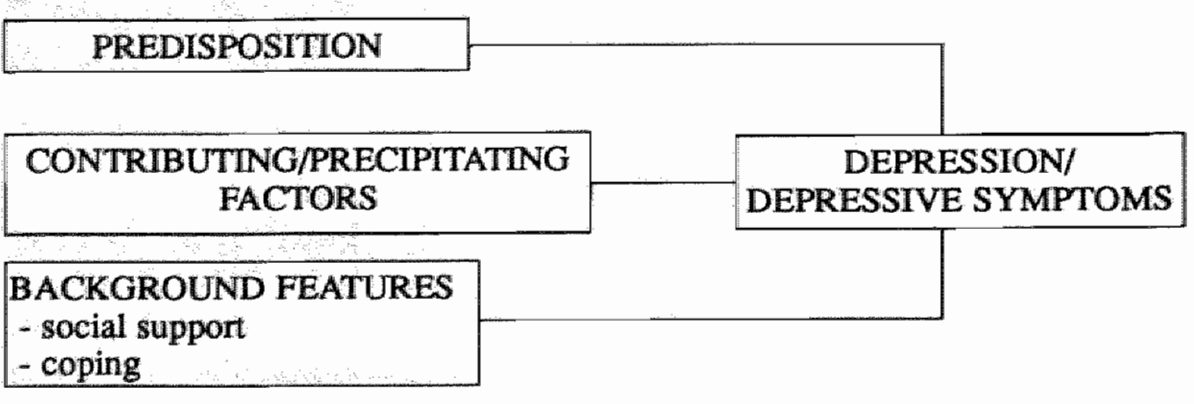

fig 6.1 general model for depression

This model can be transferred to the postpartum situation (fig. 6.2).

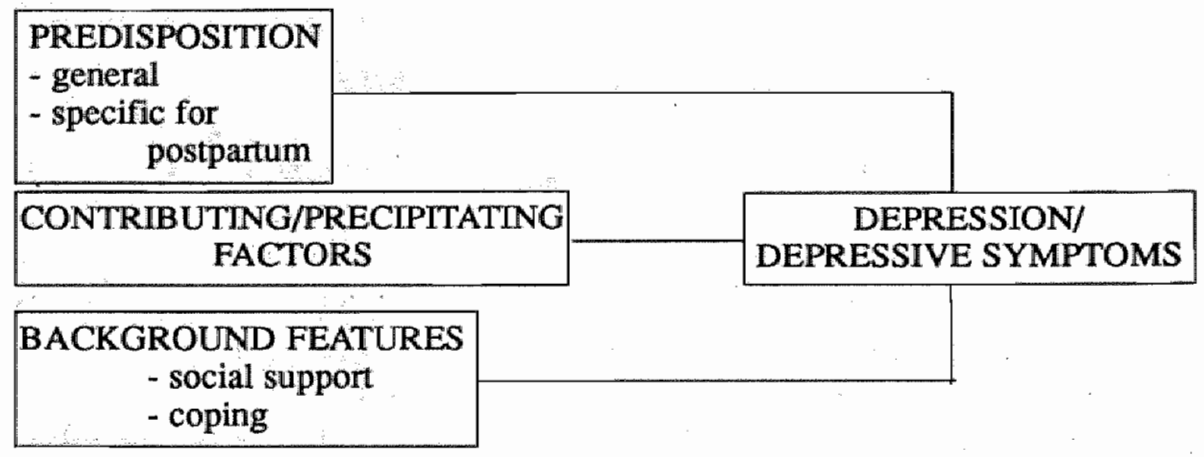

fig 6.2 general model for postpartum depression

In chapter IV, the independent variables which are investigated in literature are summarized. These variables are shown in the model of this thesis (fig 6.3).

A possible relationship between these variables and the independent variable depression/depressive symptoms will be investigated in a crosssectional manner, e.g., at one moment during the postpartum period. Moreover, during the follow-up period the extent to which possible relationships fluctuate will be investigated. Testing the model in a follow-up study will differentiate between variables showing correlations with the central variable which fluctuate during pregnancy and postpartum, and variables which show correlations which remain relatively stable during the period of screening.

As shown in the literature, the hypotheses about interactions between the above-mentioned factors are valid, and therefore (strong) correlations between these factors and depression/depressive symptoms should be found. 


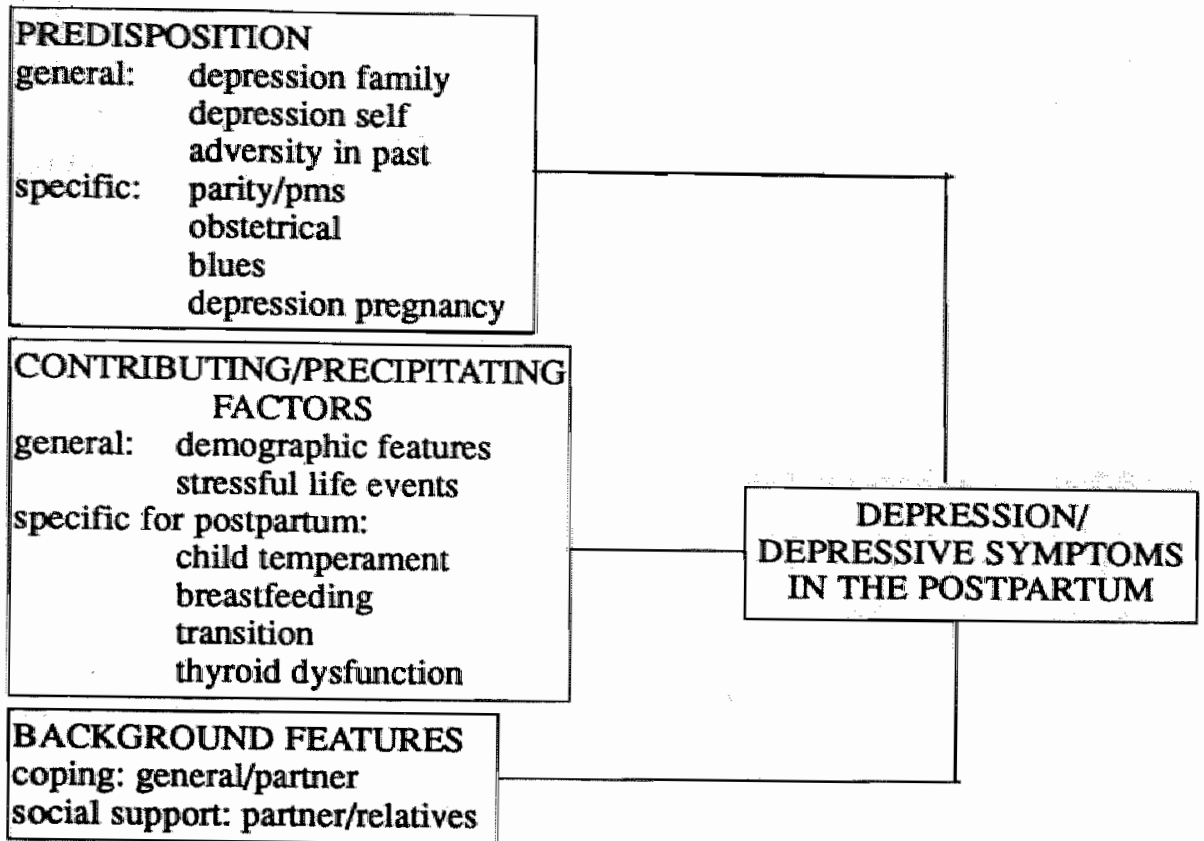

fig 6.3 model for the postpartum period in this study

Whenever the suggested interactions are non-existent in the population, it may be argued that the hypotheses are not valid.

\subsubsection{Choice of analysis}

An investigation into the etiological factors of depression in general, and hence of postpartum depression, may be carried out at three levels.

At the first level, it is interesting to discover whether there is a relationship between depression/depressive symptoms, the dependent variable, and each of the other variables. This can be done by bivariate analysis.

At the second level, an investigation can be carried out into which variables (showing a significant relationship to the dependent variable depression/depressive symptoms) contribute the most to explain the observed relationships. Moreover, the way in which the independent variables interact with each other can also be investigated. This can be done by multivariate analysis techniques.

The third level consists of an analysis which investigates the question of whether causal relationships can be found between independent variables and the dependent variable depression/depressive symptoms. Analyses such as LISREL and cross-leg-panel techniques are useful for that purpose. 
As this dissertation is part of a larger project, we will restrict ourselves in this thesis to analysis at the first level, using bivariate analysis techniques. In the future, the other two approaches will be studied in order to investigate more exhaustively the role of the independent variables in the etiology of postpartum depression.

\subsubsection{Presentation of the questions from the study}

In this section, the questions from the study are summarized.

A. Questions concerning incidence and prevalence rate.

1. What is the incidence, prevalence and course of postpartum thyroid dysfunction in The Netherlands - at least in this area?

2. What is the incidence, prevalence and course of postpartum depression in The Netherlands - at least in this area?

B. Questions concerning interactions suggested in the literature.

1. Is there a complaint pattern typically related to postpartum thyroid dysfunction?

2. Is there a relationship between thyroid dysfunction and depression in the postpartum period?

3. Are the background features 'coping behaviour' and 'social support' related to postpartum depression?

4. Are the general contributing factors 'stressful life events" and 'demographic features' related to postpartum depression?

5. Are the contributing factors specific to delivery or the postpartum period 'child temperament', 'first transition to parenthood (primipara)', 'resigning from work outside the home' and 'breastfeeding' related to postpartum depression?

6. Are the general predisposing factors previous history of depression in the women herself or in the woman's family members', "adversity in the past' related to postpartum depression?

7. Are the predisposing factors specific to delivery and the postpartum period 'depression in pregnancy', 'obstetrical complications', 'blues', and 'pms' related to postpartum depression?

After describing the results of the study in chapters IX, X, XI and XII, these questions will be re-evaluated in chapter XIII.

Once again, we emphasize the fact that if we do find a significant relationship between a certain variable (independent variable) and depression (dependent variable), we only know that this relationship exists, but not the way it is related to depression. For example, it may be possible that this relationship only exists because of interaction with 
other independent variables. The correct way to discriminate between the independent variables which contribute the most to depression is by multivariate analysis techniques. As explained before, this is beyond the scope of this thesis. 
74 


\section{Part II \\ Methods}




\section{Chapter VII}

\section{Variables and operationalization}

In this chapter the main variables will be defined and discussed. The instruments used in this study to "translate" variables, such as thyroid dysfunction and depression or social support, into terms that can be objectively be measured, will be described. The instruments which are translated from English and which have never been used before in The Netherlands are shown in the Appendix in the way in which they were used during the study: the social support list, the Edinburgh Postnatal Depression list, and the list concerning past adversity and the way the parents are perceived by the woman.

\subsection{The central variables}

7.1.1 Thyroid dysfunction and parameters of thyroid function Definition of thyroid dysfunction

As mentioned in chapter III, a major problem in research into postpartum thyroid dysfunction is the poor definition of what is to be regarded as thyroid dysfunction. We used a biochemical definition of thyroid dysfunction and decided to define thyroid dysfunction as occurring only in those cases in which abnormal TSH values were accompanied by abnormal $\mathrm{fT} 4$ and/or $\mathrm{fT} 3$ values.

\section{Parameters of thyroid function}

Microsomal antibodies were measured by hemagglutination assay. The women were classified as being microsomal-antibody positive when the titre was higher than $1 / 100$ at more than one sampling point.

Thyroid enlargement was defined to occur when the difference in thyroid size between two assessments was greater than one class, according to the WHO classification.

General complaint pattern. The classical symptoms of hyperthyroidism and hypothyroidism were assessed by a researcher who was unaware of the results of the biochemical tests summarized in table 7.1.

Operationalization

Thyroid dysfunction was determined by measuring concentrations of thyroid stimulating hormone (TSH, reference interval $0.3-3.7 \mathrm{mU} / 1$ ), free 
table 7.1 signs and symptoms of thyroid dysfunction

\begin{tabular}{|c|c|}
\hline hyperthyroidism & hypothyroidism \\
\hline tiredness, fatigue & tiredness, fatigue \\
\hline irritation & cold intolerance \\
\hline nervousness & puffy face \\
\hline tremors & dry skin \\
\hline transpiration & constipation \\
\hline excessive weight loss & paresthesia \\
\hline heath intolerance & memory disturbances \\
\hline
\end{tabular}

thyroxine (fT 4 , reference interval $8.8-23 \mathrm{pmol} / \mathrm{l}$ ), and free triiodothyronine (fT3, reference interval 4.0-8.0 pmol/1) with commercially available kits (Amerlite, and Amerlex, respectively; Amersham International PLC). The reference values as suggested by the manufacture of the assay kits, were used as a global indication. Moreover, these were based on the analyses of sera of 215 (TSH) and 483 (fT4 and fT3) non-pregnant persons of well defined euthyroid status and not on thyroid treatment. Due to the longitudinal character of our study, the patients were their own reference. Evaluation of the assays throughout the study showed interassay coefficients of variation for TSH of $16.2 \%, 4.0 \%, 4.4 \%$ and $4.0 \%$ at concentrations of $0.19,1.2,14$ and 26 $\mathrm{mU} / \mathrm{h}$, for $\mathrm{fT} 4$ of $2.3 \%, 2.8 \%$ and $3.8 \%$ at concentrations of $7.6 \mathrm{pmol} / 1,20$ $\mathrm{pmol} / \mathrm{l}$ and $62 \mathrm{pmol} / \mathrm{l}$, respectively, and for fT 3 of $2.0 \%, 4.5 \%$ and $4.5 \%$ at concentrations of $2.7 \mathrm{pmol} / 1,9.1 \mathrm{pmol} / \mathrm{l}$ and $22 \mathrm{pmol} / 1$.

TSH and fT4 was determined during each assessment. When TSH or fT4 concentrations were outside the reference interval, fT3 was also determined.

Microsomal antibodies were measured by hemagglutination assay (Fujirebio, Inc. Japan).

Thyroid enlargement is described using the most recent WHO classification system, as modified by Delange et $\mathrm{al}_{\text {.(1986), and is }}$ summarized in table 7.2 .

table 7.2

class I :
class Ia
class Ib :
class II :
class III :

WHO classification of thyroid size

\section{no struma}

thyroid enlarged, not visible even in

hyperextension of the head

Thyroid enlarged on palpation and visible

in hyperextension or palpable nodus

Thyroid visible enilarged in normal position of the head

large struma, visible on distance 
The general complaint pattern was assessed by means of a questionnaire commonly used in general medicine for symptoms relating to hyper- or hypothyroidism (Amino et al., 1982a, Fung et al., 1988, Klein et al., 1988). This contains questions on the presence or absence of the complaints summarized in table 7.1. Moreover, the Symptom Check List (SCL-90, Derogatis 1973, 1977) was used in our study, a multidimensional scale which measures all kinds of psychopathology. It comprises 90 items, each of which describes a particular distressing state. Together, the 90 items cover nine primary symptom sub-scales: somatization, anxiety, depression, hostility, psychoticism, paranoid ideation, interpersonal sensitivity, obsession-compulsion and phobic anxiety. The sumscore can be regarded as an index of psychoneuroticism: a reflection of the average level of psychological and somatic dysfunctioning during a certain period of time ( 1 week). The validity and reliability of this instrument have been proved to be satisfactory by Derogatis and others $(1973,1977)$ and, in The Netherlands, by Arindell and Ettema (1986). An example of some items: "pains in the lower back". or "suddenly being scared for no reason". For each item the respondent may score on a five-point scale from "not at all present" to "extremely present".

The alpha coefficients for the nine subscales of the SCL-90 in our study are: somatization .70 , obsession-compulsion .81 , interpersonal sensitivity .84 , depression .88 , anxiety .81 , hostility .73 , phobic anxiety .83 , paranoid ideation .80 and psychoticism .70 .

In table 8.5 , the correlation coefficients of the nine subscales in our study are shown.

table 7.3 correlation coefficients between nine subscales of the SCL-90

\begin{tabular}{llllllllll}
\hline & soma & obsc & inte & depr & anxi & host & phoa & para & psyc \\
som & - & .65 & .56 & .61 & .61 & .53 & .37 & .42 & .47 \\
obsc & - & .70 & .76 & .71 & .68 & .40 & .63 & .58 \\
inte & & - & .76 & .67 & .70 & .46 & .73 & .70 \\
depr & & & - & .73 & .75 & .45 & .58 & .63 \\
anxi & & & & - & .65 & .49 & .55 & .66 \\
host & & & & & - & .39 & .62 & .56 \\
phoa & & & & & & - & .41 & .51 \\
para & & & & & & & - & .75 \\
psyc & & & & & & & & & -
\end{tabular}

all coefficients are 2-tailed significant $p=.001$ 


\subsubsection{Depression and depressed mood}

\section{Definition}

In chapter I, a definition of depression was given and this will only briefly be summarized here. The central features of depression are not only feelings of sadness, desperation, hopelessness and pessimistic thinking, but also lack of enjoyment, loss of concentration, reduced energy, slowness and decreased appetite for or satisfaction in undertaking all kinds of activities. Low self-esteem, feelings of guilt and anxiety may allso be characteristic of depressive mood disorder. These characteristics may fluctuate during the course of the depressive disorder.

Operationalization

I. The diagnosis of depression was made using the Research Diagnostic Criteria (RDC) developed by Spitzer et al. $(1973,1978)$. These diagnostic criteria were developed for research programs and were the precursors of the DSM-III criteria. The RDC criteria can be integrated into a structured interview consisting of four main questions:

(a) Is there at least one period of dysphoric mood or a loss of interest or lack of enjoyment. Are the following symptoms present: depressed mood, sadness, desperation, hopelessness, pessimistic thinking, irritation, lack of interest, or being down. Not included are mood disturbances that change from one moment to another, as in psychotic disturbances.

(b) Are three or more of the following symptoms present:

1. significant weight loss or weight gain when not dieting;

2. sleep disturbances or hypersomnia;

3. loss of energy, lassitude or fatigue and tiredness;

4. psychomotoric agitation or retardation;

5. loss of interest or pleasure in normal activities or social and sexual activities;

6. feelings of excessive or (inappropriate) self-guilt;

7. diminished ability to think or concentrate, indecisiveness;

8. recurrent thoughts of death or suicide or suicidal behaviour.

(c) Do the mood disturbances occur for at least two weeks.

(d) Did the patient contact a health professional, was she referred, did she use medicaments, or did she have difficulty in functioning in family life, at her job or in her social life.

Delusions or hallucinations should not occur.

One can distinguish between major and minor depression: in major depression at least five of the eight symptoms set out in (b) are present; in minor depression only three or four symptoms are present. In a short 
interview the presence (or absence) of the above mentioned symptoms was investigated.

II. The intensity of depressive symptoms was assessed by means of self-rating scales. Because each of these scales only measures a limited number of aspects of depressed mood, several scales measuring different aspects were used (chapter I).

(a) The Beck Depression Inventory (BDI, Beck et al. 1961, 1972, 1988), as described in chapter $I$, measures the severity of depressive symptoms. It consists of 21 items. Each item contains four statements (covering a period of 7 days) from which a person has to indicate which is most applicable to the subject. The validity and reliability of this scale in The Netherlands was investigated by Hoevenaars and van Son (1984) and Bouman et al. $(1985,1989)$ and it proved to be satisfactory. The correlation-coefficient with HRS-D is $.75-.82$, with the $.60-.74$, and with VROPSOM .50- .83 .

An example of an item is: (a) I am not disappointed in myself; (b) I am disappointed in myself; (c) I am disgusted by myself; (d) I hate myself. There are several reports in the literature that mention a number of limitations when childbearing women are asked to rate this inventory (Cox et al. 1987, O'Hara et al., 1984, Jarjoura and O'Hara, 1987, Harris et al., 1989, Whiffen, 1988b). Especially in the postpartum period, the sensitivity of this instrument is reported to be low (68\%) (Harris et al. 1989, Whiffen 1988b). There are no clear explanations for this finding, but one hypothesis might be that women in the postpartum period 'normalize' their responses to the BDI by adjusting them to what they believe is reasonable in their special circumstances. The specificity is comparable to data reported by other investigators using the BDI in other subgroups (Whiffen 1988b). As will be explained, these findings urged some investigators to develop a postnatal depression scale (Cox et al. 1987). An alternative might be to divide the BDI into its cognitive-affective items (1-14) and into its somatic items (15-21), as proposed by O'Hara et al. (1990a) and Troutman and Cutrona (1990), and to analyze the scores of these subgroups separately in the postpartum period.

Depressed mood was defined to occur when the score was 11 or higher.

(b) The self-rating depression scale of Zung (SDS. Zung 1965) is another scale which was used in our study. This scale measures the frequency of depressive symptoms and was translated into Dutch by van Son (1978). It consists of 20 items covering a period of seven days. For each item the person has to make a choice out of four answers ranging from "seldom or never", to "sometimes", "often" or "always or almost always". Its validity and reliability has been proved to be satisfactory (Hoevenaars and 
van Son, 1984). The correlation-coefficient with BDI is $.74-.83$, and with HRS-D .56. As far as we know, there are no data reporting decreased sensitivity in the postpartum period (Bridge et al. 1985). An example of an item: "My life is pretty well filled up".

Depressed mood was defined to occur when the score was 45 or higher. (c) The VROPSOM scale is an abridged Dutch version of the Depressive Adjective Check List (DACL, Lubin 1977) developed in The Netherlands by Van Rooijen (1977). This scale measures the presence of euphoric and dysphoric moods. It consists of 34 items of one word each covering the previous seven days. The respondent has to rate all the items that reflect his mood. The validity and reliability are proved to be satisfactory (Hoevenaars and van Son 1984, Van Rooijen and Arindell, 1985). Correlations with other scales such as SDS and the depression subscale of SCL-90 are, respectively, .67 and .70 . An example of some items: "Rate the items that cover your mood during the last seven days: "happy, sad, comfortable, active, tired".

Depressed mood is defined to occur when the score is 18 or higher.

(d) The Edinburgh Postnatal Depression Scale (EPDS, Cox et al. 1987) is a self-report scale which was developed on the basis of the BDI, due to the limitations that were reported when using the BDI in the postpartum period. It consists of 10 items covering the previous seven days. Each item has four answers from which the respondent has to make a choice. The reliability and validity are reported to be high (Cox et al. 1987, Harris et al. 1989). Because the EPDS has now been translated into Dutch for the first time, no previous data are available as to reliability and validity. We gathered data in our study and investigated the consistency of the Dutch version and the correlations with other scales, such as BDI and SDS.An example of one item: "I was able to laugh and see the funny side of things." : (a) As much as I always could; (b) Not quite so much now; (c) Definitely not so much; (d) Not at all.

In our study, depressed mood was defined to occur when the score was 12 or higher. The correlation coefficients between SDS, BDI, EDPS and VROPSOM in our study are summarized in table 7.4

table 7.4 correlation coefficients between SDS, BDI, EDPS and VROPSOM

\begin{tabular}{lcccc} 
& EDPS & SDS & BDI & VROPSOM \\
EDPS & - & $.67^{*}$ & $.64^{*}$ & $.69^{*}$ \\
SDS & & - & $.57^{*}$ & $.67^{*}$ \\
BDI & & & - & $.64^{*}$ \\
VROPSOM & & & & - \\
\hline
\end{tabular}

$*=2$-tailed significant, $p=.001$ 
From this table, we can see that the four scales have a fair to moderate concurrent validity. The alpha coefficient, which reflects the internal consistency of the scale was .85 for BDI, .81 for EDPS, .74 for SDS, .86 for VROPSOM.

\subsection{Variables related to depression}

\subsubsection{Social support}

\section{Definition}

In our study, 'social support' was defined as: a supportive interpersonal relationship which provides companionship, emotional support, cognitive guidance and advice, material aid and services and reaffirmation of normative social role expectations (Billings and Moos, 1982).

As already mentioned in chapter III, while most studies on postpartum depression revealed negative correlations between perceived social support from the partner and the occurrence of postpartum depression, others did not find such a correlation (O'Hara et al.1990b). Most studies found that support perceived from the spouse was a major contributing aspect of social support.

\section{Operationalization}

In our study we used items belonging to the Social Support Interview (SSI, O'Hara et al., 1983). The respondent has to rate his findings on a five or six-point scale. The items involve instrumental (such as help with child care) and emotional support as well as mutual sharing of problems. The reliability and validity of SSI has proved to be satisfactory (O'Hara et al., 1984). We translated these items into Dutch and, in this study, we investigated the consistency of the Dutch version. Moreover, we added several items from a social support list used by de Jong (1987) which mainly cover emotional support from the spouse. Two versions of the scale were used; in pregnancy the scale consisted of 13 items, in the postpartum period it consisted of 18 items due to 5 extra items which were added concerning perceived support regarding the spouse's care of the baby. There is a six-point scale from completely true to not at all true. An example of an item is: "My husband often takes care of the baby" or "I myself feel comfortable about the way in which my parents are now involved in my daily life".

Factor analysis revealed two sections: one section of the list concerning questions on perceived social support from the partner (this section is called 'partner'), the other section concerning questions on perceived social support from parents, closest family and closest friends (this section is called 'rest'). In our study the correlation between the two subscales was found to be .44 . The alpha coefficient of the subscale 'rest' was .69 and of the subscale 'partner' .84 . 


\subsubsection{Coping behaviour}

\section{Definition}

In chapter 1 , coping was defined as the cognitive and behavioural efforts aimed at mastering, tolerating or reducing external and internal demands. Current measurements of coping are based on three broad perspectives: (a) coping conceptualized in terms of ego or defensive processes, where tension reduction is the main focus of attention rather than problemsolving; (b) coping conceptualized as a personality trait, where it is assumed that people are behaviourial, attitudinally and cognitively consistent across situations; (c) coping as a situation-oriented process implying a description of the way in which people cope with specific situations. As pointed out by Cohen and Wills (1985) and Cutrona (1990), one major problem in measuring coping is the fact that different stressful events pose different demands. Most if not all the instruments which are developed to measure coping behaviour are based on the assumption that, in general, people cope in a more or less defined way, irrespective of the event.

\section{Operationalization}

The Utrecht Coping List (UCL), developed by Schreurs et al. (1984) was used in this study. It consists of 47 items covering seven subscales: active problem solving, palliation, avoiding, social support, depressive syndrome, expression of emotions and comforting cognitions. People are invited to rate the way in which they react in general when they are confronted with unpleasant events on a four-point scale (ranging from seldom or never to very often). The internal consistency, reliability and correlation with other instruments have been proved to be satisfactory (Folkman and Lazarus 1980, Schreurs et al. 1984). Two examples of an item: When you are confronted with an unpleasant event, will you: "Try to relax" or "Show your irritation or anger to the person who is responsible for the problem encountered'.

Moreover we used three items from the list of de Jong (1987). They are specific for coping in 'disagreement in a couple'. The respondent has to answer on a five-point scale (ranging from 'never' to "always') on the question 'If we have arguments or disagreements". The answers are: (1) we avoid each other; (2) we take time to discuss and to resolve the problem; (3) we try to find a solution that seems reasonable to both of us." As described by de Jong (1987), the reliability and validity of these three items were high.

In table 7.5, the correlations in this study between the subscales of UCL (active problem solving reaction, palliative reaction, avoiding, turn for support, depressive reaction, expression of emotions, reassuring thoughts) are summarized. 
table 7.5 correlation coefficients between the seven subscales of $\mathrm{UCL}$

\begin{tabular}{|c|c|c|c|c|c|c|c|}
\hline 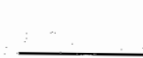 & active & palliat. & avoid & support & depres. & emotion. & reas. \\
\hline $\begin{array}{l}\text { active } \\
\text { pallia } \\
\text { avoid } \\
\text { support } \\
\text { depress } \\
\text { emotion } \\
\text { reassur }\end{array}$ & & $.19 *$ & $.26 *$ & $\begin{array}{l}.26^{*} \\
24^{*}\end{array}$ & $\begin{array}{l}-.23^{*} \\
.12 \\
.19^{*} \\
.\end{array}$ & $\begin{array}{l}.17^{*} \\
-.12 \\
.30^{*} \\
.21^{*} \\
-\end{array}$ & $\begin{array}{l}37^{*} \\
.43^{*} \\
.29^{*} \\
.20^{*} \\
-\end{array}$ \\
\hline
\end{tabular}

* significant 2-tailed $\mathrm{p}=.001$

In this table it is shown that several subscales correlate significantly with other subscales. Moreover the subscale "palliative reaction' correlates well with all the other subscales, suggesting that these scales all share one common element: that of avoiding problems which are encountered. These correlations are comparable with the results mentioned in the study of Schreurs (1987), however the coefficients in our study are higher. The alpha coefficients for the subscales are: active reaction .77 , palliative reaction .71 , avoiding reaction .65 , turn for support .84 , depressive reaction .66 , emotional expression .59 and reassuring thoughts .69 .

\subsubsection{Life events and depression}

\section{Definition}

In chapter I, stressful life events were introduced as being precipitating factors for depression with etiological implications. As pointed out by Sanderman (1989), the general conclusion is that stressful events do have etiological implications for depression (many depressed people rate stressful events to occur prior to the onset of depression), together with poor predictive value for the occurrence of depression (many people met stressful events without becoming depressed and many depressed people did not rate stressful events to occur prior to the onset of depression).

Operationalization

In our study, the Recent Life Events List was used, as developed by Van Willige et al. (1985). The questionnaire consisted of 115 items. The respondents can indicate which events they have encountered over the past 12 months and how they perceived these events in terms of (un)pleasantness. We omitted such questions as 'children who leave home' or 'retiring' for obvious reasons. Moreover, we asked the women about events occurring during pregnancy and the 8-month postpartum period. Although there are several studies in which difficulties were encountered when the reporting period was longer than 12 months (Funch 
and Marshall, 1984, Sobell et al. 1990), we argued that the pregnancy itself is a well defined period for the subject, which makes it easier to rate events happening during that particular period.

A sumscore of the total number of (un)pleasant events happening during the period before assessment was used.

\subsubsection{Past adversity}

\section{Definition}

Past adversity refers to events which occurred in the past and which are found to be associated with an increased vulnerability for provoking agents and risk factors in the current environment (Harris et al. 1987, Brown 1989). In this study, past adversity will be restricted to the following events: depression in the past, loss of parents before 16 years of age, poor relationship between parents until 16 years of age and a dramatic event before 16 years of age. The latter implies any event occurring when the woman was young and was expressed as dramatic or very significant at that time of her life.

\section{Operationalization}

A questionnaire was designed especially for this study and contains five questions on adversity in the past: the death of one or both parents (before the respondent reached the age of 16), a poor relationship between her parents, divorce, depression of one or both parents, or a dramatic episode which she recalls clearly. The items were rated as present or absent and the sumscore was used as a marker for 'high' or "low" past adversity. Another questionnaire was developed concerning the relationship between the respondent and her parents: Parental-Mother List (PML). The 11 items were rated on a six-point scale from 'totally true' to 'absolutely not true' and referred to the way in which the respondent and her parents perceived the relationship between them until her 16th year. Some examples of an item: 'I often had the feeling of being treated in the wrong way' or 'I was punished very often' or 'I often felt rejected by my mother'. No cut-off scores were used.

The parental mother list (PML) showed an alpha coefficient of .86. When we compared this scale with the list containing the five questions on adversity in the past, it correlated significantly in the expected direction (.33).

\subsection{Variables, especially related to postpartum depression}

\subsubsection{The infant temperament}

Definition

In our study, the infant's temperament includes those aspects of childcare 
contributing to the severity of the stress experienced by the recently delivered mother (Cutrona and Troutman 1986).

Operationalization

We translated the Childcare Stress Inventory (CSI, Cutrona, 1983) into Dutch. This assesses the severity of the stress resulting from events specifically related to childcare. It consists of 21 items to which the respondent can answer on a six-point scale, from totally true to absolutely not true. The reliability and correlation with other scales from the CSI are shown to be satisfactory (Cutrona 1983, O'Hara 1986, O'Hara et al. 1990b). Three examples of an item: "it is easy to change the baby"s nappy", or "the baby often disturbs my sleep at night" or "the baby loves to be carried and cuddled'.

We investigated the consistency of the Dutch version of the CSI. Factor analysis showed two distinct subscales: one subscale concerned the way in which the child is perceived as troublesome by the mother, the subsale 'trouble', and the other concerned the actual amount of care - feeding at night - that has to be given to the child, the subscale 'care'. The alpha coefficient of the CSI-trouble subscale is .72, of the CSI-care subscale .82 . The correlation-coefficient of these scales with each other is .54 .

\subsubsection{Premenstrual syndrome}

\section{Definition}

In chapter III, it was mentioned that only a few studies have been carried out on the possible relationship between pms and postpartum depression. It is a disorder with non-specific somatic, psychological or behavioural characteristics regularly recurring in the premenstrual (luteal) phase of the menstrual cycle. Symptoms must resolve completely by the end of the menstruation, leaving a symptom-free week. In our study, pms was defined to have occurred when the woman confirmed that certain complaints were responsible for disruption of social, familial and or occupational life.

Operationalization

During pregnancy the occurrence of pms was assessed retrospectively, using a questionnaire containing 7 items on the most prominent psychological (irritability, aggression, tension) and somatic symptoms (abdominal bloatedness, headache, abdominal pain, breast symptoms). The respondent was rated as a 'case' when one or more of these symptoms was present and disruption in daily life occurred.

\subsubsection{Blues}

\section{Definition}

Blues are mild mood disturbances marked by emotional instability (e.g., 
crying spells without any cause, insomnia, see chapter III). The relationship between postpartum depression and the blues has been investigated in many studies with rather conflicting results ( $O$ 'Hara and Zekoski 1988). According to Pitt (1973), blues are defined by the presence of both significant tearfulness and low mood, lasting for at least part of a day during the first 10 days' postpartum.

Operationalization

Blues were assessed at 4 weeks' postpartum, retrospectively, using Pitts" criteria (Pitts, 1973). Women were rated as "cases" if significant tearfulness and low mood during the first 10 days' postpartum were reported. As shown by O'Hara et al. (1990a) the specificity of retrospectively assessed blues by use of these two Pitts criteria is similar to the specificity of prospectively assessed blues by use of more extensive rating in Handley's criteria (Handley et al., 1980), which consist of a semi-structured interview. The sensitivity of these two scales differs in such a way that the prevalence rate of blues assessed by Handley's criteria is much lower than by the Pitts' criteria: O'Hara et al. (1990a) found $26.4 \%$ women who met Handley's criteria for blues, compared to $41.8 \%$ who met Pitts" criteria in the postpartum period. However, the ratio of childbearing to non-childbearing women who met both criteria was very similar: 4.1:1 with Pitts' criteria and 3.6:1 with Handley's criteria, suggesting that these symptoms are rather specific for the postpartum period.

\subsubsection{Obstetrical complications}

\section{Definition}

In chapter III, it was shown that studies on a possible relationship between obstetrical complications and postpartum depression revealed a rather non-conclusive outcome. In this study obstetrical complications were defined to occur in cases in which spontaneous vaginal parturition did not occur.

Operationalization

At 4 weeks' postpartum, the women were asked to report on the way in which they delivered the baby. The following responses could be given:

(a) spontaneous vaginal parturition at home, (b) spontaneous vaginal parturition in hospital, (c) vaginal parturition after stimulation with medicaments, (d) vaginal parturition with forceps/vacuum extraction, and (e) Caesarian section. The women were rated as having had obstetrical complications if they belonged to any of the last three classes.

\subsubsection{Transition to parenthood}

\section{Definition}

In chapter III, the transition to parenthood was reported in some studies to be a predictor of postpartum depression. The degree of transition in 
our study was based on the presence of two variables: parity and resigning from work outside the home.

\section{Operationalization}

Women were rated as 'cases' if they were primiparous and/or if they resigned from working outside the home, irrespective of their parity.

\subsubsection{Breastfeeding}

\section{Definition}

In chapter III, rather conflicting conclusions were presented on a possible relationship between breastfeeding and postpartum depression. Women were considered to breastfeed their babies if they fed the baby for at least one week and if this was not accompanied by a substantial amount of bottlefeeding. During the postpartum period, they were considered to have stopped breastfeeding if the frequency was less than twice a day.

Operationalization

During each assessment the women were asked whether they were breastfeeding or not, and if they had stopped, for how long had they been breastfeeding. The women were rated as: non-breastfeeding, still breastfeeding and stopped-breastfeeding.

\subsection{Statistical analyses and matching procedure}

Statistical analyses were performed at the Department of Clinical Psychology of the University of Utrecht, using the Statistical Package of Social Science (SPSS). Statistical testing was Student's t-test, chi-square test or correlation techniques. In correlation analysis, when two variables were operationalized with the aid of scales, a possible relationship was analyzed using the 2-tailed Pearson's student correlation technique. When there was one dichotomic variable, the point-biserial correlation technique was used. If there were two dichotomic variables, the correlation was expressed as a phi-coefficient. The significance of the differences between correlations, if necessary, was calculated using Fisher's $z_{r}$ transformation technique, as described by Ferguson (1959). For purpose of analysis of the data in the study, matching was performed on several occasions. Features of the women, such as age, social class and parity, were collected with the aid of a computer, and a list was made containing only the numbers and features of women who were closest to the sample under investigation. This list was used to collect at random enough matched controls for statistical analysis. 


\section{Chapter VIII}

\section{Description of subjects, assessment procedure, demographic characteristics, and study design}

\subsection{The sample}

Between November 1988 and April 1989, 382 Caucasian women who booked in for antenatal control were invited to participate in a screening programme. As there is a choice between home and hospital delivery in The Netherlands, the women were invited to participate by five midwives working in several districts near Eindhoven and by gynaecologists from the Antenatal Clinic, St Joseph's Ziekenhuis, Veldhoven. Apart from the subjects' own informed consent, permission for the study was obtained from the ethical committee of the University of Maastricht, The Netherlands. In total 303 women consented to participate. The ascertainment rate was therefore $79 \%$. The non-responders did not differ in age, parity or social class from the participants.

\subsection{Assessment procedure}

The subjects were assessed at 32 weeks' gestation and in the follow-up period which started at 4 weeks' postpartum and was continued at intervals of 6 weeks until 34 weeks' postpartum. On all occasions, the women were visited at home between 11.00 am and $4.30 \mathrm{pm}$ by the author, who received a special training in clinical examination of the thyroid at the Endocrinological Department, St Joseph's Ziekenhuis, Veldhoven. The screening started in December 1988 and lasted until June 1990.

Demographic features such as age, marital state, social class and number of other children were assessed. Social class was defined by four classes according to level of education. Class 1 comprised women who had only had a primary school education, class 2 comprised women with a low secondary educational level, class 3 comprised women with secondary educational level followed by lower further education; and finally class 4 comprised women with a university degree or a comparable educational level.

Personal and family history for autoimmune diseases and thyroid 
diseases were obtained and clinical thyroid state (complaints, signs and symptoms for thyroid dysfunction), thyroid hormones and thyroid antibodies were evaluated at each visit, as described in chapter VII.

During pregnancy, the Utrecht Coping List was completed, together with BDI, VROPSOM and SCL-90. Social support was assessed in the manner described in the previous chapter. Diagnosis of depression was made using the RDC criteria. In the postpartum period, screening started at 4 weeks" postpartum and was performed 5 times thereafter at intervals of 6 weeks until 34 weeks' postpartum. During the postpartum period, the SDS was also completed instead of the UCL, which was used only in pregnancy. Moreover, the "temperament of the baby" was investigated at each postpartum assessment, as described in the previous chapter. At the last assessment, a stressful life-event list was completed together with a list containing items on past adversity and a rating scale concerning the relationship between the woman and her parents in the past. In order to exclude anaemia as a possible cause of complaints such as lassitude and fatigue, the $\mathrm{Hb}$ status was investigated at each postpartum assessment with the aid of a colorimeter which is commonly used in general practice. The assessment procedure is summarized in table 8.1 .

table 8.1 assessment during pregnancy and in the postpartum

\begin{tabular}{|c|c|c|c|}
\hline variables & pregnancy & $\mathrm{pp} 1-\mathrm{pp} 6$ & pp6 \\
\hline \multicolumn{4}{|l|}{ thyroid function: } \\
\hline - complaints & + & + & + \\
\hline - palpation & + & + & + \\
\hline - TSH, fT4, fT3, MsAb & + & + & + \\
\hline \multicolumn{4}{|l|}{ mood state: } \\
\hline - BDI,VROP,SCL-90,RDC & + & + & + \\
\hline - SDS, EDPS & $*$ & + & + \\
\hline socilal support & + & + & + \\
\hline child temperament & - & + & + \\
\hline \multicolumn{4}{|l|}{ coping: } \\
\hline - UCL & + & - & - \\
\hline - partner & + & + & + \\
\hline liffe events & - & - & + \\
\hline adversity & - & - & + \\
\hline
\end{tabular}

*: during pregnancy, there were 100 women who filled in the EDPS

Three women moved out of the area and were lost to follow-up, two women resigned from further screening and five women became pregnant again during the period of screening and were excluded from analysis. Therefore, the results discussed in this thesis refer to 293 women who completed the study. 


\subsection{Demographic characteristics}

Of the 293 women, there were 133 primipara and 160 multipara. Only one woman was divorced, all the others were married or had a partner. The demographic features are summarized in table 8.2 .

table 8.2 demographic characteristics of the sample

\begin{tabular}{lcc}
\hline features & primipara & multipara \\
\hline number & 133 & 160 \\
mean age & 27.4 & 30.5 \\
social class: & $\%$ & $\%$ \\
1 & 10.5 & 11.7 \\
2 & 41.5 & 39.2 \\
3 & 45.1 & 43.3 \\
4 & 3.0 & 5.8 \\
work outside home: & $\%$ & $\%$ \\
- pregnancy & 80 & 31 \\
- postpartum & 34 & 21 \\
\hline
\end{tabular}

As expected, the mean age of the multipara was higher than that of the primipara. There was no significant difference in social class between the two groups. As expected, many more of the primiparous women were working outside the home before delivery, compared to the multipara. The percentage of multiparous women who worked outside the home before delivery was almost the same as the percentage of primiparous women who continued to work outside the home after delivery. More than half the primiparous women resigned from working outside the home after parturition, compared to $30 \%$ of the multiparous women.

\subsection{Design of the study}

The methods of analysis used are summarized.in table 8.3.

table. 8.3 design of the study

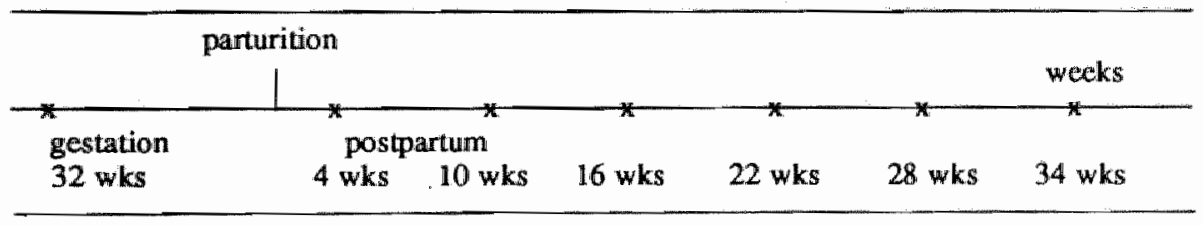
(a)
(a)
(a)
(a)
(a)
(a)
(b)
(b)
(b)
(c)
(d) (d)
(d) (d)
(d) (d)
(d)
(d)
(d)

(a) 
The incidence of thyroid dysfunction was detected by means of biochemical tests, and the incidence of depression, respectively, depressive symptoms was detected with the aid of RDC criteria and selfrating scales (' $a$ ' in table 8.3 ).

The question of whether thyroid dysfunction is related to certain complaints was investigated using the chi-square test and the Student $t$ test ( $b$ " in table 8.3). The data on the complaint pattern of all women with thyroid dysfunction from all assessments were taken together and compared with euthyroid matched controls. The relationship between postpartum thyroid dysfunction and postpartum depression was investigated by calculating the risk of women with postpartum thyroid dysfunction to develop postpartum depression, compared to women without postpartum thyroid dysfunction (relative risk).

The correlations between the dependent variables (depression/depressive symptoms) and independent variables - e.g., 'blues, 'pms' 'social support' - were investigated by the Pearson correlation technique. Because most studies in the literature reported the prevalence rate at 3 months" postpartum, in our study the assessment at 10 weeks' postpartum was taken as a reference ( $\mathrm{c}$ ' in table 8.3).

The course of postpartum depression was described comparing the pointprevalence of depression at each assessment with the pointprevalence at all the other assessments using the chi-square test ( $d$ ' in the table 8.3 ). 
Part III

Results 
96 


\section{Chapter IX}

\section{The incidence, prevalence and course of postpartum thyroid dysfunction}

\subsection{Incidence and prevalence}

The incidence, i.e., all new cases of thyroid dysfunction occurring in the postpartum assessment period, was $7.2 \%$ ( 21 women). Of these cases, 11 had transient hyperthyroidism alone, 6 hyperthyroidism followed by hypothyroidism and 4 hypothyroidism alone.

The point-prevalence, i.e., the presence of thyroid dysfunction at each assessment point, is shown in fig 9.1. Thyroid dysfunction usually occurred between 3 and 6 months' postpartum.

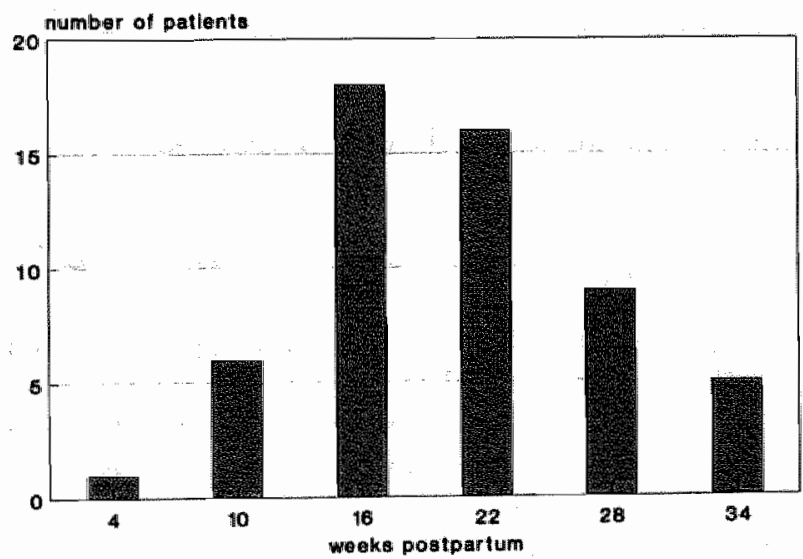

fig. 9.1: point prevalence of postpartum thyroid dysfunction

During pregnancy, no women with thyroid dysfunction were found. In table 9.1, the case of a woman with a typical biphasic pattern of thyroid dysfunction is presented: transient hyperthyroidism followed by transient hypothyroidism. The course of thyroid dysfunction pointed strongly to a diagnosis of postpartum thyroiditis. 
table 9.1 example of postpartum thyroiditis

\begin{tabular}{lcrr}
\hline time of assessment & TSH & IT4 & IT3 \\
\hline 32 weeks' gestation & 1.50 & 12.0 & - \\
4 weeks' postpartum & 1.80 & 14.0 & 15.0 \\
10 weeks' postpartum & $<0.1$ & 49.0 & 2.8 \\
16 weeks' postpartum & 37.0 & 4.0 & 4.8 \\
22 weeks' postpartum & 71.0 & 4.5 & 6.3 \\
28 weeks' postpartum & 8.90 & 17.0 & 6.3 \\
34 weeks' postpartum & 2.60 & 18.0 & \\
\hline
\end{tabular}

Table 9.1 shows that within intervals of 6 weeks, thyroid function fluctuated from normal function (4 weeks) to severe hyperthyroidism (10 weeks), followed by severe hypothyroidism. Fig. 9.2, a graphical schema of table 9.1 shows the biphasic pattern of thyroid dysfunction typical for postpartum thyroiditis.

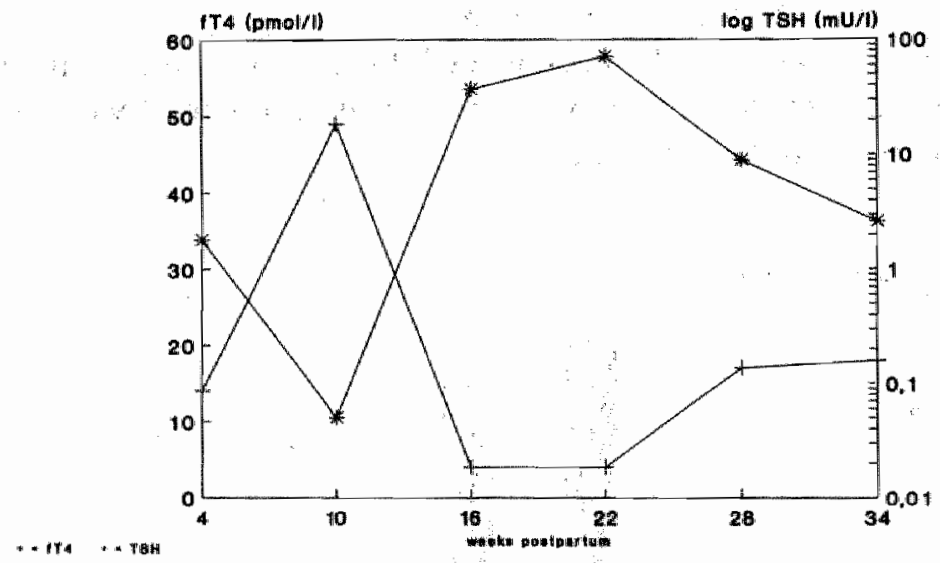

fig. 9.2 course of TSH abd fT 4 in postpartum thyroiditis

Transient hyperthyroidism alone or followed by transient hypothyroidism usually occurred between 3 and 6 months' postpartum. Transient hypothyroidism alone occurred after this period: between 6 and 8 months postpartum. Microsomal antibodies were detected in 38 women $(13 \%)$. The nature of thyroid dysfunction in these women is summarized in table 9.2. As can be seen from this table, all the women $(n=6)$ with a biphasic pattern of biochemical thyroid dysfunction had elevated microsomal antibodies titres, suggesting that postpartum thyroiditis had occurred. There were only 5 women with hyperthyroidism alone $(n=11)$ who showed increased MsAb titres, suggesting that Graves' disease might also occur in this group. 
table 9.2 occurrence of microsomal antibodies in women with and without postpartum thyroid dysfunction

\begin{tabular}{lrrr}
\hline thyroid state & $\mathrm{n}$ & \multicolumn{2}{c}{ MsAb + (\%) } \\
\hline $\begin{array}{lrrr}\text { hyperthyroidism alone } \\
\text { hyperthyroidism then hypothyroidism }\end{array}$ & 11 & 5 & $(45)$ \\
$\begin{array}{l}\text { hypothyroidism alone } \\
\text { euthyroidism }\end{array}$ & 6 & 6 & $(100)$ \\
& 272 & 4 & $(100)$ \\
total & 293 & 23 & $(8.4)$ \\
\hline
\end{tabular}

According to the titre of microsomal antibodies at 32 weeks" gestation, the women could be divided into three subgroups correlating with the occurrence of postpartum thyroid dysfunction (table 9.3).

table 9.3 the value of MsAb titre at 32 weeks' gestation in the prediction of the development of postpartum thyroid dysfunction

titre of

microsomal antibodies

postpartum

postpartum

\begin{tabular}{lrrr}
\hline $1 / 100-1 / 400$ & 8 & 1 & $(12)$ \\
$1 / 1600$ & 8 & 4 & $(50)$ \\
$1 / 6400$ or higher & 11 & 9 & $(82)$ \\
\hline total & 27 & 14 & $(52)$
\end{tabular}

Of the 27 women with positive MsAb at 32 weeks' gestation, only 14 (52\%) developed thyroid dysfunction. Of the 21 women with thyroid dysfunction in the postpartum period, $6(28 \%)$ did not have elevated titres of MsAb. This means that the presence of MsAb at 32 weeks' gestation does not adequately predict the occurrence of postpartum thyroid dysfunction $(52 \%)$. Of the 11 women with detectable MsAb in the postpartum period but not at 32 weeks' gestation, only 2 developed thyroid dysfunction.

\subsection{Subclinical postpartum thyroid dysfunction}

As defined in chapter $V$, the women with TSH values and fT4/IT3 outside reference ranges had thyroid dysfunction. Five women, however, showed abnormal TSH values with complementary changes of fT 3 and fT 4 values within normal limits. These are summarized in table 9.4

With the exception of woman No. 2, all these women showed a (marked) increase of MsAb titres in the postpartum period, suggesting that an active autoimmune process occurs. According to their changes in TSH and TT4 
Table 9.4 women with abnormal TSH values with $\mathrm{fr} 3$ and fT4 within normal limits $(n=5)$ from 32 weeks' gestation until 34 weeks' postpartum

\begin{tabular}{|c|c|c|c|c|}
\hline $\begin{array}{l}\text { women } \\
\text { No. }\end{array}$ & TSH mU/l & $\begin{array}{l}\mathrm{fr} 4 \mathrm{pmol} / \mathrm{l} \\
0.3-3.7\end{array}$ & $\begin{array}{l}\mathrm{fT} 3 \mathrm{pmol} / 1 \\
8.8-23\end{array}$ & $\begin{array}{l}\text { MsAb ** } \\
4.0-8.0\end{array}$ \\
\hline 1 & $\begin{array}{l}1.30 \\
1.20 \\
1.90 \\
0.29 \\
0.05 \\
3.50 \\
3.70\end{array}$ & $\begin{array}{l}11.0 \\
14.0 \\
14.0 \\
19.0 \\
19.0 \\
13.0 \\
12.0\end{array}$ & $\begin{array}{c}- \\
- \\
- \\
6.8 \\
5.8 \\
- \\
-\end{array}$ & $\begin{array}{l}2 \\
4 \\
4 \\
5 \\
6 \\
7 \\
7\end{array}$ \\
\hline 2 & $\begin{array}{l}0.84 \\
1.10 \\
0.52 \\
0.05 \\
0.15 \\
2.30 \\
1.80\end{array}$ & $\begin{array}{r}9.9 \\
14.0 \\
13.0 \\
22.0 \\
15.0 \\
13.0 \\
13.0\end{array}$ & $\begin{array}{c}- \\
- \\
7.8 \\
5.9 \\
- \\
-\end{array}$ & $\begin{array}{l}0 \\
0 \\
0 \\
0 \\
2 \\
1 \\
1\end{array}$ \\
\hline 3 & $\begin{array}{l}0.96 \\
1.30 \\
1.25 \\
1.00 \\
1.60 \\
4.20 \\
6.50\end{array}$ & $\begin{array}{r}11.0 \\
12.0 \\
12.0 \\
11.0 \\
12.0 \\
12.0 \\
9.9\end{array}$ & $\begin{array}{c}- \\
- \\
- \\
- \\
5.9 \\
5.4\end{array}$ & $\begin{array}{r}3 \\
3 \\
3 \\
5 \\
6 \\
11 \\
12\end{array}$ \\
\hline 4 & $\begin{array}{l}1.05 \\
0.91 \\
0.50 \\
0.05 \\
4.40 \\
2.20 \\
1.90\end{array}$ & $\begin{array}{l}14.0 \\
18.0 \\
19.0 \\
22.0 \\
11.0 \\
11.0 \\
13.0\end{array}$ & $\begin{array}{c}- \\
- \\
- \\
6.1 \\
4.7 \\
- \\
-\end{array}$ & $\begin{array}{l}1 \\
1 \\
1 \\
3 \\
4 \\
4 \\
5\end{array}$ \\
\hline 5 & $\begin{array}{l}1.70 \\
1.30 \\
1.50 \\
1.90 \\
3.30 \\
6.60 \\
5.90\end{array}$ & $\begin{array}{c}9.50 \\
12.0 \\
14.9 \\
14.0 \\
12.0 \\
12.0 \\
9.9\end{array}$ & $\begin{array}{c}- \\
- \\
- \\
5.1 \\
5.2\end{array}$ & $\begin{array}{l}2 \\
5 \\
4 \\
4 \\
4 \\
5 \\
6\end{array}$ \\
\hline
\end{tabular}

* $\quad$ fT3was only evaluated when TSH was outside refenence interval ** MsAb titre $1=1 / 100,2=1 / 400,3=1 / 1600$ etc.

values, women Nos. 1 and 2 might be diagnosed as having transient hyperthyroidism alone, women Nos. 3 and 5 as having transient hypothyroidism alone, and woman No. 4 as having transient hyperthyroidism followed by 
transient hypothyroidism. For these women, we would propose the introduction of the definition subclinical postpartum thyroid dysfunction. If we include these women, the incidence of postpartum thyroid dysfunction would rise to $8.9 \%$ ( 26 women). As will be discussed later, there is doubt about the relevance of the less restricted definition of thyroid dysfunction.

\subsection{Signs and symptoms in women with thyroid dysfunction}

The nature and frequency of complaints in women with thyroid dysfunction were compared with the complaints of those without thyroid dysfunction. The women with thyroid dysfunction complained significantly more often of lassitude and fatigue compared with a control group of 21 euthyroid women, matched for age, parity and social class ( $c h i=7.71, \mathrm{df}=1, \mathrm{p}=$ 0.005 table 9.5).

table 9.5 complaint pattern of women with thyroid dysfunction $(n=21)$ compared to the complaint pattern of 21 euthyroid controls

\begin{tabular}{lcc}
\hline complaint & $\begin{array}{c}\text { thyroid } \\
\text { dysfunction } \\
\mathbf{n}=21\end{array}$ & $\begin{array}{c}\text { matched } \\
\text { control group } \\
\mathbf{n}=21\end{array}$ \\
\hline irritation & 11 & 7 \\
nervousness & 5 & 3 \\
tremors & 3 & 0 \\
lassitude, fatigue & 15 & 6 \\
palpitations & 3 & 1 \\
transpiration & 5 & 3 \\
excessive weight loss & 1 & 0 \\
heath intolerance & 3 & 0 \\
disturbed memory & 2 & 1 \\
concentration loss & 5 & 2 \\
dry skin & 6 & 5 \\
dry hair & 5 & 5 \\
puffy faces & 4 & 3 \\
constipation & 3 & 2 \\
cold intolerance & 0 & 0 \\
paresthesia & 3 & 1 \\
\hline
\end{tabular}

$* x^{2}=7.71, d f=1, p=0.005$

In the subgroup with hyperthyroidism ( $n=17$, between 3 and 6 months' postpartum), consisting of 11 women with hyperthyroidism alone and 6 women with hyperthyroidism who subsequently developed hypothyroidism, the complaint of "lassitude and fatigue" also occurred significantly more frequently than in the matched control group ( $\mathrm{chi}=4.25, \mathrm{df}=1$, $p=0.039$, table 9.6). 
table 9.6 complaint pattern in women with postpartum thyrotoxicosis $(n=17)$ compared to matched controls

\begin{tabular}{lcc}
\hline complaint & $\begin{array}{c}\text { thyroid } \\
\text { dysfunction group } \\
\mathbf{n}=17\end{array}$ & $\begin{array}{c}\text { matched } \\
\text { control group } \\
\mathbf{n}=\mathbf{7 7}\end{array}$ \\
\hline irritation & 9 & 7 \\
nervousness & 4 & 3 \\
tremors & 2 & 0 \\
lassitude, fatigue & 12 & 6 \\
palpitations & 3 & 1 \\
transpiration & 4 & 3 \\
excessive weight loss & 1 & 0 \\
heath intolerance & 3 & 0 \\
\hline
\end{tabular}

$* x^{2}=4.25, d f=1, p=0.039$

Moreover, the mean pulse rate in the subgroup with hyperthyroidism was 79 (SD 9.6) compared with a mean pulse rate of 71 (SD 8.2) in the control group. This was significantly higher $(t=2.53, d f=30, p=0.034$, one-tailed). When the scores on the SCL-90 symptom check list in the group with thyroid dysfunction were compared with those of the control group, no difference was found between the thyroid dysfunction group as a whole and the control group. However, the scores of the women with hypothyroidism $(n=10)$ for the subscales depression (mean 17.0, SD 4.8) and somatization (mean 15.7, SD 3.7) showed a statistically significant difference between the scores for depression (mean 13.3, SD 0.5) and somatization (mean 12.8, $S D 1.0$ ) in a matched control group ( $t$-test, two-tailed, $t=2.40, p=0.038$, respectively, $\mathrm{t}=2.39, \mathrm{p}=0.038$, table 9.7 ). Women with hypothyroidism

table 9.7 mean scores on the SCL-90 in women with hypothyroidism $(n=10)$ compared with matched controls

\begin{tabular}{lrrrr} 
subscales & \multicolumn{2}{c}{$\begin{array}{c}\text { hypothyroidism } \\
\text { score(SD) }\end{array}$} & \multicolumn{2}{c}{$\begin{array}{c}\text { normal controls } \\
\text { score(SD) }\end{array}$} \\
\hline hostility & 8.4 & $(5.5)$ & 6.4 & $(0.9)$ \\
psychotycism & 11.3 & $(3.1)$ & 10.0 & $(0.0)$ \\
anxiety & 13.0 & $(6.7)$ & 10.3 & $(0.4)$ \\
depression* & 17.0 & $(4.8)$ & 13.3 & $(0.4)$ \\
paranoid ideation & 6.6 & $(1.8)$ & 6.1 & $(0.3)$ \\
somatization** & 15.7 & $(3.7)$ & 12.8 & $(1.0)$ \\
interpersonal sensitivity & 10.9 & $(4.0)$ & 9.3 & $(0.4)$ \\
obsession-compulsion & 14.7 & $(7.2)$ & 10.7 & $(1.5)$ \\
phobic anxiety & 8.0 & $(2.5)$ & 7.0 & $(0.0)$ \\
\hline$*$
\end{tabular}

* $\quad$ t-test, $t=2.40, p=0.038$ by separate variance estimate

** $t$-test, $t=2.39, p=0.038$ by separate variance estimate 
presented with more somatic and depressive complaints than normal controls between 4 and 8 months' postpartum. During the whole postpartum period, only 10 women were found with a haemoglobin concentration of between 6.0 and $7.0 \mathrm{mmol} / 1$. They did not have thyroid dysfunction.

Finally, parameters such as age, social class, family or personal history of autoimmune disease or thyroid disease, thyroid enlargement found on palpation, sex of child, parity, breastfeeding or smoking, were not found to be statistically related to thyroid dysfunction.

\subsection{Discussion}

The incidence rate of thyroid dysfunction in the present study $(7.2 \%)$ is higher than that found in three other prospective studies which met the strict methodological criteria for thyroid dysfunction (Amino et al., 5.5\%, 1982 a, Jansson et al. $6.5 \%, 1984$, Lervang et al. $3.9 \%, 1987$ ). Presumably, this can be explained by the frequent sampling and short intervals between sampling in this study. In the studies mentioned above, the women were only screened once or twice. In the present study, there were 4 women with elevated fT4 levels which were resolved within 6 weeks, so that they would have been missed if they had not been screened frequently. Moreover, the screening period in our study lasted longer than in the above-mentioned studies. There were 3 women who developed thyroid dysfunction only after 7 months (the screening lasted until 8 months' postpartum). These would have been missed as well if screening had only been carried out soon after pregnancy, as was the case in the three studies which met the methodological criteria discussed in part $\mathbf{I}$. The incidence rate in this study would then have dropped to $6.1 \%$ (18 women).

As described in chapter IV, there are some other studies with repeated sampling. However, they concerned a selected research group (Hayslip et al., 1988a), or had a definition of thyroid dysfunction which could not easily be compared with our definition (Fung et al. 1988). The definition of thyroid dysfunction in the study of Fung et al. (1988) was based on reference ranges for $\mathrm{fT} 3, \mathrm{fT} 4$ and $\mathrm{TSH}$ in normal microsomal-antibody-negative pregnant women and normal postpartum women who remained microsomal-antibody negative. The women with $\mathrm{fT} 3, \mathrm{fT} 4$ or TSH concentrations outside the mean of the corresponding group plus or minus $2 \times S D$, were classified as thyroid dysfunction. Moreover, in that study, half the women involved were $\mathrm{MsAb}$ positive, as found early in pregnancy. This means that their group is not representative of a general population (Gerstein 1990). The prevalence rate in the study of Vargas et al. (1989) was $21 \%$ (55 women). In their study, a randomized population $(n=261)$ was screened bimonthly until 1 year postpartum. However, thyroid dysfunction was partly defined 
by the presence of decreased TSH values using RIA and/or disturbed TRH tests. Their hypothesis that a transient low TSH value (RIA) is the same as transient hyperthyroidism is very doubtful.

In this study, all women with thyroid dysfunction had abnormal TSH values in combination with abnormal fT3 and fT4 values. There are other studies which also included women with abnormal TSH and normal fT4 and fT3 values in the definition of thyroid dysfunction (Jansson et al.1984, Lervang et al. 1987. Hayslip et al. 1988a). In the present study, there were 5 women who had abnormal TSH with complementary changes of IT3 and/or fT4 within normal limits. All but one of these women showed an increase of MsAb in the postpartum period. This means that an active autoimmune process in the thyroid was very likely to occur. They can be classified as women with subclinical thyroid dysfunction. According to this definition, the incidence rate in our study would then go up to $8.9 \%$. However, the relevance of these patients for general practice with regard to the complaint pattern of women with thyroid dysfunction is doubtful: there were 4 women with no complaints and none of them had clinical symptoms. However, these women have to be followed up, because women with elevated MsAb titres are at risk for another (transient) episode of thyroid dysfunction in the future, irrespective of a new pregnancy (Othman et al., 1990). Moreover, as shown by Tunbridge et al. (1981) and Bilous and Tunbridge (1988), women (and men) in a general population with elevated MsASb titres are at risk for developing permianent dysfunction of the thyroid later in life.

Thyroid dysfunction in this study, as shown in table 9.1 , predominantly consisted of hyperthyroidism alone or hyperthyroidism followed by hypothyroidism. This was also the predominate finding in Japan (Amino et al., 1982a), some parts of the USA (Nikolai et all., 1987) and Wales (Fung et al., 1988). In Sweden (Jansson et al., 1984) and Denmark (Lervang et al., 1987) hypothyroidism was generally found. There is no clear explanation for these discrepancies, but a possible role of the difference in iodine intake has been suggested (Jansson et al., 1988, Vitug and Goldman 1985).

Microsomal antibodies (MsAb or TPO-ab) have been investigated thoroughly during after pregnancy. As shown by Jansson (1986) and Fung et al. (1988), the titre is highest in the first trimester of pregnancy in women with positive $\mathrm{MsAb}$. During gestation, the titre gradually decreases until 32 to 34 weeks. Glinoer et al. (1990) showed a decrease of 59\% in TPO titres during gestation and concluded that $71 \%$ of cases with elevated TPO titres would have been missed if they had only been screened in the last trimester of gestation. Possibly, this might explain the poor predictive value of the presence of MsAb at the time of delivery for the occurrence of postpartum thyroid dysfunction (Hayslip et al., 1988a, vargas et al., 1988). Therefore, in order 
to predict the occurrence of postpartum thyroid dysfunction based on the presence of MsAb, it is important to determine these antibodies early in pregnancy. The predictive value of the presence of MsAb at 32 weeks' gestation for postpartum thyroid dysfunction (ptd), (table 9.2) is:

$\begin{array}{ll}\text { predictive value: } \\ \begin{array}{l}\text { of + test } \\ \text { weeks' gestation who develop ptd }\end{array}\end{array} \frac{\begin{array}{c}\text { number of women with MAb+at } 32 \\ \text { total number of women with MsAb } \\ \text { at } 32 \text { weeks" gestation }\end{array}}{27} \times 100=52 \%$

The predictive value of a titre of $1 / 6400$ or higher of MsAb at 32 weeks' gestation is:

predictive value:
$\begin{aligned} & \text { of + test } \\ & \text { at } 32 \text { weeks' gestation who develop ptd }\end{aligned}$

As pointed out by Amino et al. (1982a), Jansson (1986), Fung et al. (1988) and Hayslip et al. (1988a), there are several women with postpartum thyroid dysfunction who do not have elevated MsAb titres (chapter IV). This was also the case in our study: $28 \%$ of women with postpartum thyroid dysfunction did not have elevated titres and almost $50 \%$ of women who had MsAb during gestation did not develop postpartum thyroid dysfunction.

The sensitivity of the presence of MsAb as a marker for postpartum thyroid dysfunction can be calculated as follows:

sensitivity: $\frac{\begin{array}{l}\text { number of women with } \\ \text { MsAb who develop ptd }\end{array}}{\begin{array}{c}\text { MsAb+ women with ptd } \\ + \text { MsAb- women with ptd }\end{array}}=\frac{15}{21} \times 100=71 \%$.

The specificity of MsAb for postpartum thyroid dysfunction is as follows:

specificity: $\frac{\text { number of MsAb- women without ptd }}{\text { total number of women without ptd }}=\frac{249}{272} \times 100=92 \%$.

Therefore, Jansson (1986) claimed that the titre of MsAb during gestation is of greater value for predicting postpartum thyroid dysfunction than the fact that MsAb is detectable in pregnancy. The higher the titre of MsAb early in pregnancy, the more likely the woman is to develop postpartum 
thyroid dysfunction. As shown in table 9.4, these findings could be reproduced in our study, and moreover it could be demonstrated that this is still true at 32 weeks" gestation. It is reasonable to accept that the titre at 32 weeks' gestation is the same as the titre on the first day postpartum. One major implication of these findings could be that women who showed a high MsAb titre detected early after parturition - and not merely the presence of $\mathrm{MsAb}$ - are at increased risk for the occurrence of postpartum thyroid dysfunction and should be followed up during the first postpartum year.

From an epidemiological point of view, it is important to know whether women with microsomal antibodies during gestation have an increased risk for developing postpartum thyroid dysfunction: what is the relative risk for women with MsAb during gestation to develop postpartum thyroid dysfunction? This can be calculated by dividing the incidence of postpartum thyroid dysfunction in women with MsAb at 32 weeks' gestation (Ie) by the incidence of postpartum thyroid dysfunction in women without MsAb at 32 weeks' gestation (Iu), as shown in table 9.8 .

$\mathrm{RR}=\frac{\mathrm{Ie}}{\mathrm{Iu}}=\frac{\mathrm{a} / \mathrm{a}+\mathrm{b}}{\mathrm{c} / \mathrm{c}+\mathrm{d}}=\frac{14 / 14+13}{7 / 7+259}=\frac{0.52}{0.026}=20$

table 9.8 the relative risk of MsAb positive women at 32 weeks' gestation for postpartum thyroid dysfunction

\begin{tabular}{lccl}
\hline & women with ptd & women without ptd & \\
\hline women with MsAb & $\mathrm{a}=14$ & $\mathrm{~b}=13$ & $\mathrm{a}+\mathrm{b}=27$ \\
women without MsAb & $\mathrm{c}=7$ & $\mathrm{~d}=259$ & $\mathrm{c}+\mathrm{d}=266$ \\
& $\mathrm{n}=21$ & $\mathrm{n}=272$ & $\mathrm{~N}=293$ \\
\hline
\end{tabular}

The $95 \%$-confidence interval for an RR of 20 is 10.3 to 38.6 . Therefore, it may be concluded that the presence of MsAb at 32 weeks' gestation is an important risk factor for developing thyroid dysfunction during the postpartum period.

The question of whether postpartum thyroid dysfunction is specifically related to a typical complaint pattern has so far never been investigated in an appropriate way, as explained in part I of this thesis. In this study, the group of women with thyroid dysfunction and the group with hyperthyroidism, in particular, more often complained of lassitude and fatigue. It should be stressed here that many women complain of lassitude and fatigue in the first two months after delivery. Both the health professional and the 
mother accept these complaints as being normal for the postpartum period. Women with thyroid dysfunction, however, who complain of lassitude and fatigue do so in the period after these two months: between 3 and 6 months' postpartum. Amino et al.(1982a), who screened 507 Japanese women once at 3 months' postpartum, also reported a significant difference in frequency of fatigue between women with thyrotoxicosis and normal controls. This was also found for palpitation. Other studies that only screened once or twice did not find any difference. Hayslip et all.(1988a) followed 33 women with microsomal antibodies every 4 to 8 weeks up to 6 months' postpartum. They found a statistically significant difference in the total number of complaints between women with thyroid dysfunction and women without dysfunction. However, it is very difficult in every day practice to standardize the number of complaints for use as an appropriate tool to discriminate between women who suffer from thyroid dysfunction and those who do not.

On the SCL-90 symptom-check list, no difference was found in the scores on the subscales between the thyroid dysfunction group as a whole and normal controls. Nevertheless, women with hypothyroidism did show significantly higher scores on the somatization and depression subscales. The subscale depression will be discussed in chapter $X$. The subscale somatization consists of 14 items covering all kinds of somatic symptoms, such as: "low back pain, headache, dizziness, nausea etc." These findings suggest that, in women who present with all kinds of somatic complaints later on in the postpartum period, it is useful to assess thyroid function. Thyroid enlargement, assessed by palpation, was not found to be related to thyroid dysfunction. The clinical relevance of thyroid palpation as a useful tool for discriminating between normal and abnormal thyroid functioning is questionable. Firstly, although there is international consensus about the classification system which should be used in describing thyroid size (Delange et al., 1986), in most of the studies published on postpartum thyroid dysfunction, the women were investigated by different researchers, implicating interpersonal variation in palpation of the thyroid.

As explained in chapter II, thyroid size in pregnancy is usually increased physiologically to compensate for a relative deficiency in iodine. These theoretical reflections are confirmed by several prospective studies carried out on postpartum thyroid dysfunction (Amino et al.,1982a, Jansson et al., 1984, Fung et al., 1988): no relationship was found between enlargement of the thyroid and occurrence of thyroid dysfunction. Moreover, Hegedius et al. (1983) showed on ultrasonography that, in normal healthy women during their menstrual cycle, thyroid enlargement occurs in up to $20 \%$ without any clinical relevance. Rasmussen et al. (1988) found enlargement of thyroid 
size on ultrasonography during pregnancy and the postpartum period to be unrelated to serum TSH. In a latter study (1990), they concluded that initial thyroid volume or changes during pregnancy and the postpartum period are not useful indicators of the development of postpartum thyroiditis. Although, in our study, thyroid size was estimated by one physician, no relationship with thyroid dysfunction was found.

Finally, it was shown in this study that women with an elevated fT4 and/or fT3 had a significantly higher pulse rate at rest compared to a control group. The clinical relevance of this finding should not be overestimated. To evaluate thyroid function in women solely because they have an elevated pulse rate, does not make sense in every day practice. Only when other signs, such as fatigue and lassitude, are also prominent, should an evaluation of thyroid function be considered. 


\section{Chapter X}

\section{Incidence, prevalence and course of postpartum depression}

\subsection{Incidence and prevalence of postpartum depression}

According to the RDC criteria, the incidence of depression developing during the postpartum period of assessment was $20.8 \%$ (61 women). Twenty women $(6.8 \%)$ met the criteria for major depression, and 41 women $(13.9 \%)$ met the criteria for minor depression. The pointprevalences, the percentages of women depressed at each assessment point (including those women who were already depressed in pregnancy), are shown in fig. 10.1. The highest prevalence rates were found between 2 and 6 months' postpartum.

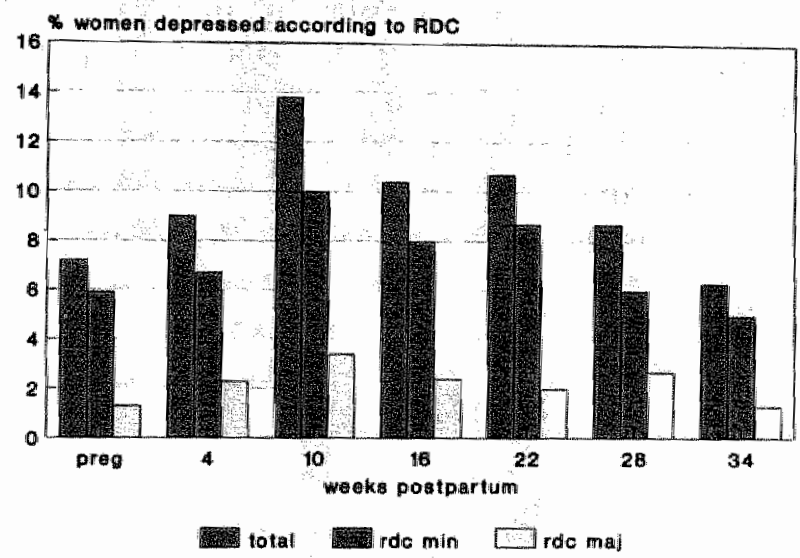

fig. 10.1 pointprevalence of ppd

From fig.10.1, it can be seen that there is a peak in the point-prevalence at 10 weeks' postpartum (14\%). This is commonly reported in the literature. Moreover, it can be seen that the point-prevalence of depression at 34 weeks' postpartum is rather similar to the pointprevalence at 32 weeks' gestation. The mean point-prevalence for the 
postpartum period of screening is $9.7 \%$, which is also in accordance with point-prevalences from most other studies which assessed once or twice. The scores of the BDI, SDS and EPDS compared to the RDC criteria are shown in fig 10.2

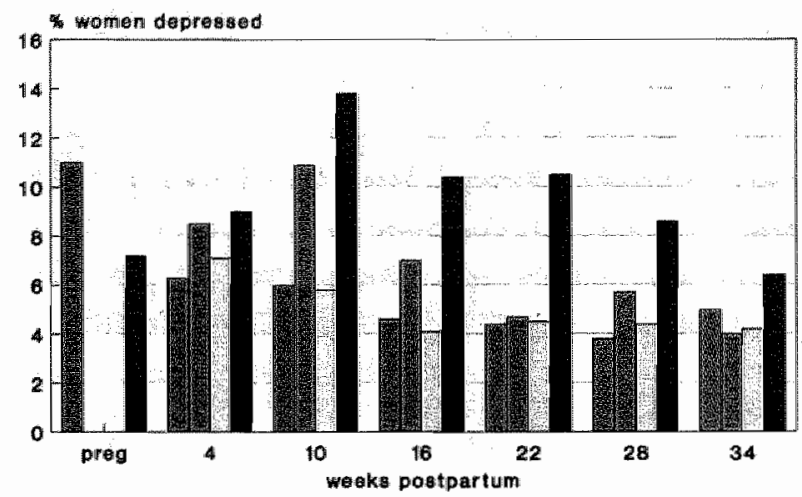

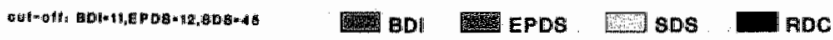

fig. 10.2 BDI-EPDS-SDS scores and RDC

It should be noted that during pregnancy the prevalences of depressed symptoms assessed by the BDI and EPDS (100 women filled in the EPDS at 32 weeks' gestation) were similar, but they were higher than the prevalence of depression according to the RDC. In contrast, during the postpartum period, the point-prevalences of depression according to the RDC are constantly higher than the prevalence rate of depressed symptoms. Moreover, prevalence rates found with the SDS and BDI do not seem to fluctuate in the same way as those for depression, according

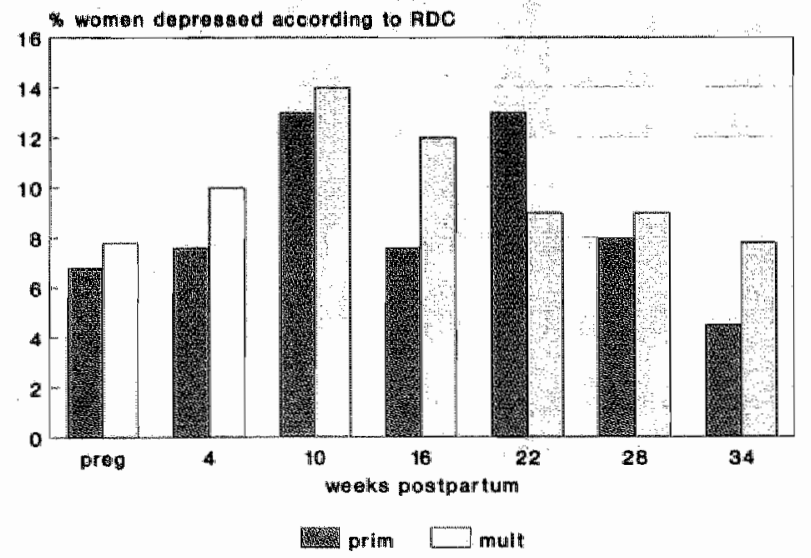

fig. 10.3 depression and parity 
to the RDC and EPDS, with a distinct peak at 10 weeks" postpartum. In pregnancy, 22 women were depressed according to the RDC, 4 of them with major and 18 of them with minor depression. All these women, except one, were also depressed in the postpartum period.

Because there are frequent investigations in the literature as to whether primiparous women have a higher incidence rate for postpartum depression than multiparous women, the differences in the occurrence of postpartum depression between the two groups are shown in fig 10.3.

Multiparous women are usually depressed more often than primiparous women, but the difference was not significant. However, one remarkable finding is the fact that 22 weeks' postpartum is the only time that more primiparous than multiparous women were depressed. No difference was found in the occurrence of depression between women who were breastfeeding and those who were not.

\subsection{The course of postpartum depression}

In fig. 10.4, the severity of depression in terms of its duration at each assessment point is shown.

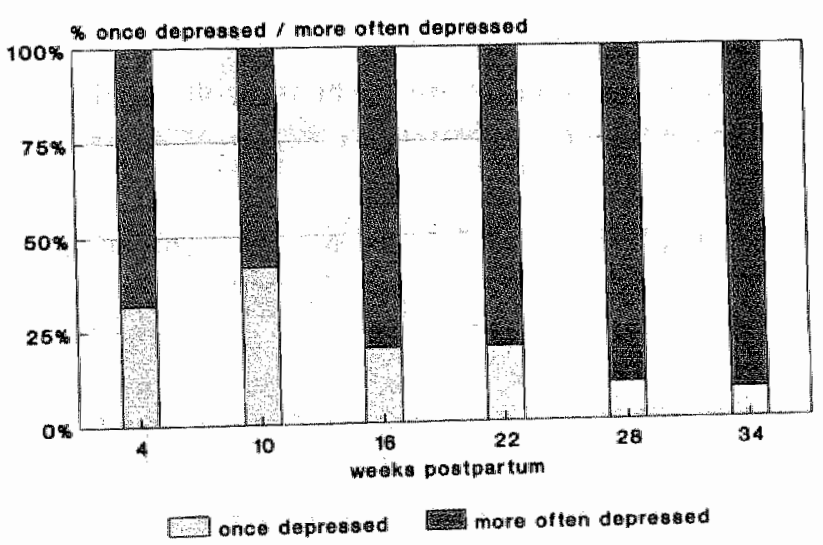

fig. $10.4 \%$ of women who were only once minor depressed (RDC) at each assessment

It can be seen from this histogram that $40 \%$ of the women who were depressed at 10 weeks" postpartum were only depressed once, while at 28 weeks' postpartum only $10 \%$ of the total of depressed women were depressed once. This suggests that a woman who becomes depressed later on in the postpartum period is more likely to be depressed for more than 6 weeks than a woman who becomes depressed at an earlier stage. 
During the whole postpartum period, 40 women were depressed only at one assessment, and 31 of them within 16 weeks' postpartum. This suggests that longer-lasting depressions are predominantly found later on in the postpartum period. Finally, it can be seen from figure 10.4 that, at 10 weeks' postpartum when the highest point-prevalence is found, $40 \%$ of women were no longer depressed at the next assessment, nor were they depressed at the previous assessment.

\subsection{Characteristics of depressed women according to RDC}

\subsubsection{Major depression}

The women with major postpartum depression $(n=24,20$ newly detected women in the postpartum period with major depression, and 4 who had already had major depression during pregnancy) were compared with a group of 24 women matched for age, parity and social class who were not depressed during the period of screening (including pregnancy). There was a significant difference between the two groups regarding the occurrence of blues, pms, breastfeeding, a previous episode of depression in the woman herself, depression in the family, depression in pregnancy, and the subscale dramatic episode of past adversity. These findings are summarized in table 10.1 .

table 10.1: features of 24 postpartum women with major depression compared with 24 matched controls

\begin{tabular}{|c|c|c|c|c|c|}
\hline & major depression & matched controls & chi-square & $\mathrm{p}$ & \\
\hline blues & 17 & 10 & 4.14 & .04 & * \\
\hline pms & 11 & 4 & 4.75 & .03 & * \\
\hline breastfeeding & 20 & 13 & 4.75 & .03 & * \\
\hline prev dep self & 10 & 2 & 7.11 & .008 & * \\
\hline dep family & 9 & 3 & 4.0 & .04 & * \\
\hline dep pregnancy & 10 & 0 & 12.63 & .0004 & * \\
\hline adversity & 16 & 4 & 12.34 & .0004 & * \\
\hline
\end{tabular}

* = statistically significant, $\mathrm{df}=1$

dep pregnancy: min and maj depression in pregnancy according to RDC

In the group who had major depression, only four women were depressed at one assessment during the postpartum period and they were not depressed at 32 weeks' gestation. The other 20 women were found to be depressed three or more times during the postpartum period and 10 of these women were also depressed at 32 weeks' gestation. 
Features which were also investigated and were shown not to be related to postpartum depression include obstetrical complications, oral contraceptives, and place of giving birth.

\subsubsection{Minor depression}

Of the women with minor depression $(n=58), 41$ women became depressed in the postpartum period and 17 were already depressed at 32 weeks" gestation. When this group was compared with a group of 58 women matched for age, parity and social class, who were not depressed at 32 weeks' gestation or in the postpartum period, the characteristics mentioned earlier were also investigated. The results are summarized in table 10.2 .

table 10.2: features of 58 postpartum women with minor depression compared to 58 matched controls

\begin{tabular}{lccccc}
\hline & minor depression & matched & controls & chi-square & p \\
\hline blues & 30 & 23 & 1.70 & 19 & \\
pms & 17 & 11 & 1.69 & .19 & \\
breastfeeding & 50 & 46 & .96 & .33 & \\
prev dep self & 2 & 5 & .61 & .43 & \\
dep family & 18 & 8 & 4.95 & .026 & $*$ \\
dep pregnancy & 16 & 1 & 15.5 & .0001 & $*$ \\
adversity & 30 & 17 & 6.04 & .014 & $*$ \\
\hline
\end{tabular}

* = statistically significant, $\mathrm{df}=1$

dep pregnancy: min and maj depression in pregnancy according to RDC

As a whole, women with minor depression did not rate blues more often or complain of pms more often than the non-depressed control group. Neither was 'breastfeeding' nor 'a previous episode of being depressed oneself related to depression. It is obvious that the variable "depression at 32 weeks" gestation' occurred significantly more often in the depressed group. In the women who were only depressed once during the postpartum period, no differences could be found compared with the nondepressed controls. However, among the women who had minor depression more than once during the postpartum period, the relationship between some factors and postpartum depression were significantly different from non-depressed controls. These findings are summarized in table 10.3. 
table 10.3 characteristics of women with minor depression according to the frequency of being depressed compared with matched controls

\begin{tabular}{|c|c|c|c|c|}
\hline & $\begin{array}{c}\text { depressed only } \\
\text { once } \\
\mathrm{n}=40\end{array}$ & $\begin{array}{l}\text { matched controls } \\
n=40\end{array}$ & chi-square & $\mathrm{p}$ \\
\hline $\begin{array}{l}\text { blues } \\
\text { pms } \\
\text { breastfeeding } \\
\text { prev dep self } \\
\text { dep family } \\
\text { dep pregnancy } \\
\text { adversity }\end{array}$ & $\begin{array}{r}20 \\
8 \\
33 \\
1 \\
9 \\
4 \\
17\end{array}$ & $\begin{array}{r}17 \\
4 \\
32 \\
2 \\
5 \\
0 \\
11\end{array}$ & $\begin{array}{r}.45 \\
1.57 \\
.08 \\
.00 \\
1.38 \\
2.37 \\
1.98\end{array}$ & $\begin{array}{r}.49 \\
.20 \\
.76 \\
1.00 \\
.23 \\
.12 \\
.16\end{array}$ \\
\hline adversity & $\begin{array}{l}\text { depressed more } \\
\text { than once } \\
n=18\end{array}$ & $\begin{array}{l}\text { matched controls } \\
n=18\end{array}$ & chi-square & $\mathrm{p}$ \\
\hline $\begin{array}{l}\text { blues } \\
\text { pms } \\
\text { breastfeeding } \\
\text { prev dep self } \\
\text { dep family } \\
\text { dep pregnancy } \\
\text { adversity }\end{array}$ & $\begin{array}{r}9 \\
8 \\
15 \\
1 \\
8 \\
5 \\
13\end{array}$ & $\begin{array}{r}5 \\
5 \\
13 \\
1 \\
2 \\
0 \\
6\end{array}$ & $\begin{array}{r}1.87 \\
1.08 \\
.16 \\
.00 \\
4.98 \\
3.72 \\
5.46\end{array}$ & $\begin{array}{l}.17 \\
.29 \\
.69 \\
1.00 \\
0.025 * \\
.05 * \\
.02 *\end{array}$ \\
\hline
\end{tabular}

* = statistically significant, $\mathrm{df}=1$

dep pregnancy: minor and major depression in pregnancy

\subsection{Discussion}

The incidence of postpartum depression according to the RDC was $20.8 \%$ ( 61 women), the point-prevalence varied between 8 and $14 \%$. The mean point-prevalence of postpartum depression was $9.7 \%$, which is in accordance with most studies published so far in which depression was assessed only once or twice. Studies which used the same criteria for depression (Kumar and Robson 1984, O'Hara et al.1984, 1990) found the same prevalence rate at 3 months' postpartum. In our study, there was a peak in the point-prevalence of depression at 10 weeks" postpartum, this was comfirmed by most studies which screened several times. Nott (1982), however, reported the highest prevalence rate of postpartum depression at 9 months' postpartum. In our study, the lowest prevalence rate was reported at 8 months" postpartum, this was even lower than the prevalence of depression at 32 weeks' gestation. If we consider the changing of point-prevalences over time, we can conclude that, at 10 weeks" postpartum, the prevalence is much higher than at any other assessment time during the postpartum period. The point-prevalence at 
this particular assessment (10 weeks' postpartum) was compared with the point-prevalences at the 6 other assessments by the chi-square test, and the p-values are shown in table 10.4 .

table 10.4 difference in prevalence rates of depression between assessment at 10 weeks' postpartum and other assessments $(n=293)$

\begin{tabular}{lccc}
$\begin{array}{l}\text { assessment } \\
\text { n of dep on RDC }\end{array}$ & $\begin{array}{l}\text { 10 weeks' ppartum } \\
\text { n of dep on RDC }\end{array}$ & chi-square & p \\
\hline 32 wk ges $n=21$ & $n=41$ & 7.21 & $.007^{*}$ \\
4 wk pp $n=27$ & $n=41$ & 3.26 & .07 \\
16 wk pp $n=31$ & $n=41$ & 1.58 & .20 \\
22 wk pp $n=31$ & $n=41$ & 1.58 & .20 \\
28 wk pp $n=26$ & $n=41$ & 3.79 & .05 \\
34 wk pp $n=19$ & $n=41$ & 8.99 & $.003^{*}$ \\
\hline
\end{tabular}

* significantly different, $\mathrm{df}=1$.

It can be seen from table 10.4 that the peak in point-prevalence at 10 weeks' postpartum differs significantly from the point-prevalences at 32 weeks' gestation and 34 weeks' postpartum and is very close to a significant difference at 4 and 28 weeks' postpartum. This might suggest that there is indeed a period in the postpartum - between 8 and 20 weeks' postpartum - when more women are depressed than at other times during the postpartum period, such as during the first 8 weeks after delivery and from 20 weeks' postpartum. Another striking finding is the fact that, during the first 8 weeks after parturition, women are not found to be more frequently depressed than during gestation or six to eight months' postpartum.

As far as the course of depression in the postpartum period is concerned, it was found that in $78 \%$ of the women who were depressed only once, this occurred during the first 16 weeks after delivery. The peak reported at 10 weeks' postpartum was composed of $40 \%$ of women who had had minor depression for a short period of time. Later in the postpartum period, most of the women who were found depressed according to the RDC were depressed for a longer period of time. This finding, taken together with the significant difference between the prevalence rate at 10 weeks" postpartum and assessments early and later on in the postpartum period is strongly in favour of the conclusion that women are indeed more prone to depression during a specific period of the postpartum period, but that this proneness mainly refers to the occurrence of minor depression.

In the group of women with major depression according to the RDC ( $\mathrm{n}=$ 24 ), it was found that the variables 'blues', "pms", 'a previous episode of 
depression in the woman herself or in the woman's family', 'past adversity', "breastfeeding' and 'depression in pregnancy' distinguished them from non-depressed controls. The variables 'resigning from work outside the home' and 'obstetrical complications' were not significantly related to postpartum depression. As far as adversity was concerned, there were 106 women who had had a dramatic experience before the age of 16 years. The most commonly rated experiences are summarized in table 10.5 .

table 10.5 dramatic episodes rated in 106 women

\begin{tabular}{lc}
\hline experience & $\mathrm{n}$ \\
\hline death of family member & 30 \\
severe illness in family & 12 \\
poor parental relationship & 12 \\
divorce of parents & 9 \\
move & 8 \\
severe accident of parents & 6 \\
miscellaneous & 29 \\
\hline
\end{tabular}

It was interesting to note that, in the group with major depression as a whole, in the group with minor depression as a whole, in the women who had minor depression more than once in the postpartum period, and in the group of women who were depressed at each assessment, adversity was reported significantly more often than in the matched non-depressed control group. Women who were depressed only once did not report adversity more often. However, as can also be put forward for 'depression in the family' and for 'a previous history of depression in the woman herself', these variables are not likely to be specifically related to postpartum depression but rather to depression in general.

One unexpected finding was the significant relationship between breastfeeding and depression in the group of women with major depression: these women breastfed significantly more often than the women in the control group. As summarized by Mattox and Bernstein (1988), from endocrinological studies it is known that patients with hyperprolactinemia show increased levels of anxiety, decreased libido and more depression. Alder and Cox (1983) reported that women who totally breastfed their babies for at least 12 weeks had a higher incidence of postpartum depression. However, Harris et al. (1989) found that salivary prolactin levels were rather low - although within normal physiological limits - in depressed breastfeeding women. Alder et al. (1986), in a later study, and O'Hara et al. (1990b) did not find any relationship between prolactin levels and postpartum depression. On a 
bivariate analysis level, we cannot find an explanation so far for the significant relationship between major depression and breastfeeding. As summarized by George and Sandler (1988), prolactin appears to have a regulatory effect on dopamine release. Relative dopamine deficiency has been implicated in major depressive disease. One challenging hypothesis - although simplistic - might be that high prolactin levels would cause low dopamine secretion. However, in our study, there was no difference in the occurrence of depression between the women who were breastfeeding and women who were not.

In the group with minor depression. only a "previous episode of depression in the family', 'past adversity' and 'depression in pregnancy', occurred significantly more often than in normal controls.

Parity was not related to postpartum depression. In this study, as can be seen in fig. 10.3, more multiparous women were depressed than primiparous women, except for 22 weeks' postpartum when primiparous women showed a higher prevalence rate. However, the differences were not statistically significant. Bridge et al. (1985) also screened several times in the postpartum period ( 6 weeks, 6,9 and 12 months). They found no difference between primiparous and multiparous women, except for the assessment at 6 months' postpartum when a significant relationship was found between high depression scores (SDS) and primiparity. It is worth noting that this assessment point is consistent with the only assessment point ( 22 weeks" postpartum) in our study when more primiparous than multiparous women were found to be depressed. Therefore we looked once again at the women who were depressed at each assessment according to the RDC and divided the group into major and minor depression. In the 'major" group, at all assessments, multiparous women were more often represented than primiparous but because of the small numbers it is not possible to come to definite conclusions. However, in the minor depression group, the same results as shown in fig.10.4 were found, and they are summarized in table 10.6.

table 10.6 minor depression in 133 primipara compared with 133 matched multipara

\begin{tabular}{cccc}
\hline assessment & multipara & primipara \\
\hline 4 & weeks & 17 & 8 \\
10 & weeks & 16 & 13 \\
16 & weeks & 15 & 7 \\
22 & weeks & 8 & 14 \\
28 & weeks & 11 & 7 \\
34 & weeks & 14 & 5 \\
\hline
\end{tabular}


Primiparous women showed a tendency to be depressed less frequently than multiparous women, except at 22 weeks' postpartum. There is no obvious explanation for this finding so far. 


\section{Chapter XI}

The relationship between postpartum depression and postpartum thyroid dysfunction

\subsection{Incidence and prevalence of postpartum depression and thyroid dysfunction}

As discussed in the previous chapters of this thesis, the incidence of postpartum thyroid dysfunction was $7.2 \%$ and of postpartum depression $20.8 \%$. In fig 11.1 the percentage of total incidence of thyroid dysfunction and postpartum depression at each assessment is shown.

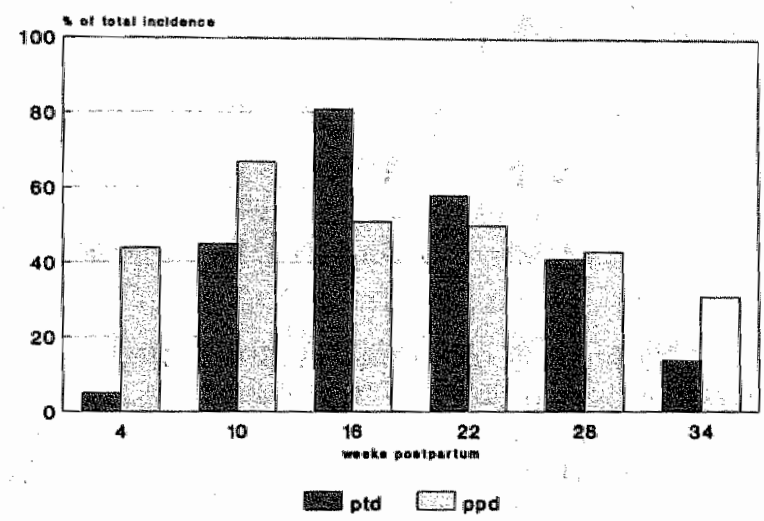

fig 11.1 occurrence of postpartum thyroid

This histogram shows that postpartum thyroid dysfunction and postpartum depression usually occurred between 2 and 6 months' postpartum.

\subsection{Nature of depression in women with thyroid dysfunction}

In the group with thyroid dysfunction $(n=21)$, the mood state at the assessment point when thyroid dysfunction was most seriously disturbed was investigated. Eight women with thyroid dysfunction were depressed. Of these, 4 women had major depression ( 3 with hypothyroidism and 1 with hyperthyroidism) and 4 had minor depression ( 3 with hyperthyroidism and 1 with hypothyroidism). These findings are summarized in table 11.1. 
table 11.1. women with thyroid dysfunction and depression

\begin{tabular}{cclll}
\hline depression (RDC) & \multicolumn{3}{c}{ nature of thyroid dysfunction } \\
\hline major depression & $\mathrm{n}=4$ & $\begin{array}{l}\text { hypothyroidism } \\
\text { hyperthyroidism }\end{array}$ & $\mathrm{n}=3$ \\
& & $\mathrm{n}=1$ \\
minor depression & $\mathrm{n}=4$ & $\begin{array}{l}\text { hyperthyroidism } \\
\text { hypothyroidism }\end{array}$ & $\mathrm{n}=3$ \\
& & $\mathrm{n}=1$ \\
\hline
\end{tabular}

\subsection{Depression in women with thyroid dysfunction versus euthyroid women.}

In table 11.2, the incidence of depression in women with thyroid dysfunction, is compared with the incidence of depression in euthyroid women. From this table it can be calculated whether women with postpartum thyroid dysfunction have an increased risk for developing postpartum depression. As shown in chapter IX the relative risk (RR) for women with postpartum thyroid dysfunction to develop postpartum depression is:

$$
\mathrm{RR}=\frac{\mathrm{I}_{\mathrm{e}}}{\mathrm{I}_{\mathrm{u}}}=\frac{\mathrm{a} / \mathrm{a}+\mathrm{b}}{\mathrm{c} / \mathrm{c}+\mathrm{d}}=\frac{8 / 8+13}{53 / 53+219}=\frac{0.38}{0.19}=2 .
$$

table 11.2 the relative risk of women with postpartum thyroid dysfunction to develop depression.

\begin{tabular}{lccc}
\hline & women with ppd & \multicolumn{2}{c}{ women without ppd } \\
\hline women with ptd & $\mathrm{a}=8$ & $\mathrm{~b}=13$ & $\mathrm{a}+\mathrm{b}=21$ \\
women without ptd & $\mathrm{c}=53$ & $\mathrm{~d}=219$ & $\mathrm{c}+\mathrm{d}=272$ \\
& $\mathrm{n}=61$ & $\mathrm{n}=232$ & $\mathrm{~N}=293$ \\
\hline
\end{tabular}

The $95 \%$ confidence interval for the relative risk is 1.1 to 3.6 .

This finding suggests that women with postpartum thyroid dysfunction actually have a small increased risk to develop postpartum depression.

\subsection{Discussion}

As far as we know, this is the first study that investigates the relationship between postpartum thyroid dysfunction and postpartum depression in a general population. 
In the studies of Hamilton (1977) and George and Wilson (1983), assessment was carried out in the first weeks after parturition and the studies failed to demonstrate a relationship between mood changes and thyroid parameters. Harris et al. (1989) showed an association between depressed mood and the presence of microsomal antibodies which are often found in postpartum thyroid dysfunction, but failed to demonstrate a relationship between depression and thyroid dysfunction at 6 to 8 weeks' postpartum. However, in their study thyroid dysfunction was assessed in a selected group of women, half of whom were selected because of their elevated microsomal antibodies titres. Moreover, they used a definition of thyroid dysfunction based on normal values of thyroid function in the women in their sample who did not have microsomal antibodies, which makes it difficult to compare their results with other studies (Fung et al., 1988). Hayslip et al. (1988a) screened 51 microsomal antibody-positive women up to 6 months' postpartum. They found a substantial increase in psychological symptoms - impaired concentration, impaired memory - in women who developed postpartum thyroid dysfunction compared to euthyroid women. Moreover, they reported that the women with hypothyroidism more often complained of depression. However, it is generally accepted that asking a person whether he or she is suffering from depression, as was the case in Hayslip's study, is not the best way to make a diagnosis of depression. Moreover the findings were not representative of an open population: only microsomal antibody-positive women were screened.

Very recently, some preliminary data published by Othman et al. (1991) showed a significant difference in the occurrence of depressive symptomatology in women with microsomal antibodies (whether they subsequently developed postpartum thyroiditis or not) as compared to $\mathrm{MsAb}$ negative matched controls at 8 weeks' postpartum. In their study, a large sample of 1500 antenatal women was screened for thyroid antibodies and MsAb positive women (95) were matched with MsAb negative women, who were subsequently followed four times during the postpartum period. However, in their study, postpartum thyroiditis was defined by the presence of microsomal antibodies, abnormal fT3, fT4, or by a TSH of $>10 \mathrm{mU} / \mathrm{h}$. It is very doubtful whether these criteria reflect an accurate diagnosis of postpartum thyroiditis. Moreover, screening was not carried out in a unselected population and, in a substantial number of cases, both the researcher and the women knew the results of biochemical tests, suggesting that bias might have occurred.

In our study, we found that women with postpartum thyroid dysfunction only had a small increased risk of developing postpartum depression, 
suggesting that other factors also contribute to the occurrence of depression during the postpartum period. Therefore, it may be concluded that this study does not support the hypothesis that thyroid dysfunction is of major importance in the etiology of depression during the postpartum period. 


\section{Chapter XII}

\section{The correlations between postpartum depression/depressive symptoms and other variables}

In the first part of this chapter, the correlations between several variables and postpartum depression/depressive symptoms will be investigated. However, it is beyond the scope of this thesis to present all data from all assessments. Because most of the research reported in the literature concerns studies that were carried out between 2 and 3 months' postpartum, the data from the second assessment after parturition - 10 weeks' postpartum - will be shown in more detail. Results from other assessments will be discussed thereafter, as far as they proved to be relevant to the reported data on the second assessment postpartum. In the second part of this chapter, the main conclusions to be drawn from these data will be discussed.

Most of the data to be presented are analyzed by means of correlations. In those cases where one dichotomic variable is correlated with a variable expressed as a score, point-biserial correlations have been used, in all other cases two-tailed Pearson's correlations were used. When two dichotomic variables are correlated, the correlation is expressed as a phicoefficient.

For the purpose of clarity, the tables contain only the significant correlations $(p<0.01)$. The correlations which showed a significance of $\mathrm{D}<0.001$ are followed by the symbol:*.

When two groups with a different number of women were compared, the significance of the differences between correlations was calculated using Fisher's $z_{\mathrm{T}}$ transformation technique, as described by Ferguson (1959).

\subsection{Correlations between postpartum depression/depressive symptoms and other variables}

In fig 12.1 the model of the study is shown. As explained in chapter VI, these variables were thought to correlate with depression/ depressive symptoms. 


\section{b. Coping behaviour (fig 12.1.2)}

In table 12.2 the scores of correlations between the UCL scales and the depressive symptoms/depression are shown.

table 12.2 coefficients of correlation between UCL and depression/depressive symptoms $(\mathrm{n}=293)$

\begin{tabular}{lccccccc}
\hline & activ & palli & avoid & supp & depri & emoti & reas \\
\hline BDI & - & .17 & .14 & - & $.27^{*}$ & - & - \\
SDS & -.14 & - & .14 & - & $.30^{*}$ & - & - \\
EPDS & - & .17 & - & - & $.26^{*}$ & - & - \\
VROPSOM & -.17 & .15 & - & - & $.23^{*}$ & - & - \\
SCLdep & - & $.20^{*}$ & $.19^{*}$ & - & $.27^{*}$ & - & - \\
SCLsom & - & $.21^{*}$ & - & - & $.22^{*}$ & - & - \\
MIN & - & .15 & - & - & $.26^{*}$ & - & - \\
MAJ & - & - & - & - & - & - & - \\
\hline
\end{tabular}

SCLdep+SCLsom: subscales of the SCL-90

MIN/MAJ: minor/major depression

From this table, it can be concluded that only correlations between certain subscales of the UCL and depressive symptoms and depression are significant: depressive reaction, palliative reaction, active reaction and avoiding behaviour. With the exception of the subscale "depressive reaction', these correlations are rather low or even absent. However, when they are significant, they are significant in the expected direction: women with high scores on the subscale "active reaction" have low scores on the depression scales, and women with low scores have relatively high depression scores. Women with high scores on the subscales 'avoiding behaviour' and 'palliative reaction' have more depressive symptoms. In general, we could observe a correlation between some scores on a few coping-subscales and the severity of depressive symptoms rather than a relationship with depression.

No correlations were found between the three items concerning coping behaviour in conflicts with the partner and depressive symptoms/ depression. Moreover, there was no correlation between these scores, taken together, and any of the subscales of the UCL.

If we look at the correlations of the subscales of the UCL and the severity of depressive symptoms and depression during the whole postpartum period - again the BDI is taken as our example - it can be seen (fig 12.3) that the correlation at 10 weeks' postpartum remains rather stable throughout the whole postpartum period, except at 28 weeks' postpartum. 


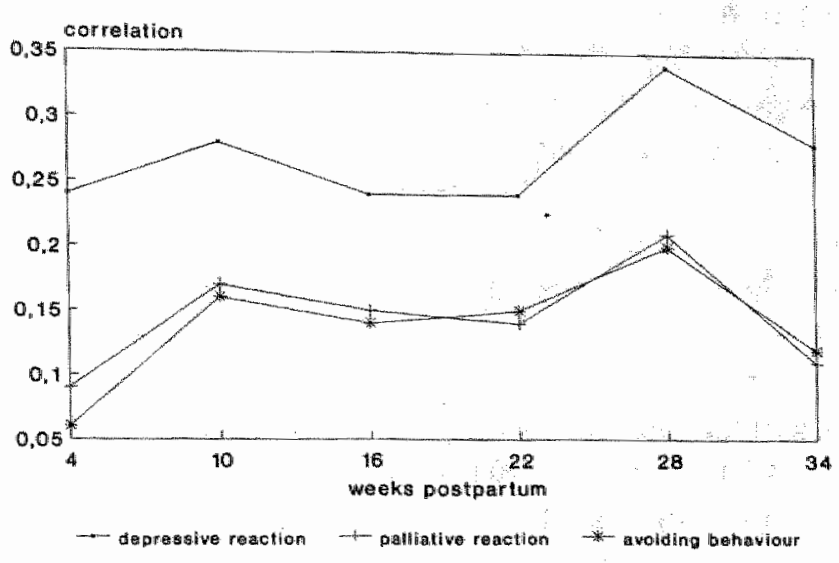

fig 12.3 correlations between BDI and subscales UCL

As can be seen from fig 12.3, the correlation between depression and the subscales palliative reaction and avoiding behaviour show exactly the same pattern. The correlations all increase substantially at 28 weeks' postpartum and decline thereafter.

The other subscales of the UCL and the short coping list, with three items concerning coping in spouse relationship, showed no significant correlation at any time during the postpartum period.

\subsubsection{Contributing factors}

a. Specific for the postpartum period (fig.12.1.4)

The infant temperament

In table 12.3, the correlations between infant temperament and occurrence of depressive symptoms and depression are shown.

table 12.3 coefficients of correlation between child temperament and depression/depressive symptoms $(n=293)$

\begin{tabular}{lll} 
& trouble & care \\
\hline BDI & $.32^{*}$ & $.23^{*}$ \\
SDS & $.35^{*}$ & $.22^{*}$ \\
EDPS & $.37^{*}$ & $.25^{*}$ \\
VROPSOM & $.38^{*}$ & $.24^{*}$ \\
SCLdep & $.31^{*}$ & 15 \\
SCLsom & .19 & - \\
MIN & $.31^{*}$ & .16 \\
MAJ & .18 & - \\
\hline
\end{tabular}

MIN/MAJ: minor/major depression

SCLdep+SCLsom: subscales of the SCL-90 
In chapter VIII it was explained that factor analysis in the Childcare Stress Inventory (CSI, which measures child temperament) reveals two subscales: one subscale includes items on the way the child is perceived as troublesome by the mother (trouble) and the other includes items on the actual care that is given to the child (care). The higher the score on the trouble-subscale, the more troublesome the child is, as perceived by the mother. The higher the score on the care-subscale, the more the actual care that has to be given to the child, according to the mother.

A significant correlation between these variables and depressive symptoms and depression was found in the expected direction. It can be seen that the subscale 'trouble' correlates more highly than the subscale 'care' (without becoming significant, however) and that the correlation with major depression is low, respectively; absent.

In fig 12.4, the way in which correlations between the BDI and child temperament fluctuate during the whole postpartum period are presented.

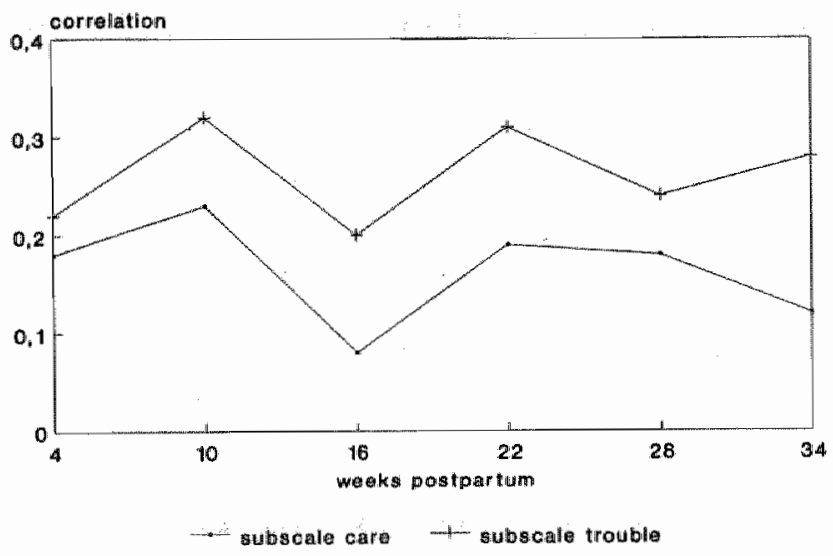

fig 12.4 correlations between BDI and subscales child temperament

A pattern, which is comparable to social support, can be identified: a high correlation found at 10 weeks' postpartum followed by a decline later in the postpartum period. It should be noted that, at 16 weeks" postpartum, there is no longer a significant correlation between the subscale 'care' and the BDI score.

Transition

We hypothesized that two aspects may be especially important as far as transition is concerned. Firstly, primiparity, which means that the woman becomes a mother for the first time and that the impact of transition is 
supposed to be more forcible than in multiparity, A second important feature of transition may be "resigning from working outside the home". However, no significant correlation was found between parity and depressive symptoms and depression, nor between resigning from or continuing to work outside the home and depressive symptoms at any assessment in the postpartum period.

The relationship between thyroid dysfunction and depression was discussed in detail in chapter XI. No correlations were found between depression/depressive symptoms and thyroid dysfunction.

\section{b. General contributing factors to depression (fig.12.1.3)}

Demographic features such as age, parity, social class or education, were not correlated with depressive symptoms or depression. Stressful events were significantly correlated with depressive symptoms or depression, as shown in table 12.4 .

table 12.4 coefficients of correlation between stressful events and depressive symptoms/depression $(n=293)$

\begin{tabular}{lccc} 
& event(tot) & unpleasant & pleasant \\
\hline BDI & - & $.24^{*}$ &. \\
SDS & - & $.22^{*}$ & - \\
EDPS & - & $.24^{*}$ & - \\
VROPSOM & - & $.21^{*}$ & - \\
SCLdep & - & $.21^{*}$ & - \\
SCLsom & - & $.18^{*}$ & - \\
MIN & - & $.23^{*}$ & - \\
MAJ & -15 & .15 & \\
\hline
\end{tabular}

SCLdep/SCLsom: subscales of SCL-90

MIN/MAJ: minor/major depression

It can be seen from this table that only unpleasant events are correlated with depressive symptoms and depression and that pleasant events showed no correlation with depression and depressive symptoms.

When we looked at the correlations during gestation and the postpartum period, it was found that all the scales correlated significantly (table 12.5). 
table 12.5 coefficients of correlation between unpleasant events and depression/depressive symptoms in pregnancy and in the postpartum period $(n=293)$

\begin{tabular}{llllllll}
\hline & preg & pp1 & pp2 & pp3 & pp4 & pp5 & pp6 \\
\hline BDI & $.20^{*}$ & $.24^{*}$ & $.24^{*}$ & $.25^{*}$ & $.36^{*}$ & $.29^{*}$ & $.26^{*}$ \\
SDS & n.u. & $.22^{*}$ & $.22^{*}$ & $.20^{*}$ & $.27^{*}$ & $.31^{*}$ & $.29^{*}$ \\
EDPS & n.u. & $.19^{*}$ & $.24^{*}$ & $.28^{*}$ & $.35^{*}$ & $.33^{*}$ & $.23^{*}$ \\
VROPSOM & $.23^{*}$ & $.23^{*}$ & $.20^{*}$ & $.26^{*}$ & $.30^{*}$ & $.26^{*}$ & $.24^{*}$ \\
SCLdep & $.22^{*}$ & $.30^{*}$ & $.21^{*}$ & $.25^{*}$ & $.27^{*}$ & $.24^{*}$ & $.25^{*}$ \\
SCLsom & - & $.19^{*}$ & $.18^{*}$ & $.20^{*}$ & $.23^{*}$ & $.19^{*}$ & - \\
MIN & .14 & $.20^{*}$ & $.23^{*}$ & $.28^{*}$ & $.28^{*}$ & $.28^{*}$ & $.21^{*}$ \\
MAJ & .15 & .14 & .15 & $.21^{*}$ & $.19^{*}$ & $.21^{*}$ & - \\
\hline
\end{tabular}

$\mathrm{nu} .=$ not used in pregnancy

SCLdep/SCLsom: subscales of SCL-90

MIN/MAJ: minor/major depression

\subsubsection{Predisposition}

a. Specific predisposing factors for postpartum depression (fig 12.1.6)

Depression in pregnancy. Table 12.6 shows the correlations between depressive symptoms and depression in pregnancy - at 32 weeks' gestation - and depressive symptoms and depression at 10 weeks' postpartum.

table 12.6 coefficients of correlation between mood state in pregnancy (p) and postpartum depression $(n=293)$

\begin{tabular}{lccccc}
\hline & BDIp & SCLdepp & SCLsomp & RDCMINp & RDCMAp \\
\hline BDI & $.55^{*}$ & $.50^{*}$ & $.32^{*}$ & $.33^{*}$ & $.33^{*}$ \\
SDS & $.40^{*}$ & $.42^{*}$ & $.29^{*}$ & $.23^{*}$ & .14 \\
EDPS & $.33^{*}$ & $.34^{*}$ & $.20^{*}$ & $.23^{*}$ & .14 \\
VROPSOM & $.36^{*}$ & $.37^{*}$ & $.26^{*}$ & $.22^{*}$ & $.20^{*}$ \\
SCLdep & $.51^{*}$ & $.56^{*}$ & $.30^{*}$ & $.25^{*}$ & $.34^{*}$ \\
SCLSOm & $.42^{*}$ & $.45^{*}$ & $.37^{*}$ & - &. \\
MIN & $.28^{*}$ & $.28^{*}$ & $.18^{*}$ & $.29^{*}$ & $.20^{*}$ \\
MAJ & $.29^{*}$ & $.28^{*}$ & $.18^{*}$ & $.35^{*}$ & $.20^{*}$ \\
\hline
\end{tabular}

SCLdep/SCLsom: subscales of SCL-90

MIN/MAJ: minot/major depression

SCLdep/SCLsom: subscales of SCL-90

Almost all correlations are highly significant. Moreover, all correlations remained high during the whole postpartum period with little variance. Premenstrual syndrome (pms). The correlations between pms (before pregnancy) and depressive symptoms at 10 weeks' postpartum were only 
significant for SDS (.17), EDPS (.19 p<.001) and SCLdep (.15). In table 12.7, an overview of the correlations between pms and depressive symptoms during the whole postpartum period is given.

table 12.7 coefficients of correlation between pms and depressive symptoms at different assessment points during postpartum $(n=293)$

\begin{tabular}{lclllll} 
& $\mathrm{pp} 1$ & $\mathrm{pp} 2$ & $\mathrm{pp3}$ & $\mathrm{pp4}$ & $\mathrm{pp5}$ & $\mathrm{pp6}$ \\
BDI & - & - & .18 & .18 & .18 & $.19^{*}$ \\
SDS & .16 & .17 & $.23^{*}$ & $.26^{*}$ & $.29^{*}$ & $.22^{*}$ \\
EPDS & .15 & $.20^{*}$ & $.34^{*}$ & $.32^{*}$ & $.30^{*}$ & $.27^{*}$ \\
VROPSOM & - & - & $.19^{*}$ & .18 & .16 &. \\
SCLdep & - & .15 & $.25^{*}$ & $.22^{*}$ & $.27^{*}$ & $.21^{*}$ \\
SCLSOm & - & - & $.19^{*}$ & .16 & .17 & $.19^{*}$ \\
MIN & - & - & $.19 \#$ & $.20 \#$ & $.26 \#$ & $.18 \#$ \\
MAJ & - & - & $.18 \#$ & $.17 \#$ & - & $.16^{*}$ \\
\hline
\end{tabular}

MIN/MAJ: major/minor depression

SCLdep/SCLsom: subscales SCL-90

\#= phi-coefficient

It should be noted that, at the time the women resumed menstruation, the correlations between pms and depressive symptoms became significant. Parity and obstetrical complications. No significant correlations were found between parity and depressive symptoms and depression postpartum or between obstetrical complications and postpartum depression. Blues. The correlations between blues and depressive symptoms at 10 weeks" postpartum are shown in table 12.8 .

table 12.8: coefficients of correlation between

blues and depressive symptoms $(n=293)$

\begin{tabular}{lc} 
& blues \\
\hline BDI & .17 \\
SDS & .18 \\
EDPS & .19 \\
VROPS & .19 \\
SCLdep & .16 \\
SCLsom & - \\
MTN & $.16 \%$ \\
MAJ & - \\
\hline
\end{tabular}

MIN/MAJ: minor/major depression

\#: phi-coefficient

SCLdep/SCLsom: subscales SCL-90 
This table shows that blues - occurring within the first week postpartum correlate significantly with the severity of depressive symptoms at 3 to 4 weeks' postpartum. As shown in table 12.9, the correlations between 'blues' and depressive symptoms decrease in magnitude and degree of significance over time.

table 12.9: coefficients of correlation between blues and depressive symptoms at 4,10 and 16 weeks' postpartum $(n=293)$

\begin{tabular}{lccc} 
& 4 weeks & 10 weeks & 16 weeks \\
\hline BDI & $.25^{*}$ & .17 & - \\
SDS & $.25^{*}$ & .18 & - \\
EDPS & $.29^{*}$ & .19 & .17 \\
VROPS & .16 & .19 & .15 \\
DDEP & .20 & .16 & - \\
DSOM & $-.17 *$ & $-16 \#$ & - \\
MIN & - & $.16 \#$ & - \\
MAJ & & - & - \\
\hline
\end{tabular}

MIN/MAJ: minor/major depression

\#: phi-coefficient

SCLdep/SCLsom: subscales SCL-90

No correlations were found at 22,28 or 34 weeks' postpartum. From these data, it can be seen that blues correlated significantly with depressive symptoms shortly after parturition. Moreover, this significance disappeared at 16 weeks' postpartum and no correlation was found thereafter.

\section{b. General predisposing factors (fig. 12.1.5)}

Past adversity. As explained in part II of this thesis, past adversity may be operationalized from dramatic episodes (DRAMA) in the past (before 16 years of age) and relationship (PML) with the parents (before 16 years of age). The correlations with depressive symptoms and depression in the postpartum period are shown in table 12.10

table 12.10 coefficients of correlation between past adversity and depressive symptoms and depression $(n=293)$

\begin{tabular}{lcl}
\hline & DRAMA & PML \\
BDI & $.24^{*}$ & $-.29^{*}$ \\
SDS & $.26^{*}$ & $-.26^{*}$ \\
EDPS & .14 & -.15 \\
VROP & $19^{*}$ & $-.20^{*}$ \\
SCLdep & 18 & $-.29^{*}$ \\
SCLsom & .17 & -.18 \\
MIN & $.23 \#$ & - \\
MAJ & $.20 \#$ & - \\
\hline
\end{tabular}

SCLdep/SCLsom: subscales SCL-90 DRAMA and PML: subscales past adversity \#: phi-coefficient 
It can be seen that the correlations between previous dramatic episodes and postpartum depressive symptoms are significant. The correlations between the woman's relationship with her parents (PML scale) and postpartum depressive symptoms, are also significant. During the postpartum period, these correlations remained stable and significant.

Previous episode of depression in the parents (DEPPAR) and a previous episode of depression in the woman herself (DEPSELF) - both rated as present or absent - showed a strong correlation with depressive symptoms in the postpartum period (table 12.11).

table 12.11 coefficients of correlation between past history of depression of the parents and the woman herself and postpartum depressive symptoms $(n=293)$.

\begin{tabular}{lll}
\hline & $\begin{array}{c}\text { depression } \\
\text { parents }\end{array}$ & $\begin{array}{c}\text { depression } \\
\text { self }\end{array}$ \\
\hline BDI & $.24^{*}$ & $.32^{*}$ \\
SDS & $.20^{*}$ & $.24^{*}$ \\
EDPS & .15 & $.22^{*}$ \\
VROPSOM & $.18^{*}$ & .17 \\
SCLdep & .19 & $.34^{*}$ \\
SCLSOm & $.22^{*}$ & $.33^{*}$ \\
MIN & $.20 \#$ & - \\
MAJ & $.21 \#$ & $.36 \#$ \\
\hline
\end{tabular}

MIN/MAJ: minor/major depression

\#: phi-coefficient

SCLdep/SCLsom: subscales SCL-90

This table reveals that almost all the correlations are highly significant. It should be noted that a correlation was found between major depression and a previous episode of depression, but not between minor depression and a previous episode of depression.

\subsection{Discussion}

In this section the data shown in the first part of this chapter will be discussed.

12.2.1 Background features

\section{a.Social support}

In table 12.1 , both subscales of social support correlate significantly with depressive symptoms and depression. However, there is a significant difference in several correlations between the two subscales. One conclusion may be that the buffering effect of social support against the occurrence of depressive symptoms or depression is predominantly 
dependent on perceived support from relatives rather than from the partner: this conclusion was also found by Cutrona (1984). Moreover, it can be seen from fig 12.2 that these differences in correlations between the two sub-scales and BDI scores become larger later on in the postpartum period, and that perceived support from the partner hardly ever correlated after 22 weeks' postpartum. This suggests that, if there is a relationship between support from the partner and depression/depressive symptoms, in this study this could only be demonstrated in the early puerperium.

\section{b.Coping}

Coping, as reflected in the UCL, only partially correlated with depressive symptoms and depression. Although this suggests that there is no relationship between several subscales of the UCL and depression/ depressive symptoms, another explanation is that, even if all the UCL subscales measure coping behaviour, it is still uncertain whether measuring coping behaviour at 32 weeks" gestation has any predictive value on the way in which women will be able to cope with the problems they encounter in the postpartum period. As pointed out in part I, Cutrona and Russel (1990) argued that different situations demand different types of coping behaviour. As summarized by O'Hara and Zekoski (1988), there are several other studies which could not find a relationship between coping behaviour and postpartum depression/ depressive symptoms.

\subsubsection{Contributing factors}

\section{a. Specific for the postpartum period}

Infant temperament correlates significantly with depressive symptoms and depression (table 12.3). It was shown in fig 12.4 that correlation of the BDI scores with the subscales of child temperament declines during the postpartum period. 'The subscale 'care' (reflecting the actual care that has to be given to the child) is no longer significantly correlated after 10 weeks' postparturn, the subscale "trouble' (which reflects the way in which the child is perceived as troublesome by the mother) correlated significantly during the whole postpartum period. The mean scores of the BDI declined from 3.7 early in the puerperium to 2.0 at 34 weeks' postpartum. The mean scores of the subscale 'trouble' did not fluctuate much in the postpartum period (30.6 at 4 weeks' postpartum and 32.4 at 34 weeks' postpartum). However, the mean scores of the subscale 'care" increased predominantly during the postpartum period from 4 weeks' postpartum (68.6) until 16 weeks' postpartum (77.4). Thereafter, the mean scores did not increase further. Although this increase was not 
significant, it is interesting that the mean scores increased later on in the postpartum period. These results confirm the conclusions of other studies published on this subject (O'Hara et al. 1990b, Cutrona 1986, Whiffen and Gotlib, 1989).

Transition was operationalized by resigning from work outside the home and parity. Neither variable correlated with depression/depressive symptoms, in accordance with most studies in the literature (O'Hara and Zekoski, 1988).

\section{b. General contributing factors for depression}

Demographic features were not related to depressive symptoms or depression, as often found in the literature.

Stressful events showed a significant correlation with depression/depressive symptoms throughout the whole period of screening. As summarized in chapter III, several other studies also demonstrated a significant correlation between stressful life events and postpartum depression/ depressive symptoms.

\subsubsection{Predisposition}

\section{a. Specific predisposing factors for the postpartum period}

Depression in pregnancy was shown to be most strongly correlated with depressive symptoms and depression and this correlation remained stable during the postpartum period. This is consistent with most studies investigating factors related to postpartum depression (O'Hara and Zekoski 1988).

The correlations between premenstrual syndrome and depression/depressive symptoms showed a pattern which was the opposite of what was expected. In chapter III, it was assumed that women who were susceptible for pms were also more prone to depression early in the postpartum period. This theory was based on the observation that the changing-over time of hormones caused mood disturbances (Halbreich 1987). Table 12.9 shows significant correlations later in the postpartum period, mainly between pms and the BDI, SDS and EPDS scales. An explanation might be that, early in the puerperium, there is no correlation with postpartum depression, because at that time most women have not resumed menstruation and it is the actual appearance of pms that affects depression depressive symptoms. Only after several months, when most women have resumed menstruation, can a correlation between pms and postpartum depression be expected. As a consequence, it can be speculated that screening for depression in the postpartum period will partially overlap screening of pms, given the fact that some important 
features of pms (depressed mood, irritation, aggression) are measured by scales such as BDI, SDS, and EPDS (O'Brien 1987).

Parity and obstetrical complications showed no correlation with depression/depressive symptoms during the postpartum period. The latter finding is of importance because data in the literature are rather inconclusive on this issue. As pointed out by Kendell (1985), most of the differences are attributable to the poor definition of what should be considered obstetrical complications. Several studies incorporated factors such as anemia in their definition of obstetrical complications. In our study, obstetrical complications were strictly confined to the way in which the mother delivered the baby. As proposed by Kendell (1985), an explanation for the absence of a correlation might be that women with troublesome deliveries receive much support from medical staff, partner and relatives which could 'protect' against postpartum depression.

Blues were only significantly correlated to postpartum depression at 4 and 10 weeks' postpartum. Later on in the postpartum period no correlation was found. These findings might explain why some studies (Pitt, 1968. Paykel et al. 1980, Kendell et al. 1981) revealed a relationship between blues and postpartum depression when screening for postpartum depression started early after delivery, while others (Gard et al. 1986), who screened later on in the postpartum period, did not find a relationship. In the latter study, screening was carried out at 9 months' postpartum. In our study, we did not find a relationship between blues and postpartum depression at 8 months' postpartum either. Kennerly and Gath (1989b) reported no relationship between blues and depression at 12 weeks' postpartum. One interpretation may be that a relationship between blues and postpartum depression is dependent on the time of assessment in the postpartum period.

\section{b. General predisposing factors for depression}

Past adversity, the relationship with the parents and dramatic episodes in the past were significantly correlated with depressive symptoms and depression during the whole postpartum period. As mentioned in chapter III, delivery of a baby is thought to be an event which might actualize problems with the mother's parents, especially when the woman becomes a mother for the first time. Past adversity, as far as we know, has not frequently been reported in the literature with regard to postpartum depression but rather with regard to research into depression in general (Brown, 1989).

The presence of an episode of depression in the parents in the past correlated significantly with depression/depressive symptoms throughout the postpartum period. This is in accordance with most studies in the 
literature, not only on postpartum depression but also studies on depression in general.

The presence of a previous episode of depression in the woman herself also correlated significantly throughout the postpartum period. As mentioned earlier, this was also true of depression in pregnancy. However, at 32 weeks" gestation depression was also significantly correlated with a previous episode in the woman's earlier past, suggesting that being depressed in pregnancy should not be considered a predisposing factor specifically related to postpartum depression, but rather a previous episode of depression in general, which is supposed to be a major predisposing factor for depression.

In summarizing these data, three categories of variables can be distinguished.

Firstly, there is a set of variables which correlates significantly during the whole postpartum period with depression/depressive symptoms: 'depression in pregnancy', 'stressful events', 'a previous episode of depression in the woman herself', 'depression in the women's parents', the subscale 'relationship with the parents" of adversity, "sociall support as perceived from relatives', the UCL subscales 'depressive reaction' and 'palliation' reflecting coping behaviour, and the subscale 'trouble' in the child temperament scale. These variables are summarized in fig. 12.5 .

\section{PREDISPOSITION:}

general: depression family depression self adversity in past specific: depression pregnancy

CONTRIBUTING FACTORS:
general:
specific:
child temperament life events
subscale trouble

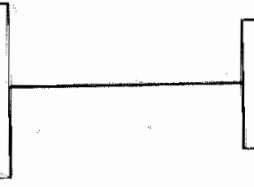
DEPRESSIVE SYMPTOMS IN THE POSTPARTUM

\section{BACKGROUND FEATURES coping: general social support: relatives}

fig.12.5 model containing variables which correlated significantly during the whole postpartum period

It can be speculated as to whether or not the specific predisposing factor, 'depression in pregnancy", is in reality the same as 'a previous episode of 
depression in the women herself'. The correlation 'perceived social support from relatives' with depression/depressive symptoms also remains stable during the postpartum period. This was also found for the earlier mentioned UCL subscales. We do not believe that any of these variables are specific for the postpartum period, and it is our hypothesis that the extent to which these variables correlate with depressive symptoms and depression reflects correlations with depression in general rather than a pattern which is typical for the postpartum period. There is only one variable which seems to be especially related to the postpartum period: the subscale 'trouble" in child temperament.

Secondly there is a set of variables which correlates significantly, but only temporarily, during the postpartum period: 'blues", "pms', 'perceived social support from the partner' and the subscale 'care' in child temperament. (fig. 12.6).

\section{PREDISPOSITION: \\ specific: pms \\ blues}

CONTRIBUTING FACTORS:

specific: child temperament subscalle care
DEPRESSION/ DEPRESSIVE SYMPTOMS IN THE POSTPARTUM

\section{BACKGROUND FEATURES}

social support: partner

fig.12.6 model containing variables which correlated significantl- but only temporarily - during the postpartum period

One explanation might be that, at different assessments in the postpartum period, different women may be depressed, women who do not necessarily share the same characteristics. The variables "social support from the partner', 'child temperament' - subscale 'trouble' - and 'blues' seem to be specific for the postpartum period. They all have the same pattern: significant correlation with depression/depressive symptoms early in the postpartum period and no correlation later on in the postpartum period. On the contrary the variable 'pms' is not actually related to the early postpartum period. One challenging hypothesis could be that women suffering from pms are not affected by the factor pms as a contributor to the occurrence of depression/depressive symptoms in the early puerperium. Again, this finding could be an argument against the theory 
that hormonal changes shortly after parturition are directly related to postpartum depression.

Finally, there are variables which do not correlate in any way with depression/depressive symptoms during the postpartum period: 'obstetrical complications", 'demographic features', the variable "transition' (including parity and resigning from or continuing to work outside the home), the short coping list with three items, and the UCL subscales: 'active reaction', 'turn for support', 'emotional reaction' and 'reassuring thoughts'.

We realize it might be possible that several variables which are shown to be significantly correlated with depression/depressive symptoms only show a relationship because of interaction with other variables. The variable 'depression in pregnancy' shows the strongest correlation. The interaction with other variables may be so important that, after adjustment of its influence, variables which correlate significantly on a bivariate level with depression/depressive symptoms, no longer correlate significantly when investigated at a multivariate level. As mentioned before, multivariate analysis is beyond the scope of this thesis. However, without the results of this analysis the relationship between depression/depressive symptoms and independent variables must be interpreted with caution. 


\section{Part IV}

\section{General discussion and conclusions}


142 


\section{Chapter XIII}

\section{Evaluation of the questions from the study, general discussion and conclusions}

\subsection{Evaluation of the questions from the study}

Although most of the questions have been answered in part III of this thesis, for sake of clarity they will be summarized here.

A. Questions concerning the incidence, prevalence and course of thyroid dysfunction and depression in the postpartum period:

1. The incidence of postpartum thyroid dysfunction in The Netherlands, the area where the study was carried out, is $7.2 \%$ ( 21 women). There were 11 women with transient hyperthyroidism alone, 6 women with transient hyperthyroidism followed by transient hypothyroidism and 4 women with transient hypothyroidism. When women with subclinical thyroid dysfunction are also included, the incidence rate rises to $8.9 \%$. As far as the course of postpartum thyroid dysfunction is concerned, it has been shown that most of the women with thyroid dysfunction are found between 2 and 6 months' postpartum, with hyperthyroidism predominantly in the early postpartum period and hypothyroidism later on in the postpartum period.

2. The incidence of postpartum depression - according to RDC criteria in this area of The Netherlands is $20.8 \%$ (61 women). The pointprevalence rates vary between 6 and $14 \%$ depending on the time of assessment in the postpartum period. The mean prevalence rate is $10 \%$. As far as the course of postpartum depression is concerned, there is a significant difference between the prevalence at 10 weeks' postpartum compared to the prevalence of depression in pregnancy, the early puerperium and to the late postpartum period. There is evidence that, at 10 weeks' postpartum, women are at particular risk for (minor) depression. Moreover, it was shown that different women may be depressed at different times during the postpartum, women who do not necessarily share the same characteristics.

B. Questions concerning relationships suggested in literature:

1. Significantly more women with thyroid dysfunction complain of lassitude and fatigue than women of a matched control group without 
thyroid dysfunction. This is also the case in women with hyperthyroidism. Significantly more women with hypothyroidism present with depressive symptoms and somatic complaints than matched controls without thyroid dysfunction.

2. Thyroid dysfunction in the postpartum period was not strongly related to depression. Women with thyroid dysfunction had a small increased risk of developing postpartum depression, suggesting that thyroid dysfunction is of minor importance in the etiology of postpartum depression.

3. Coping behaviour is not strongly related to postpartum depression. The significant correlations found between social support and depression show that perceived social support from the partner and relatives may influence the occurrence of depression, perceived social support from the partner being especially important early in the postpartum period. Perceived social support from relatives shows a stable relationship with depression during the whole postpartum period.

4. Only one general factor - in the literature indicated as being a contributing factor - showed a significant relationship with postpartum depression during the whole postpartum period: stressful life events. Demographic features showed no relationship to postpartum depression.

5. Contributing factors specific to the postpartum period include child temperament, transition to parenthood and breastfeeding. It was shown that the extent to which the child is perceived as stressful by the mother is significantly correlated with depression. Moreover, only in the early postpartum period did the 'degree of the actual care that has to be given to the child' show a relationship with depression. As far as parity and resigning from work outside the home is concerned in the transition to parenthood, no correlations were found with depression/depressive symptoms. Women who are breastfeeding are not depressed more often than women who are not. However, in the group of women with major depression as a whole, it was found that significantly more of these women breastfed than matched nondepressed controls.

6. There are several 'general contributing factors' that show a significant relationship with postpartum depression. Factors such as 'a previous history of depression in the women themselves', 'a previous history of depression in the family', and 'reported past adversity' are all significantly correlated with postpartum depression/depressive symptoms, a relationship which remained stable during the whole 
postpartum period. Moreover, these factors are reported significantly more often in women with major depression.

7. Depression during pregnancy shows the highest correlation with depression/depressive symptoms. Blues were only significantly related to depression in the early puerperium. In contrast to what was expected, pms was only significantly related to depression later on in the postpartum period. No relationship was found between obstetrical complications and postpartum depression.

\subsection{General discussion and conclusions}

Postpartum thyroid dysfunction was frequently observed $(7.2 \%)$, at least in the area where the research was carried out. As mentioned in part I of this thesis, it was recently demonstrated that there are only minor differences in iodine intake in different parts of The Netherlands (van Rees-Wortelboer et al. 1987). Because iodine intake is thought to be one of the main environmental factors influencing the prevalence rate of postpartum thyroid dysfunction, and other environmental factors are not likely to play an important role between different parts of the country, it is reasonable to assume that the incidence of $7.2 \%$ is representative for The Netherlands as a whole. Every year, approximately 190,000 women deliver a baby in this country. In The Netherlands, the number of nonCaucasian women is very much in the minority. This is of importance because, as mentioned before, racial differences may cause differences in the prevalence rate of postpartum thyroid dysfunction. Therefore, these data suggest that, every year in The Netherlands, about 14,000 women will develop postpartum thyroid dysfunction. As already described in the literature, follow-up reveals that after 8 years $30 \%$ of these women still have (transient) biochemical thyroid dysfunction, which would imply 4000 women for this country.

The incidence rate in our study is the highest of any study meeting the strict methodological criteria discussed in chapter VIII (incidence rate between 3.9 and $6.5 \%$ ). Although racial, environmental and genetic factors may contribute to this difference in outcome, the main factor is the methodology used in different studies, such as definition of thyroid dysfunction and frequency of assessment. As mentioned in chapter VIII, the short time between assessments has proved to be necessary, as otherwise $20 \%$ of women with thyroid dysfunction would have been lost if the interval had been longer (2-3 months). Compared with other studies, our incidence rate is only slightly more elevated, which is rather surprising in view of our frequent assessments. However, in our study, thyroid dysfunction was very strictly defined. If we applied the criteria 
used in two other studies (Lervang et al., 1987, Jansson et al. 1984), our incidence rate would have gone up to $8.9 \%$, which is considerably higher than the above-mentioned studies. This is the first blind study investigating the morbidity of thyroid dysfunction in the postpartum period. Significantly more women with postpartum thyroid dysfunction complained of lassitude and fatigue, usually in the period after 3 months' parturition, than euthyroid controls. Therefore, one important conclusion could be that in women who complain of lassitude and fatigue later on in the postpartum period thyroid dysfunction should be considered. Pulse rate was also significantly higher in women with thyrotoxicosis compared to euthyroid controls. However, the clinical relevance of this finding in every day practice should not be overestimated.

Finally, microsomal antibodies showed a high specificity for postpartum thyroid dysfunction, but showed a low sensitivity as a marker for postpartum thyroid dysfunction. When a cut-off point for the titre of microsomal antibodies was taken at $1 / 6400$, the predictive value of this titre (or higher) for women for developing postpartum thyroid dysfunction was $82 \%$. However, women with microsomal antibodies at 32 weeks' gestation have a markedly (twenty-fold) increased risk for developing postpartum thyroid dysfunction compared to MsAb negative pregnant women. Consequently, it can be speculated as to whether or not screening women immediately after delivery (which is supposed to reflect the antibody status at 32 weeks' gestation) for microsomal antibodies, is an appropriate way of detecting women who should be followed during the postpartum period because they are at particular risk for developing thyroid dysfunction. There are several authors who suggest screening early in pregnancy for the presence of microsomal antibodies - or recently for TPO antibodies, which seems to be a more sensitive way of screening for antibodies - because the titre of antibodies declines during pregnancy. However, at least in this study, of the 10 women with elevated titres during postpartum but not at 32 weeks' gestation, only 2 (reflecting $10 \%$ of the 21 women who developed thyroid dysfunction) developed postpartum thyroid dysfunction. It could be possible that these women already had elevated titres early in pregnancy - which should have been detected when screening was carried out at that time - with a decline of this titre during pregnancy, and became microsomal-antibody-negative at the end of pregnancy. Further research is needed to investigate the clinical relevance of screening (all) pregnant women for the presence of microsomal antibodies.

In conclusion, this study, which is the first with frequent assessments up to 34 weeks" postpartum in an unselected population, clearly shows that 
postpartum thyroid dysfunction is a common phenomenon and that symptoms such as lassitude and fatigue may be symptoms caused by thyroid dysfunction in the postpartum period.

The incidence of postpartum depression in this study during 8 months of assessment was $20.8 \%$. The point-prevalences varied between 6 and $14 \%$. The mean prevalence rate was $10 \%$, which is comparable with most other studies in the literature. Contrary to the incidence rate of thyroid dysfunction, the prevalence rate of postpartum depression in this area may not be representative of The Netherlands as a whole. There is one important demographic feature which positively influences the incidence of postpartum depression: being divorced or living without a partner. Several studies showed this feature to be correllated with depression in general and depression in the postpartum period. In our sample, only one woman did not have a partner in the period when she delivered her baby. The area in which the study was carried out is a semi-rural, semi-urban area. In purely urban areas many more women without a partner deliver a baby, and these women are at higher risk for postpartum depression. Troutman and Cutrona (1990) reported an incidence of $26 \%$ of postpartum depression in a group of largely unmarried young mothers (aged between 14 and 18 years). Therefore it is likely that, in areas where more unmarried or single mothers deliver a baby, the incidence rate of postpartum depression is even higher than in the area in which this study was carried out.

As far as the course of postpartum depression is concerned, this study clearly shows that there is a period after delivery when women are specifically prone to depression. However, one striking finding is that this period does not occur immediately after delivery, but rather after the second month postpartum: there is a significant increase in depression between 8 and 20 weeks' postpartum. It can be concluded that there is period after parturition - between about 8 to 20 weeks' postpartum - when women are at particular risk for postpartum depression. As a consequence one may speculate that it is unlikely that postpartum depression is directly related to hormonal changes occurring immediately after delivery because in the first month after parturition - when the most important hormonal changes occur - a high prevalence of postpartum depression does not usually occur. There is no consensus in the literature on the natural course of postpartum depression, as explained in part I of this thesis. This study suggests that the prevalence rate of depression increases at 10 weeks' postpartum, remains high until 20 weeks' postpartum and declines thereafter to levels which are equal to the prevalence rates in pregnancy and the early postpartum period. 
This study does not put forward evidence for a strong relationship between thyroid dysfunction and depression in the postpartum period: women with postpartum thyroid dysfunction only have a slightly increased risk (a factor of 2) for developing postpartum depression, suggesting only a minor role in the etiology of postpartum depression. There were several variables - as proposed in the model of the study which were significantly related to depression or significantly correlated with depression/depressive symptoms during the whole postpartum period. These consist of variables which were specific for postpartum depression and variables which did not seem to be specifically related to depression in the postpartum period but rather to depression in general. There was another set of variables which was only significantly related to depression or correlated significantly with depression/depressive symptoms during a specific period of the postpartum period. This set mainly consisted of variables which were specific for the postpartum period: 'blues' and 'child temperament'. There was one interesting finding about the relationship between premenstrual syndrome and postpartum depression: in contrast to what was expected, pms was significantly correlated with postpartum depression only several months after parturition. This means that the theory of pms as a risk factor for postpartum depression, due to the rapid hormonal changes immediately after parturition, is not supported by the results of this study. Another consequence of this study is that screening for postpartum depression partially overlapped screening for pms, especially during the period when the women resumed menstruation. Therefore it can be argued that the 'detected' relationship between pms and ppd is an artefact of the study. In chapter III, in which the literature on etiological factors of postpartum depression was reviewed, the expression "the results are not conclusive or equivocal" was used frequently. It was explained that this discrepancy was thought to have been caused by differences in the definition of depression or assessment of depression in the postpartum period. However, we believe that this study makes it clear that, whether a relationship is found between a variable and postpartum depression or not depends on the time of assessment in the postpartum period, suggesting that different women may be depressed at different times during the postpartum period, women who do not share necessarily the same characteristics.

The most relevant facts that can be used in general practice, and more specifically in family medicine, may be summarized as follows:

First of all, thyroid dysfunction is not an uncommon phenomenon in The Netherlands. It is estimated that every year 14,000 women will have 
thyroid dysfunction after delivery. There are about 6000 general practitioners in The Netherlands. This means, that on average every general practitioner will see two women a year with thyroid dysfunction in his practice. The complaint of lassitude and fatigue is significantly related to thyroid dysfunction, especially in the period after 3 months" postpartum. Therefore, it is important to realize that in women who present with vague complaints, such as fatigue, lassitude and tiredness, thyroid dysfunction may also be present - when there is no other reason to explain these complaints - especially when these complaints occur later on in the postpartum period. Although it can be argued that the impact of (transient) thyroid dysfunction on a woman"s health does not seem to be dramatic, and therefore that the consequences when this condition is not diagnosed as such are not detrimental, it is important to find out whether the woman's complaints are related to a specific organic dysfunction, in this case dysfunction of the thyroid. This will facilitate the way in which the woman can accept and handle these complaints. Moreover, case reports where women with these vague complaints are treated with antidepressant drugs are not rare (Jansson et al. 1988).

Secondly, women in the postpartum period are at risk for depression, especially during specific periods. Most of the depressions which occur early in the postpartum only last for a short period of time, contrary to depressions later on in the postpartum period which last longer.

Thirdly, although there are several case reports in literature of women with postpartum depression who also had thyroid dysfunction, it was found that thyroid dysfunction is only of minor importance in the etiology of postpartum depression.

Finally, it is important to realize that there is evidence in the literature so far that women with thyroid dysfunction in the postpartum period are prone to thyroid dysfunction in the future, irrespective of another pregnancy or postpartum period. It should be realized that if women present with vague complaints of lassitude and fatigue in general practice - even if this happens several years after a pregnancy - they might in fact be presenting with another period of transient thyroid dysfunction. Moreover, several authors report that women with postpartum transient thyroid dysfunction are at particular risk for developing definite hypothyroidism. 
150 


\section{Summary}

Thyroid dysfunction is frequently reported to occur in the postpartum period. Transient hyperthyroidism and transient hypothyroidism are described and there is evidence that they have an autoimmune origin. In the literature the prevalence rates vary between 1.9 and $16 \%$. Most of the differences are thought to be explained by differences in the methodology of the studies involved, such as frequency of sampling, definition of thyroid dysfunction and nature of the sample: whether it is an unselected population or whether mainly microsomal-antibody-positive women are involved. The three studies which met the strict methodological criteria only screened the women once or twice during the postpartum period. Because thyroid dysfunction during the postpartum period is of a transient nature, many cases will not have been detected. The question of whether postpartum thyroid dysfunction is related to a specific complaint-pattern has never been investigated adequately: assessment of clinical signs and symptoms without knowing the results of biochemical tests. During the postpartum period women often present with vague complaints such as lassitude and fatigue and both the health professional and the mother accept these complaints as being normal for the postpartum period. A possible relationship with thyroid dysfunction has never been investigated. The incidence of thyroid dysfunction in The Netherlands is not known.

Postpartum depression is believed to occur in $10 \%$ of women after delivery. However, studies investigating etiological factors of postpartum depression show rather conflicting data. Although methodological differences are thought to cause these discrepancies, an important issue could be the time and frequency of assessment in the postpartum period. Therefore, it is important to screen for postpartum depression in a followup study: some factors may only be significantly related to depression in the early puerperium (blues), while other factors only show a significant relationship several months' postpartum. The incidence of postpartum depression in The Netherlands is not known.

There are several case reports of women who were seriously depressed in the postpartum period and who proved to have thyroid dysfunction. After thyroid function had normalized the depression also improved. No systematic study in a general population investigating thyroid dysfunction and depression for several months during the postpartum period has ever been undertaken. 
The main issues of the present study, therefore, involved the incidence, prevalence and course of postpartum thyroid dysfunction and postpartum depression in The Netherlands. Moreover, we were interested in finding out whether thyroid dysfunction was related to typical clinical signs and symptoms. Factors, which are shown in literature to be related to postpartum depression, were allso investigated in a follow-up study in order to find out whether possible significant relationships fluctuate during the postpartum period. Finally, we investigated the relationship between thyroid dysfunction and depression in the postpartum.

Of 380 women who booked in for antenatal control, 303 consented to participate in a screening programme. Ten women dropped out for various reasons and therefore 293 women completed the study. The women were assessed at 32 weeks' gestation and thereafter at intervals of 6 weeks from 4 weeks' postpartum until 34 weeks' postpartum. Thyroid function was assessed by measuring fT 4, fT 3 and TSH concentrations and by clinical examination of the participant. During the study, neither the researcher nor the participant knew the results of biochemical tests. Thyroid dysfunction was defined as occurring only when TSH was abnormal together with abnormal fT4 and/or fT3 values. Moreover, a diagnosis of depression was made using RDC criteria, and depressive symptoms were detected by means of several self-rating scales, commonly used in clinical psychology. Factors related to postpartum depression, which are commonly described in the literature, were investigated such as blues, social support, coping behaviour, premenstrual syndrome and the infant temperament.

The incidence of thyroid dysfunction, all new cases of thyroid dysfunction which developed during the postpartum period of screening, was $7.2 \%$ ( 21 women). Of these women, 11 had transient hyperthyroidism alone, 6 hyperthyroidism followed by hypothyroidism and 4 hypothyroidism alone. Hyperthyroidism usually occurred within the first 4 to 5 months, hypothyroidism usuaaly after 5 months. Women with thyroid dysfunction complained significantly more often of lassitude and fatigue compared with a control group matched for age, parity and social class. The pulse rate in women with hyperthyroidism was significantly higher than that in a matched control group.

The incidence of postpartum depression, all new cases of depression that developed during the postpartum period of screening, was $20.8 \%$ (61 wormen). The point-prevalences varied between 6 and $14 \%$. There was a peak at 10 weeks' postpartum: at that time significantly more women were depressed than during gestation, early puerperium or late postpartum. These findings suggest that there is indeed an increase in the 
occurrence of depression in the postpartum period but, contrary to what was expected, not immediately after delivery but rather between 2 and 4 months" postpartum. This makes it unlikely that abrupt fluctuations in hormones such as progesterone or oestradiol, which occur after delivery, play an important role in the etiology of postpartum depression.

No strong relationship between thyroid dysfunction and depression could be demonstrated: the relative risk for women with postpartum thyroid dysfunction to develop postpartum depression was small (2), suggesting that other factors are of importance in the etiology of postpartum depression as well.

As far as other factors with regard to the relationship to depression are concerned, it was found that some factors were only significantly related during the early puerperium - blues, perceived social support from the partner, the actual care that had to be given to the child - but had no significant relationship in the late postpartum period, while another factor - premenstrual tension - was only significantly related later on in the postpartum period and not in the puerperium. This suggests that at different times in the postpartum different women may be depressed, women who do not necessarily share the same characteristics.

The consequences of this study for general practice can be summarized as follows: postpartum thyroid dysfunction occurs frequently in The Netherlands and it is estimated that general practitioners will see on average two or more women a year with thyroid dysfunction in their practice. Women with postpartum thyroid dysfunction complain more often of lassitude and fatigue, especially later on in the postpartum period. Women are at particular risk between 2 and 4 months for postpartum depression. The depression that lasts for a short period of time is predominantly found early in the postpartum period, while later on in the postpartum period the depression has a tendency to last longer. Women with postpartum thyroid dysfunction only have a small increased risk for postpartum depression. 
154 


\section{References}

Ahmann AJ, Burman KD.: The role of T lymphocytes in autoimmune thyroid disease. Endocrinol Metabol Clin 1987;16:287-325.

Albersnagel FA.: Classificatie en meting van depressief gedrag.

Gedragstherapie 1986; 3: 171-94.

Albersnagel FA.: Het cognitieve model. In: Depressie, theorie diagnostiek en behandeling. Editors: Albersnagel FA et al. Van Loghum Slaterus 1989.

Alder EM and Cox JL.: Breastfeeding and postmatal depression.

J Psychosomat Res 1983;27:139-44.

Alloway $\mathbf{R}$ and Bebbington P.: The buffer theory of sociall support- a review of the literature. Psychological Med, 1987; 17: $91-108$.

American Psychiatric Association. Diagnostic and Statistical Manual of Mental Disorders. Third Edition-Revised (DSM-III-R), 1987.

Washington DC: American Psychiatric Association.

Amidi D, Berghuis PH.: Hyperthyreoidie ten gevolge van pijnloze thyreoiditis. Ned Tijdschr Geneesk 1983; 127:492-5.

Amino N, Miyai K, Onishi T et al.: Transient hypothyroidism after delivery in autoimmune thyroiditis. J Clin Endocrinol Metabol 1976;42:296-300.

Amino N, Miyai K, Kuro $\mathbf{R}$ et al.: Transient postpartum hypothyroidism: fourteen cases with autoimmune thyroiditis. Ann Int Med 1977; 87: 155-9.

Amino $\mathbf{N}$, Kuro $\mathbf{R}$, Tanizawa $\mathbf{O}$ et al.: Changes of serum anti-thyroid antibodies during and after pregnancy in autoimmune thyroid disease.

Clin Exp Immunol 1978;31:30-37.

Amino N, Mori H, Iwatani Y, Kawashima M, Miyai K.: Significance of thyroid microsomal antibodies. Lancet 1980 ii:1369.

Amino $N$, Mori $H$, Iwatani $Y$ et al.: High prevalence of transient post-partum thyrotoxicosis and hypothyroidism. N Engl J Med 1982a;306:849-52.

Amino N. Miyai K, Yamamoto $T$ et al.: Aggravation of thyrotoxicosis in early pregnancy and after delivery in Graves's disease.

$J$ Clin Endocrinol Metabol 1982b; 55: 108-15.

Amino N, Miyai K.: Postpartum autoimmune endocrine syndromes. In: Autoimmune endocrine disease. Ed:" Davies T. New-York, John Wiley and Sons 1983.

Amino $\mathbf{N}$, Iwatani $\mathbf{Y}$, Tamaki $\mathbf{H}$, Mori H, Aozasa M, Miyai K. Postpartum autoimmune thyroid syndromes. In: Walfish $P G$, Wall $J R$, Volpe $\mathbb{R}$ (eds). Autoimmunity and the Thyroid. Orlando: Academic Press 1985; pp 289-314.

Amino N, Tamaki H, Aozasa $M$ et al.: Postpartum onset of Graves disease. In: Thyroid and Autoimmunity. Ed:. Pinchera A et al.; New York, Plenum 1987a.

Amino N, Iwatani $\mathbf{Y}$, Tamaki $H$ et al.: Mechanism of postpartum thytoid disease. In: Thyroid Autoimmunity. Ed: Pinchera A el al.; New York, Plenum 1987b.

Amino N.: Autoimmunity and hypothyroidism. In: Bailliere's Clinical Endocrinology and Metabolism 1988; 2:591-614.

Arindel WA and Ettema JH.: SCL-90. Een Multidimensionele Psychopathologie Indicator. Lisse: Swets \& Zeitlinger.

Arizmendi TG and Affonso DD.: Stressful events related to pregnancy and postpartum. J Psychosomat Res 1987;31:743-56.

Atkinson AK and Rickel AU.: Postpartum depression in primiparous patients. J Abnorm Psychol, 1984; 93: 115-9.

Barry $S$ and Dinan TG.: Neuroendocrine challenge tests in depression: a study of growth hormone, TRH and cortisol release. J Affective Dis 1990;18:229-34.

Bebbington PE, Brugha T, MacCarthy B et all.: The Camberwell collaborative depression study. Br J Psychiat, 1988; 152: 754-65.

Beck AT, Ward CH, Mendelson M, Mock JE, Erbaygh JK.: An inventory for measuring depression. Arch Gen Psychiat 1961; 4: 561-71. 
Beck AT and Beck RW.: A rapid technique for screening depressed patients in general practice. Postgrad Med 1972;52:81-5.

Beck AT, Rush AJ, Shaw BF, Emery G.: Cognitive Therapy of Depression. New York: Wiley 1979.

Beck AT, Steer RA, Garbin MG.: Psychometric properties of the beck depression inventory: 25 years of evaluation.

Clin Psycholl Rev 1988;8:77-100.

Billings $\mathrm{AG}$ and Moos RH.: Psychosocial Theory and research on Depression: an integrative framework and review. Clin Psychol 1982;2:213-37.

Bilous RW and Tunbridge WM.: The epidemiology of hypothyroidism - an update.In: Bailliere Clinical Endocrinology and Metabolism 1988;2:531-40.

Bouman TK.: Assessment van stemmingsstoornissen. In: Depressie, theorie, diagnostiek en behandeling. Editors: Albersnagel FA et al. Van Loghum Slaterus 1989.

Bouman TK, Luteijn F, Albersnagel FA, Ploeg FA.: Enige ervaringen met de Beck Depression Inventory (BDI). Gedrag, Tijdschrifi voor Psychol 1985;12:13-24.

Boyd JH and Weissman MM.: Epidemiology. In: Handbook of Affective Disorders. ES Paykel (ed). Churchill Livingstone, Edinburgh 1982.

Bridge LR, Little BC, Hayworth J, Dewhurst J, Priest RG.: Psychometric antenatal predictors of postnatal depressed mood.

J Psychosomat Res 1985;29:325-31.

O'Brien PM.: Premenstrual Syndrome. Blackwell Scientific Publications: 1987.

Broadhead WE, Kaplan BH, James SA et al.: "The epidemiologic evidence for a relationship between social support and health.

Am IJ Epidemiol,1983; 117: 521-37.

Brockington IF: Puerperal psychosis. In: Motherhood and Mental Illness. London Academic Press 1982;37-69.

Brockington IF and Cox-Roper A.: The nosology of puerperal mental illness. In: Motherhood and Mental Illness. Kumar R and Brockington IF (eds), London Wright 1988.

Brown GW and Harris TO.: Social origins of depression, a reply. Psychol Med 1978;8:577-88.

Brown GW, Andrews B, Harris T, Adler Z, Bridge L.: Sociall support, self esteem and depression. Psychol Med 1986; 16: 813-31.

Brown GW, Bifulco A, Harris TO.: Life events, vulnerability and onset of depression. Br J Psychiat. 1987; 150: 30-42.

Brown GW.: Depression: a radical social perspective. In: Depression, an Integrative Approach. Herbst K and Paykel E (eds). Heineman Medical Books 1989. pp 21-44.

Bruin de TW, Riekhoff FP, Boer de JJ.: An outbreak of thyrotoxicosis due to atypical subacute thyroiditis.

J Clin Endocrinol Metabol 1990;70: 396-402.

Calabrese JR, Kling MA, Gold PW.: Alterations in immunocompetence during stress, bereavement, and depression: focus on neuroendocrine regulation. Am J Psychiat 1987; 144: 1123-34.

Caldwell G, Gow SM, Sweeting VM et al.: A new strategy for thyroid function lesting. Lancet 1985;1117-9.

Camara EG and Danao TC.: The brain and the immune system: a psychosomatic network. Psychosomatics, 1989; 30:231-8.

Caroll BJ, Feinberg M, Greden JF et al.: A specific laboratory test for the diagnosis of melancholia: standardization, validation and clinical utility. Arch Gen Psychiat $1981 ; 38: 15-22$.

Czarnocka B, Ruf J, Ferrand M, Lissitzky S, Carayon P.: Interaction of highly purified thyroid peroxidase with anti-microsomal antibodies in autoimmune thyroid disease. J Endocrinol Invest 1986;9:135-8.

Chalmers BE \& Chalmers BM.: Postpartum depression: a revised perspective. J Psychosomat Obstet Gynaecol 1986;6:93-105. 
Cogill SR, Caplan HL, Alexandra H, Robson KM, Kumar R. Impact of matemal depression on the cognitive development of young children.

Br Med J 1986; 292:1165-7.

Cohen S and Wills TA.: Stress, social support and the buffering hypothesis. Psychol Bull 1985; $98: 310-57$.

Cooper PJ, Campbell EA, Day A, Kennerley H, Bond A.: Non-psychotic psychiatric disorder after childbirth.

Br J Psychiat 1988; 152:799-806.

Cox JL.: Clinical and research aspect of post-natal depression

J Psychosomat Obstet Gynaecol 1982;2:46-52.

Cox JL.: Postnatal depression: a comparison of African and Scottisch women. Socpsychiat $1983 ; 18: 25-8$.

Cox JL, Rooney A, Thomas PF, Wrate RW.: How accurately do mothers recall

postnatal depression? J Psychosomat Obstet Gynaecol 1984; 3: 185-9.

Cox JL, Holden JM, Sagovsky R.: Detection of postnatal depression.

Br J Psychiat 1987; 150:782-86.

Cox JL.: The life event of childbirth: sociocultural aspects of postnatal depression.

In: Motherhood and Mental Illness 2.

Kumar R and Brockington IF (eds) Wright 1988.

Coyne $J$ and Bolger $N$.: Doing without social support as an explanatory concept. $J$ Soc Clin Psychol. 1990; 2: 148-57.

Coyne $\mathrm{JC}$ and $A$ Idwin $\mathrm{C}$ :: Depression and coping in stressful episodes.

J Abnormal Psychol. 1981; 90;439-47.

Cutrona CE.: Nonpsychotic postpartum depression: a review of recent research.

Clin Psychol Rev 1982; 2: 487-503.

Cutrona CE.: Causal attributions and perinatal depression.

J Abnormal Psychol 1983;92:161-72.

Cutrona CE.: Social support and stress in the transition to parenthood. J Abnormal Psychol 1984;93:378-90.

Cutrona CE. and Troutman BR.: Social support, infant temperament and parenting self-efficacy: a mediational model of postpartum depression. Child Dev. 1986; 57 : 1507-18.

Cutrona CE.: Stress and social support-in search of optimal matching.

J Soc Clin Psychol 1990:;2: 3-14.

Dahlberg PA, Jansson R.: Different aetiologies in postpartum thyroiditis. Acta Endocrinol 1983;104:195-200.

Dalton K.: Depression after Childbirth. Oxford: Oxford University Press, 1980.

Daruna JH and Morgan JE.: Psychosocial effects on immune function: neuroendocrine pathways. Psychosomatics 1990;31:4-12.

Davidson J and Robertson $E_{*}$ : A follow-up study of post-partum illness, 1946 1978. Acta Psychiat Scand 1985;71:451-7.

Davies TF, Martin A, Graves P.: Human autoimmune thyroid disease: cellular and molecular aspects.In: Bailliere's Clinical Endocrinology and Metabolism 1988; 2:911-39.

Delange F, Bastiani S, Benmiloud M et al.: Definitions of endemic goiter and cretinism, classification of goiter size and severity of endemias, and survey techniques. In: Towards the Eradication of Endemic Goiter, Cretinism and Iodine Deficiency, pp 373-6.

Washington, PAHO Sci Publ 502, 1986

Derogatis LR, Lipman RS, Covi L.: SCL-90: an outpatient psychiatric rating scalepreliminary report.

Psychopharmacol Bull 1973;9:13-28.

Derogatis LR and Cleary PA.: Confirmation of the dimensional structure of the

SCL-90: a study in construct validation.

J Clin Psychiat 1977:33:981-9. 


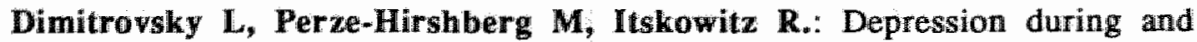
following pregnancy: quality of family relationships.

J Psychol 1987;121:213-8.

Donovan BT.: Hurnors, Hormones and the Mind. 1988

Editor McMacmillan Press Lud.

Dussault JH, Rousseau F.: Immunologically mediated hypothyroidism. Endocrinol Metabol Clin 1987;16:417-29.

Ehlert U, Patalla U, Kirschbaum C, Piedmont E, Hellhammer DH.: Postpartum blues: salivary cortisol and psychological factors. J Psychosomat Res 1990;34:31925.

Extein IL and Gold MS.: Thyroid hormone potentiation of tricyclics.

Psychosomatics 1988; 29: 166-74.

Farid NR: Immunogenetics of autoimmune thyroid disorders.

Endocrinol Metabol Clin 1987;16:229-45.

Farid NR and Balazs C.: Immunogenetics of thyroiditis and thyroid carcinoma. In: Immunogenetics of Endocrine Disorders. Farid NR et al. (eds) Alan R.Liss, 1988.

Faulk WP and McIntyre JA.: Immunogenetics aspects of human pregnancy and fertility: role of trophoblast antigens. In: Immunogenetics of Endocrine Disorders, pp401-32. Alan R. Liss, Inc 1988.

Feggether P and Gath D.: Non-psychotic psychiatric disorders in women one year after childbirth. J Psychosomat Res 1981;25:369-72.

Feksi A, Harris B, Walker RF, Riad-Fahmy D, Newconbe RG.: Maternity blues and hormones levels in saliva.

J Affective Disorders. 1984; 6: 351-55.

Fein HG, Goldman JM.: Postpartum lymphocytic thyroiditis in American women: a spectrum of thyroid dysfunction.

Am J Obstet Gynecol 1980;138:504-10.

Fein HG, Goldman JM, Weintraub BD.: HLA antigens in thyroiditis.

In: Autoimmunity and the Thyroid pp 373-5. Academic Press 1985.

Ferguson DM and Horwood LJ.: Vulnerability to life events exposure.

Psychol Med 1987; 17: 739-49.

Folkman $S$ and Lazarus RS.: An analysis of coping in a middle-aged community sample. J Hith Soc Behav 1980; 21 : 219-39.

Freeman R, Rosen H, Thysen $\mathbf{B}_{\text {. }}$ : Incidence of thyroid dysfunction in an unselected postpartum population. Arch Intern Med 1986;146:1361-4.

Friedhoff A.J and Simkowitz P.. A new conception of the relationship between psychological coping mechanism and biological stress buffering systems. $\mathrm{Br} J$ Psychiat 1989; 154: 61-6.

Funch DP and Marshall JR.: Measuring life stress: factors affecting fall-off in the reporting of life events.

J Hith Soc Behav 1984; $25: 453-64$.

Fung H, Kologlu M, Collison K.: Postpartum thyroid dysfunction in Mid Glamorgan. Br Med J 1988;296:241 -4.

Gard PR, Handley SL, Parsons AD, Waldron G.: A multivariate investigation of postpartum mood disturbance.

Br J Psychiat 1986; 148: 567-75.

Gelder M, Gath D, Mayou R.: Oxford Textbook of Psychiatry.

Oxford Medical Publications 1989.

George $\mathbf{A J}$ and Wilson KC.." Beta-endorphin and puerperal psychiatric symptoms.

Br J Pharmacol 1983;80:493-6.

George A.J and Sandler M.: Endocrine and biochemical studies in puerperal mental disorders. In: Motherhood and Mental Illness 2. Kumar $\mathbf{R}$ and Brockington IF Wright (eds) 1988.

Gerstein HC.: How common is postpartum thyroiditis. Arch Intern Med 1990; 150: $1397-1400$. 
Gewirtz GR, Malaspina D, Hatterer JA, Feureisen S, Klein D, Gorman JM.: Occult thyroid dysfunction in patients with refractory depression.

Am J Psychiat 1988; 145: 1012-4.

Gilbert P.: Depression, from Psychology to Brain State: 1984

Lawrence Eribaum Assoc. Ltd.

Ginsberg $J$ and Walfish PG.: Postpartum transient thyrotoxicosis with painless thyroidlitis. Lancet $\mathrm{i} ; 1977: 1125-28$.

Gitlin MJ and Pasnau RO.: Psychiatric syndromes linked to reproductive function in women: A Review of Current Knowledge. Am J Psychial 1989;146:1413-22.

Glick ID, Quitkin FM, Bennett SE:: The influence of oestrogens and oral contraceptives on depression. In: Halbreich U. ed, Hormones and depression. pp 339-55. Raven Press New-York 1987.

Glinoer P, Nayer de $\mathbf{P}$, Lejeune B et al.: Antithyroid peroxidase antibodies in normal pregnancy. In: Thyroperoxidase and Thyroid Autoimmunity. Carayon $\mathbf{P}$ and Ruf J (eds) 1990, Colloques Inserm. 303-11.

Gold MS and Pearsall HR.: Hypothyroidism, or is it depression.

Psychosomat 1983; 24: 646-56.

Gold PW, Goodwin FK, Chrousos GP: Clinical and biochemical manifestations of depression.I Relation to the neurobiology of stress N Engl J Med 1988; 319: 348-20.

Gold PW, Goodwin FK, Chrousos GP: Clinical and biochemical manifestations of depression. II Relation to the neurobiology of stress. N Engl J Med 1988: 319: 413 20 .

Goldberg D and Huxley P.: Mental IIIness in the Community, Tavistock London 1980.

Goldman J.M.: Postpartum thyroid dysfunction.

Arch Intern Med 1986; 146:1296-8.

Greenwood J and Parker G.: The dexamethasone suppression test in the puerperium. Aust N-Z J Psychiat 1984;18:282-4.

MeGuffin P, Katz R, Aldrich J, Bebbington P.: The Camberwell collaborative depression study. II. Investigation of Family Members. Br J Psychiat 1988a; 152: 766-74.

McGuffin P, Katz R, Bebbington P.: The Camberwell collaborative depression study. III. Depression and adversity in the relatives of depressed probands. Br J Psychiat 1988b; 152: 775-82.

McGuffin P.:. Major genes for major affective disorder? Br J Psychiat 1988c; 153: 591-6.

McGuffin $P$ and Katz $R$.: The genetics of depression and manic-depressive disorder. Br J Psychiat 1989; 155: 294-304.

Gutekunst R, Haferman W, Mansky T, Scriba PC.: Ultrasonography related to clinical and laboratory findings in lymphocytic thyroiditis. Acta Endocrinol Scand 1989;121:129-35.

Haggerty JJ, Simon JS, Evans DL, Nemeroff CB.: Relationship of serum TSH concentration and antithyroid antibodies to diagnosis and DST response in psychiatric inpatients. Am J Psychiat 1987; 144: 1491-93.

Halbreich U:: Hormones and depression - conceptual transitions.

In: Halbreich U. ed, Hormones and depression. pp 3-20. Raven Press New York 1987.

Hall RC.: Psychiatric effects of thyroid hormone disturbance.

Psychosomatics $1983 ; 24: 7-18$.

Hall R. and Besser M.: Fundamentals of Clinical Endocrinology.

Churchill Livingstone 1989.

Hamada N, Jaeduck N, Portmann L, Ito K, DeGroot L.J.: Antibodies against denatured and reduced thyroid microsomal antigen in autoimmune thyroid disease. I Clin Endocrinol Metabol 1987;64:230-8.

Hamilton JA.: Puerperal Psychosis. In: Gynaecology and Obstetrics, Voll 2, pp 1-8. Haggerston: Harper Row, 1977. 
Hamilton JA.: The identity of postpartum psychosis. In: Motherhood and Mental Ilness. pp 1-17. London Academic: Press, 1982.

Hamilton M.: Development of a rating scale for primary depressive illness. Br J Soc Clin Psychol 1967; 6: 278-96.

Handley SL, Dunn TL, Waldron G, Baker JM.: Tryptophan, cortisol and puerperal mood. Br J Psychiat 1980:136:498-508.

O'Hara MW and Rehm LP.: Predicting depressive symptomatology: cognitivebehavioural models and postpartum depression.

J Abnormal Psychol 1982;91:457-61.

O'Hara MW, Rehm LP, Campbell SB.: Postpartum depression, a role for social network and life stress variables.

J Nerv Ment Hlth, 1983; 171: 336-41.

O'Hara MW, Neunaber DJ, Zekoski EM.: Prospective study of postpartum depression: prevalence, course and predictive factors.

J Abnormal Psychol 1984;93:158-71.

O'Hara MW.: Social support, life events and depression during pregnancy and the puerperium. Arch Gen Psychiat, 1986; 43: 569-73.

O'Hara MW and Zekoski EM.: Postpartum depression, a comprehensive review. In: Motherhood and Mental Illnes 2. Kumar R and Brockington IF (eds) Wright 1988.

O'Hara MW, Zekoski EM, Philipps LH, Wright EJ.: Controlled prospective study of postpartum mood disorders: comparison of childbearing and nonchildbearing women. J Abnormal Psychol, 1990a; 99: 2-15.

OHAra, Schlechte JA, Lewis DA, Wright EJ.: Controlled prospective study of postpartum mood disorders: psychological, environmental and biological factors. I Abnormal psychology $1990 \mathrm{~b}$ in press.

Harris B, Johns $\mathbf{S}$, Fung $\mathbf{H}$ et al.: The use of raring scales to identify post-natal depression. Br J Psychiat 1989; 154:813-7.

Harris B, Huckle P, Thomas R, Johns S, Fung H.: The hormonal environment of post-natal depression. Br J Psychiat 1989; 154: 660-7.

Harris B, Fung H, Johns $\mathrm{S}$ et al.: Transient post-partum thyroid dysfunction and postnatal depression.

Affective Disorders, 1989; 17: 243-9.

Harris TO, Brown GW, Bifulco A.: Loss of parent in childhood and adult psychiatric disorder: The Walthamstow study I. The role of lack of adequate parental care. Psychol Med 1986;16:641-59.

Harris TO, Brown GW, Bifulco A.: Loss of parent in childhood and adult psychiatric disorder: the role of social class position and premarital pregnancy. Psychological Medicine 1987;176:163-83.

Hawkins BR, Dawkins RL, Burger HG et al.: Diagnostic significance of thyroid microsomal antibodies in randomly selected population. Lancet 1980; 1057-59.

Hay ID and Klee GG.. Thyroid dysfunction. Endocrinol and Metabol 1988; 17: 473-509.

Hayslip CC, Feim HG, O'Donnell VN, Friedman DS, Klein TA, Smallridge RC.: The vallue of serum antimicrosomal antibody testing in screening for symptomatic postpartum thyroid dysfunction.

Am J Obstet Gynecol 1988a; 159: 203-9.

Hayslip CC, Baker JR, Wartofsky L, Klein TA, Opsahl MS, Burman KD.: Natural killer cell activity and serum auto-antibodies in women with postpartum thyroiditis. J Clin Endocrinol Metabol 1988b;66:1089-93.

Hegedüs L, Perrild H, Poulsen LR.: The determination of thyroid volume by ultrasound and its relationship to body weight, age and sex in normal subjects. J Clin Endocrinol Metabol 1983;56:260-3.

Hobfoll SE.: Conservation of resources.

Am Psychol 1989; 44: 513-24. 
Hobfoll SE and Freedy JR.: The availability and effective use of social support. $J$ Soc Clin Psychol, 1990; 2: $91-113$.

Hodiamont $\mathbf{P}$ et al.: Epidemiological aspects of psychiatric disorder in a Dutch health area. Psychol Med 1987; 17:495-505.

Hoevenaars JP and Son van MJ.: Drie Nederlandse zellfreportage lijsten in de diagnostiek van depressie. Gedragstherapie 1984;17:225-39.

Hoevenaars JP and Son van MJ.: Het operante model: In: Depressie, Theorie, Diagnostiek en Behandeling. Albersnagel FA et al. (eds) Van Loghum Slaterus 1989. Holden JM, Sagovsky $\mathbf{R}$, Cox JL.: Counselling in a general practice setting. controlled study of health visitor intervention in treatment postnatal depression. $\mathrm{Br}$ Med J 1989; 298: 223-6.

Hoofdakker RH et al.: Begripsbepaling, syndromale classificatie, differentielle diagnostiek, casuistiek en epidemiologie. In: Depressie, Theorie, Diagnostiek en Behandeling. Albersnagel FA et al. (eds) Van Loghum Slaterus 1989a.

Hoofdakker RH.: Biologische concepten en strategien. In: Depressie, Theorie, Diagnostiek en Behandeling. Albersnagel FA et al. (eds) Van Loghum Slaterus $1989 \mathrm{~b}$.

Hopkins J, Marcus M, Campbell SB.: Postpartum depression: a critical review. Psychol Bull 1984;95:498-515.

Hopkins $J$ and Campbell SJ.: Role of infant-related stressors in postpartum depression. J Abnormal Psychol 1987;96:237-41.

Iles S, Gath D, Kennerley H.: "Maternity Blues": a comparison between postoperative women and post-natal women.

Br I Psychiat 1989;155;363-366.

IItaka M, Aguyao JF, Iwatani Y, Row VV, Volpe R.: Studies of the effect of suppressor $T$ lymphocytes on the induction of antithyroid microsomal antibodysecreting cells in autoimmune thyroid disease.

$J$ Clin Endocrinol Metabol 1988; 66: 708-14.

Inada $\mathbf{M}$, Nishikawa $\mathbf{M}$, Oishi $\mathbf{M}$, Kurata S, Imura H.: Transient thyrotoxicosis associated with painless thyroiditis and low radioactive iodine uptake. Arch Intern Med 1979;139:597-9.

Inada M, Nishikawa M, Naito K, IshiiH, Tanaka K, Imura H.: Reversible changes of histological abnormalities of the thyroid in patients with painless thyroiditis. J Clin Endocrinol Metabol 1981;52:431-5.

Jacobson DE.: Types and timing of social support. J Hith Soc Behav 1986; 27 : 25064.

Jadresic, DP.: Psychiatric aspects of hyperthyroidism. J Psychosomat Res 1990; 34: 603-15.

Jansson $\mathbf{R}$, Bernander $\mathbf{S}$, Karlsson $\mathbf{A}$, Levin $\mathbf{K}$, Nilsson Gl.: Autoimmune thyroid dysfunction in the postpartum period.

J Clin Endocrinol Metabol 1984; 58: 681-6.

Jansson R.: Postpartum thyroid disease. Mol Biol Med 1986; 3:201-11.

Jansson R, Karlisson FA, Linde A, Sjoberg O.: Postpartum activation of autoimmunity: transient increase of total IgO levels in normal women and in women with autoimmune thyroiditis.

Clin Exp Immunol 1987;70:68-73.

Jansson R, Dahlberg PA, Karlsson FA.: Postpartum thyroiditis.

In Bailliere's Clin Endocrinol and Metabol 1988; 2: 619-35.

Jarjoura $D$ and $O^{\prime} H a r a M . W .:$ A structurall model for postpartum responses to the somatic and cognitive items on the beck depression inventory.

J Psychopathol Behav Assess 1987;9:389-402.

Jeste DV, Lohr JB, Goodwin FK.: Neuroanatomical studies of major affective disorders. Br J Psychiat 1988; 153: 444-59.

Kämpe O, Jansson R, Karisson FA.: Effects of $\mathbb{L}$-Thyroxine and lodided on the development of autoimmune postpartum thyroiditis. $\mathrm{J}$ Clin Endocrinol Metabol 1990; 70: 1014-18. 
Kathol RG, Jaeckle RS, Lopez JF, Meller WH.: Pathophisiology of HPA axis abnormalities in patients with major depression: an update.

Am J Psychiat 1989; 146: 311-7.

Kendell RE, Rennie D, Clarke JA, Dean C.: The sociall and obstetric correlates of psychiatric admission in the puerperium.

Psychol Med 1981;11:341-9

Kendell RE:. Emotional and physical factors in the genesis of puerperal mental disorders. J Psychosomat Res 1985;29:3-11.

Kendell, Chalmers JC, Platz C.: Epidemiology of puerperal psychosis.

Br J Psychiat 1987; 150:662-73.

Kennerly $H$ and Gath $D .:$ Maternity blues reassessed.

Psychiat Dew 1986;1:1-17.

Kennerly $H$ and Gath D.: Maternity Blues I. Detection and measurement by questionnaire. Br I Psychial 1989a;155:356-62.

Kennerly $\mathbf{H}$ and Gath D.: Maternity Blues II. Associations with obstetric, psychological, and psychiatric Factors.

Br J Psychiat 1989b;155:367-73.

Kerkhof A.: Suicide en de geestelijke gezondheidszorg. 1985. Thesis at the University of Leiden.

Kinney JS, Hurwitz ES, Fishbein DB et al.: Community outbreak of thyrotoxicosis: epidemiology, immunogenetic characteristics, and long-term outcome, Am J Med 1988; 84: 10-18.

Klee GG, Hay ID.: Assessment of sensitive thyrotropin assay for an expanded role in thyroid function testing: proposed criteria for analytic performance and clinical utility.

J Clin Endocrinol Metabol 1987;64:461-71.

Klein I, Trzepacz PT, Roberts M, Levey $G$ et al.: Symptom rating scale for assessing hyperthyroidism. Arch Intern Med 1988; 148: 387-90.

Krenning EP and Wiersinga WM.: Schildklierziekten.

Samsom Stafleu 1988.

Klompenhouwer JL et al.: Psychische stoomissen na de bevalling. Mndbld Geest.Gez.1988;3:268-83.

Klopper A.: Pregnancy proteins and hormones in the immune response of pregnancy. In: Immunology of pregnancy and its disorders, pp 9\-113. Stern C. ed. Kluwer Academic Publishers, 1989.

Koerselman GF.: Postnatalle depressie.

Mindbld Geest.Gez.1982; 9:921-30.

Koerselman GF. "Postnatale" depressie. Ned Tijdschr Geneesk 1983;1 27:516-7.

Kortmann FA.: Postpartum depressie, een wetenswaardig verschijnsel Mndbld Geest.Gez. 1983; 10: 1031-43.

Kuevi V, Causon R, Dixon AF et al.: Plasma amine and hormones changes in postpartum blues. Clin Endocrinol.1983;19:39-46.

Kumar $\mathbf{R}$ and $K M$ Robson.: A prospective study of emotional disorders in childbearing women. Brit J Psychiat 1984;144:35-47.

Lazarus RS and Folkman S.: Stress, appraisal, and coping.

New York: Springer 1984.

Lervang HH, Pryds O, Kristensen HP.: Thyroid dysfunction after delivery. Incidence and clinical course. Acta Med Scand 1987:222: 369-74.

Levy $V_{\text {*: }}$ The maternity blues in post-partum and post-operative women. $\mathrm{Br}$ Psychiat 1987; 151:368-372.

Levy AB and Stern SL.: DST and TRH stimulation test in mood disorder subtypes. Am J Psychiat 1987; 144: 472-4.

Lewinsohn PM and Talkington $\mathbf{J}_{\text {.: }}$ Studies on the measurements of unpleasant events and relations with depression. Appl Psychol Meas 1979;3;:83-101.

Lewinsohn PM, Hoberman HM, Rosenbaum M.: A prospective study of risk factors for unipolar depression. J Abnormal Psychol 1988;97:251-64. 
Loke YW: Human trophoblast antigens. In: Immunology of Pregnancy and its Disorders, pp 61-90. Stern C. ed., Kluwer Academic Publishers 1989.

Loosen PT and Prange AJ Jr.: Serum thyrotropin response to thyrotropin-releasing hormone in psychiatric patients: a review. Am J Psychiat 1982;139;405-16.

Loosen PT.: Thyroid homones and affective state. In: Halbreich U. ed. Hormones and Depression pp 357-83. Raven Press New York 1987.

Mampunza M.: Postpartum psychosis in Kinshasa.

Acta Psychiat Belg 1984;84:284-93.

Male D, Champion B, Cooke A.: Advanced immunology. Gower Medical Publishing London, New York 1987.

Mariotti S, Anelli S, Ruf J et al.: Comparison of serum thyroid microsomal and thyroid peroxidase autoantibodies in thyroid disease.

J Clin Endocrinol Metabol 1987; 65: 987-93.

Mattox JH and Bernstein J.: Prolactin and depression: two models.

J Psychosom of Obstet Gynecol 19:88;9:111-5.

Meltzer HY: An overview of hormones and monoamino-receptors. In: Halbreich U. ed. Hormones and Depression. pp 49-57 Raven Press New York 1987.

Meltzer HY.: Serotonergic dysfunction in depression.

Br J Psychiat 1989; 155: 25-31.

Montgommery SA and Asberg M.: A new depression scale designed to be sensitive to change. Br J Psychiat 1979; 134:382-9.

Newcomb MD.: Social support and personal characteristics: a developmental and interactional perspective. J Soc Clin Psychol 1990; 2* 54-67.

Nikolai TF, Brosseau J, Kettrick MA, Roberts R, Beltaos E.: Lymphocytic thyroiditis with spontaneously resolving hyperthyroidism (silent thyroiditis). Arch Intern Med 1980;140:478-82.

Nikolai TF, Coombs GJ, MeKenzie AK.: Lymphocytic thyroiditis with spontaneously resolving hyperthyroidism and subacute thyroiditis.

Arch Intern Med 1981;141:1455-8.

Nikolai TF, Turney SL, Roberts RC.: Postpartum lymphocytic thyroiditis. Arch Intern Med 1987;147:221-4.

Nordström UL, Dallas JH, Morton HG, Patel NB.: Mothering problems and child morbidity amongst " mothers with emotional disturbances". Acta Obstet Gynecol Scand 1988a;67:155-8.

Nordstròm UL, Dallas JH, Morton HG, Patel NB.: Antenatal Heallth questionnaire to identify "mothers with emotional disturbances" as a potential risk group. Acta Obstet Gynecol Scand 1988b;67:327-31.

Nott PN, Franklin M, Armitrage C, Gelder MG.: Hormonal changes and mood in the puerperium. Br J Psychiat 1976;379-83.

Nott PN.: Psychiatric illness following childbirth in Southampton: a case register study. Psychol Med 1982;12;409-13.

Nott PN.: Extent, timing and persistence of emotional disorders following childbirth. Br J Psychiat 1987:151:523-527.

Oakley A, Rajan L, Grant A.: Social support and pregnancy outcome. Br J Obstet Gynecology 1990;97:155-62.

Ormel J, Brokk FG, Wiersma D.: Depressie, de behandelde en de onbehandelde morbiditeit in de (Nederlandse) bevolking.

Tdschrft Soc Gez, 1984; 62: 670-8.

Othman S, Phillips DI, Parkes AB et al.: A long-term follow-up of postpartum thyroiditis. Clin Endocrinol 1990; 32: 559-564.

Othman S, Harris B, Richards CJ, Hall R, Lazarus JH.: Postpartum

Thyroiditis is associated with Psychiatric Ilness. 10th International Thyroid Conference, Feb 1991, The Hague, The Netherlands, Abstr 98, p 58.

Paffenbarger RS.: Epidemiological aspects of mental illness associated with childbearing. In: Motherhood and Mental Illness pp 19-35 London. Academic Press 1982. 
Paykel ES.: Contribution of life events to causation of psychiatric illness. Psychol Med 1978; 8: 245-53.

Paykel ES.: Emms EM, Fletcher J, Rassaby ES.: Life events and social support in puerperal depression. Br J Psychiat 1980; 136: 339-46.

Paykel ES.: The background: extent and nature of the disorder. In: Depression, an Integrative Approach pp 3-21. Herbst $K$ and Paykel E. (eds) Heineman Medical Books 1989a.

Paykel ES.: Treatment of depression. Br I Psychiat 1989b;155:754-63.

Pinchera $\mathbf{A}$ et al.: Significance of thyroid auto-antibodies in autoimmune thyroid disease. In: Autoimmunity and the Thyroid, pp 139-51. Academic Press 1985.

Pitt B.: 'Atypical' depression following childbirth.

Br J Psychiat 1968; 114: 1325-35.

Pitt B.: Maternity Blues. Br J Psychiat 1973;122:431-3.

Prange $\mathbf{A J}$ et al.: Enhancement of imipramine antidepressant activity by thyroid hormone Am J Psychiat 1969;126:457-69.

Prentice LM, Phillips DI, Beever K, McLachlan SM, Smith BR.: Geographical distribution of subclinical autoimmune thyroid disease in Britain: A study using highly sensitive direct assays for autoantibodies to thyroglobulin and thyroid peroxidase. Acta Endocrinol 1990; 123: 493-498.

Rasmussen N, Hornness P, Hegedüs L, Feldt-Rasmussen U.: Thyroild volume, serum $\mathrm{Tg}$ and $\mathrm{TSH}$ during the menstrual cycle, pregnancy, and the postpartum. Abstract 151. ETA Conference Montpellier, France 1988.

Rasmussen NG, Hornnes PJ, Hoier-Madsen M, Feldt-Rasmussen U, Hegedüs L.: Thyroid size and function in healthy pregnant women with thyroid autoantibodies. Relation to development of postpartum thyroididtis. Acta Endocrinol 1990; 123:395-401.

Rees-Wortelboer MM, Schröder-van der Elst JP, Lycklama A, Heỉde van der D.: Jodium en krop in Nederland. Ned Tdschr Geneesk 1987;131:1821 -4.

Regier DA, Boyd JH, Burke JD et al.: One-month prevalence of mental disorders in the United States: based on five epidemiologic catchment area sites. Arch Gen Psychiat, 1988; 45: 977-86.

Robins LN, Helzer JE, Croughan J, Rateliff K.: National Institute of Mental Health Diagnostic Interview Schedule.

Arch Gen Psychiat 1981;38: 381-390.

Roitt I, Brostoff J, Male D.: Immunology. Churchill Livingstone 1990.

Rook KS.: Parallels in the study of social support and social strain.

J Soc Clin psychol 1990; 2:118-31.

Rooy HA and Pop V.J.: Postpartale thyreoiditis, een overzicht. Ned Tdschr Geneesk $1989 ; 133 * 810-4$.

Rooijen L. van.: Depressiegevoelens van Sociale Oorsprong. Deventer: Van Loghum Slaterus 1979.

Rooijen L and Arrindell WA.: Depressiegevoelens bij Psychiatrissche Patienten en hun Partners: validiteit van de VROPSOM.

Onderzoeksmemorandum RM-PS 85-20, 1985.

Ruf J, Czarnocka B, Ferrand M, Lissitsky S, Carayon P.: Novel routine assay of thyroperoxidase autoantibodies. Clin Chem 1988;34:2231-4.

Roy $A$ and Pickar D.: TRH-induced prolactin release in unipolar depressed patients and controls. J Psychiat Res 1988;22:221-5.

Sachar EJ.: Neuroendocrine studies of major depressive disorder. In: American Handbook of Psychiatry, Freedman DX and Dyrud JE.(eds) pp 299-313. Basic Books, New York 1975.

Sackeim HA, Prohownik I, Moeller JR et al.: Regional cerebral blood flow in mood disorders. Arch Gen Psychiat 1990; 47: 60-70.

Safran M, Paul TL, Roti E, Braverman LE : Environmental factors affecting autoimmune thyroid disease.

Endocrinol Metabol Clin 1987; 16: 327-41. 
Saks BR, Frank JB, Lowe TL et al.: Depressed mood during pregnancy and the puerperium. Am J Psychiat 1985;142:728-31.

Salvi M, How J.: Pregnancy and autoimmune thyroid disease.

Endocrinol Metabol Clin 1987;16:431 44 .

Sanderman R.: Life-events, persoonlijkheid en depressie: In: Depressie, Theorie, Diagnostiek en Behandeling. Albersnagel FA et al. (eds) Van Loghum Slaterus 1989. Sarason IG, Sarason BR, Pierce GR.: Social support: the search for theory. I Soc Clin Psychol, 1990; 2: 133-41.

Sargent IL and Redman CW: Maternal response to the fetus in human pregnancy. In: Immunology of Pregnancy and its Disorders, pp 115-42. Stern C. ed. Kluwer Academic Publishers 1989.

Schreurs PJ, Tellegem B, Willige G.: The Utrecht coping list.

Gedrag - Tdschrft voor Psychol 1984; 12: 101-16.

Schreurs PJ.: Persoonskenmerken en Essentiele Hypertensie. Thesis at the University of Maastricht 1987.

Schulz $\mathbf{R}$ and Tomkins CA.: Life events and changes in social relationships: examples, mechanisms and measurement.

J Soc and Clin Psychol 1990;2; 69-77.

Seel RM.: Birth rite. Hth Visitor $1986 ; 59: 182-4$.

Smith R, Cubis J, Brinsmead $\mathbf{M}$ et al.: Mood changes, obstetric experience and alterations in plasma cortisol, beta-endorphin and corticotrophin releasing hormone during pregnancy and the puerperium.

J Psychosomat Res 1990; 34:" 53-69.

Sobell LC, Toneatto T, Sobell MB, Schuller R, Maxwell M.: A procedure for reducing errors in reports of life events.

J Psychosomat Res 1990; 34: 163-70.

Spitzer RL et al: Clinical criteria for psychiatric diagnosis and DSM II. Am J Psychiat 1975; 132: 773-82.

Spitzer RL et al.: Research diagnostic criteria: rationale and reliability. Arch Gen Psychiat, 1978; 35: 773-82.

Sridama V, Pacicni F, Yang SL, Moawad A, Reilly M, DeGroot L.J.: Decreased levels of helper $T$ cells: a possible cause of immunodeficiency in pregnancy. $N$ Engl J Med 1982;307:352-6.

Stein G.: The maternity blues. In: Motherhood and mental illness pp 119-54 London. Academic Press. 1982.

Stein MB and Uhde TW.: Autoimmune thyrouditis and panic disorder.

Am J Psychiat 1989; 146: 259-60.

Stern $\mathbf{G}$ and Kruckman $\mathbf{L}_{\text {: }}$ : Multidisciplinary perspectives on postpartum depression: an anthropological critique. Soc Sci Med 1983;17:1027-41. Stewart DE, Addison AM, Robinson GE, Joffe R, Burrowe GN, Olmsted MP:. "Thyroid function in psychosis following childbirth.

Am. J Psychiatry 1988; 145: 1579-81.

Stites DP, Stobo JD, Wells JV: Basic and Clinical Immunology.

Prentice-Hall International 1987.

Stokes PE and Sikes CR.: The hypothalamic-pituitary-adrenocortical axis in major depression. Neurol Clin 1988; 6: 1-19.

Tachi J, Amino N, Tamaki H, Aozasa M, Iwatani Y, Miyai K.: Long term followup and HLA association in patients with postpartum hypothyroidism. I Clin Endocrinol Metabol 1988;66:480-4.

Tennant $\mathbf{C}$, Bebbington $\mathbf{P}$, Hurry $\mathrm{J}$.: The role of life events in depressive illness: is there a substantial causal relation?

Psychol Med. 1981; 11: 379-89.

Thoits PA.: Conceptual, methodological and theoretical problems in studying social support as a buffer against life stress. J Hith Soc Behav, 1982; $23: 145-59$.

Troutman BR and Cutrona CE.: Nonpsychotic postpartum depression among adolescent mothers. J Abnormal Psychol 1990;99:69-78. 
Tunbridge WM. Evered DC, Hall $\mathbf{R}$ et al: The spectrum of thyroid disease in a community: the Whickham survey. Clin Endocrinol 1977;7:481-93.

Tunbridge WM, Brewis M, French $\mathbf{J M}$ et al.: Natural history of autoimmume thyroiditis. Br Med J 1981;282:258-62.

Uddenberg $\mathbf{N}$ and Englesson L: Prognosis of postpartum mental

disturbance. Acta Psychiat Scand 1978,58:201-12.

Uddenberg $\mathbf{N}$ and Nilsson L.: The longitudinal course of para-natal emotional disturbance. Acta Psychiat Scand 1975;52:160-9.

Vargas MT, Briones-Urbina R, Gladman D, Papsin FR, Walfish PG.:

Antithyroid microsomal autoantibodies and HLA-DR5 are associated with postpartum thyroid dysfunction: evidence supporting an autoimmune pathogenesis. $J$ Clin Endocrinol Metabol 1988;67:327-33.5.

Vitug AC and Goldman J.M.: Silent painless thyroiditis.

Arch Intern Med 1985; 145:473-5.

Volpe $\mathbf{R}$ and Row V.V.: Role of antigen-specific suppressor $T$ lymphocytes in the pathogenesis of autoimmune thyroid disease.

In: Autoimmunity and the thyroid. pp 79-93. Academic Press 1985.

Volpe R.: Is silent thyroiditis an autoimmune disease?

Arch Intern Med 1988; 148: 1907-8.

Walfish PG, Ginsberg J.: Post-partum transient thyrotoxicosis with painless thyroiditis. Lancet $1977 ; 1: 1125-7$.

Walfish PG and Farid NR.: Postpartum thyroid dysfunction. N Engl J Med 1982;307:1024-25.

Walfish PG, Chan JY.: Post-partum hyperthyroidism.

Clin Endocrinol Metabol 1985a;14:417-47.

Wallitish PG, Farid NR.: The immunogenetic basis of autoimmune thyroid disease. In: Autoimmunity and the thyroid. pp 9-35. Academic Press 1985 b.

Watson JP, Elliott SA, Rugg AJ, Brough DI.: Psychiatric disorder in pregnancy and the first postnatal year. Br J Psychiat 1984;144:453-62.

Weissman MM.: Advances in psychiatric epidemiology: rates and risks for major depression Am J Publ HIth, 1987; 77: 445-51.

Werner"s The Thyroid. A fundamental and Clinical Text, 5 th edn, SH Ingbar and LE Braverman (eds), JP Lippincott Co, Philadelphia, 1986.

Whiffen VE.: Vulnerability to postpartum depression: a prospective multivariate study. J Abnormal Psychol 1988a;97:467-74.

Whiffen VE.: Screening for postpartum depression: a methodological note. J Clin Psychol 1988b;44:367-71.

Whiffen VE and Gotlib IH.: Infants of postpartum depressed mothers: temperament and cognilive status. J Abnormal Psychol 1989:98:274-9.

Willige G, Schreurs P, Tellegem B, Zwart F.: Het meten van 'life events:" de vragenlijst recent meegemaakte gebeurtenissen (VRMG).

Ned Tdsch Psychol 1985; 40:1-19.

Wing JK, Cooper JE, Sartorius N.: Description and Classification of Psychiatric Symptoms. Cambridge: Cambridge Uniwersity Press, 1974.

Woolf PD.: Transient painless thyroiditis with hyperthyroidism

A variant of lymphocytic thyroiditis? Endocrinol Rev 1980;1:411-20.

Yoshida H, Amino N, Yagawa K et al.: Association of serum antithyroid antibodies with lymphocytic infiltration of the thyroid gland:

Studies of seventy autopsied cases. J Clin Endocrinolo Metabol 1978; 46: 859-62.

Zuckerman BS and Beardslee WR.: Maternal depression: a concern for pediatricians. Pediatrics $1987 ; 79: 110-7$.

Zung WW.: A self rating Depression Scale. Arch Gen Psychiat 1965;12: 63-70. 


\section{Samenvatting}

Schildklierfunctiestoornissen na de partus blijken frequent voor te komen. Hierbij kan het gaan om een tijdelijke hyperfunctie van de schildklier, een tijdelijke hypofunctie of beide. Als oorzaak wordt aan een autoimmuun proces gedacht. De incidentie loopt in de literatuur uiteen van $1.9-16 \%$. De verschillen worden hoofdzakelijk veroorzaakt door verschillende methoden van onderzoek die zijn gebruikt in diverse studies zoals de frequentie van screenen, de definitie van een schildklierfunctiestoornis en de samenstelling van de onderzoeksgroep: gaat het om een open populatie of betreft het hoofdzakelijk vrouwen met positieve microsomale antilichamen. De drie studies die voldeden an strenge methodologische criteria screenden bijvoorbeeld slechts én of tweemaal in de postpartum periode. Omdat het meestal een tijdelijke schildklierfunctiestoornis betreft, wordt bij eenmalige screening een aantal gevallen gemist. De vraag of schildklierfunctiestoornissen na de bevalling een typisch klachtenpatroon kennen, is nooit op nauwkeurige wijze onderzocht. Het voorkomen in Nederland is eveneens onbekend.

Postpartum depressie komt bij ongeveer $10 \%$ van de vrouwen voor. Studies waarbij onderzoek werd gedaan naar mogelijke oorzaken van postpartum depressie gaven uiteenlopende resultaten. Alhoewel ook hier weer verschillen in methoden van onderzoek een rol spelen, is mogelijk het tijdstip van meten na de bevalling een belangrijk gegeven. Het is heel goed mogelijk dat sommige factoren vlak na de bevalling wel een samenhang vertonen met postpartum depressie terwijl dit enkele maanden na de bevalling niet meer het geval hoeft te zijn (blues). Omgekeerd zijn er factoren die pas later in de postpartum periode een significant verband vertonen met postpartum depressie en niet vlak na de bevalling. Dit betekent, dat het belangrijk is om ook het vórkomen van postpartum depressie in een follow-up studie te onderzoeken. Dit is nog nooit gedaan. Hoe vaak depressie na de bevalling in Nederland vórkomt is niet bekend.

Er zijn verschillende 'case' studies gepubliceerd waarin melding wordt gemaakt van vrouwen met een ernstige postpartum depressie die bij nader inzien een schildklierfunctiestoornis bleken te hebben. Nadat de schildklierfunctie genormaliseerd was, bleek ook de depressie te zijn verdwenen. Follow-up studies waarbij het bestaan van een samenhang tussen postpartum schildklierfunctiestoornissen en depressie werd onderzocht tot lang na de bevalling zijn nog nooit uitgevoerd. 
De belangrijkste vraagstellingen van dit onderzoek zijn: hoe vaak komen schildklierfunctiestoornissen voor na de bevalling, hoe vaak komt postpartum depressie voor en is er een verband tussen beide. Bovendien wordt het verband onderzocht tussen postpartum depressie en factoren, waarvan bekend is uit de literatuur dat ze samenhangen met postpartum depressie. Een belangrijke hypothese hierbij is, dat mogelijke samenhangen met depressie fluctueren tijdens de postpartum periode.

Er werden 380 vrouwen benaderd om mee te doen aan de studie, hiervan stemden 303 vrouwen in waarvan er uiteindelijk 293 overbleven die de studie helemaal afrondden. Bij 32 weken zwangerschap vond de eerste screening plaats, vervolgens werd vanaf 4 weken na de bevalling tot 34 weken postpartum met een interval van 6 weken telkens opnieuw gescreend. Tijdens iedere meting werden de fT3, de fT4 en het TSH bepaald. Alle onderzoeken werden door én onderzoeker uitgevoerd. Zowel de onderzoeker als de deelneemsters waren tijdens de periode van screenen niet op de hoogte van de resultaten van biochemische bepalingen. Een schildklierfunctiestoornis werd gedefinieerd als het bestaan van een abnormale TSH waarde met tegelijkertijd een abnormale fT4 en/of fT3 waarde. Bovendien werd bij ieder onderzoek het bestaan van een depressie met behulp van RDC-criteria vastgesteld. Tevens werden enkele zelf-rapportage lijsten gebruikt om depressieve symptomen op te sporen. Factoren waarvan in de literatuur wordt beschreven dat zij een voorspellende waarde zouden hebben voor het ontstaan van een postpartum depressie werden tenslotte ook onderzocht, zoals sociale ondersteuning, coping gedrag, de bewerkelijkheid van het kind, het vóorkomen van blues en het premenstrueel syndroom.

De incidentie van schildklierfunctiestoornissen na de bevalling in dit onderzoek bedraagt $7.2 \%$ ( 21 vrouwen). Hiervan hebben 11 vrouwen een tijdelijke hyperfunctie van de schildklier, 6 vrouwen een hyperfunctie gevolgd door een hypofunctie en 4 vrouwen alleen een tijdelijke hypofunctie. De hyperfunctie komt vooral voor gedurende de eerste 3-4 maanden, de hypofunctie na deze periode. Het blijkt dat vrouwen met een schildklierfunctiestoornis significant meer klagen over moeheid dan een euthyreote controle groep. Bovendien blijkt de subgroep met een hyperfunctie een duidelijk hogere polsfrekwentie in rust te hebben dan een controle groep.

De incidentie van postpartum depressie is $20.8 \%$ (61 vrouwen). De punt prevalentie varieert tussen 6-14\% waarbij een piek wordt gevonden rond 10 weken na de bevalling. Op dit tijdstip blijken significant meer vrouwen depressief te zijn dan tijdens de zwangerschap, de eerste weken na de bevalling en de periode van 6-8 maanden na de bevalling. Een 
groot gedeelte van de vrouwen die op tien weken depressief zijn blijkt slechts 'minor' depressief te zijn. Deze bevindingen suggereren dat depressie na een bevalling inderdaad vaak voorkomt maar in tegenstelling tot wat algemeen wordt aangenomen niet onmiddellijk na de bevalling maar pas enkele maanden daarna. Dit maakt het onwaarschijnlijk dat de abrupte concentratie veranderingen van vrouwelijke hormonen die plaatsvinden vlak na de bevalling een belangrijke directe rol spelen in het ontstaan van een postpartum depressie.

Het blijkt dat het risico voor vrouwen met een schildklierfunctiestoornis op het krijgen van een postpartum depressie slechts een factor twee hoger is dan voor vrouwen zonder een schildklierfunctiestoornis. Dit gegeven komt overeen met de algemeen geaccepteerde hypothese dat de etiologie van depressie multifactorieel is en niet aan eén causale factor is toe te schrijven.

Wat betreft mogelijke verbanden tussen psycho-sociale variabelen en postpartum depressie blijkt dat sommige factoren zoals 'blues', ondersteuning vanuit de echtgenoot en bewerkelijkheid van het kind, vroeg in de postpartum periode significant correleren met postpartum depressie, terwijl deze significantie later in de postpartum periode niet meer aanwezig is. Andere factoren, zoals bijvoorbeeld pms, blijken juist vlak na de bevalling geen significante samenhang te vertonen met postpartum depressie maar wel na enige maanden. Deze gegevens suggereren dat op verschillende tijdstippen na een bevalling, verschillende vrouwen depressief zijn en dat deze vrouwen niet noodzakelijkerwijze dezelfde eigenschappen vertonen wat betreft de relatie tussen uitlokkende factoren en depressie.

De belangrijkste resultaten van dit onderzoek voor de dagelijkse huisarts praktijk kunnen het beste als volgt worden samengevat: schildklierfunctiestoornissen na de bevalling komen vaak voor in Nederland. De huisarts ziet gemiddeld per jaar twee vrouwen met een schildklierfunctiestoornis na de bevalling in zijn praktijk. Vrouwen met een schildklierfunctiestoornis klagen vaak over moeheid vooral in een latere periode na de bevalling. Er blijkt een periode te zijn na de bevalling waarin vrouwen een verhoogd risico hebben voor een depressie. In tegenstelling tot wat algemeen werd aangenomen is dit niet vlak na de bevalling, maar de periode tussen 2 - 4 maanden na de bevalling. Vrouwen met een schildklierfunctiestoornis blijken slechts een licht verhoogd risico te hebben voor het krijgen van een postpartum depressie. 
170 


\section{Appendix}

\section{Child temperament list}

Wilt $u$ op een zespunt schaal aangeven in hoeverre $u$ het eens bent met de volgende uitspraken:

1. De baby slaapt regelmatig en goed.

2. De baby huilt erg veel.

3. De baby is gemakkelijk tot bedaren te brengen.

4. De baby reageert rustig op andere mensen.

5. De baby is vlug opgewonden en schreeuwerig.

6. De baby lacht vaak en maakt tevreden geluidjes.

7. De baby laat zich graag opnemen en knuffelen.

8. De baby reageert rustig als ze verplaatst wordt.

9. De baby protesteert vaak heel driftig en fel.

10 De baby laat zich gemakkelijk verschonen.

11 De baby wordt op regelmatige tijden gevoed.

12 De baby moet 's nachts gevoed worden.

13 De baby slaapt heel licht.

14 De baby reageert rustig op plotse verstoringen.

15 De baby verzet zich tegen het baden.

16 De baby is vaak ziek.

17 Ik vind de baby veel bewerkelijker dan ik had gedacht.

18 Ik maak mij vlug bezorgd over de baby.

19 De baby is een moeilijke baby.

20 Ik ondervind veel plezier in het omgaan met de baby.

21 Het zorgen voor de baby heeft mij erg uitgeput.

22 Sinds de geboorte van de baby is mijn gedrag naar mijn echtgenoot toe veranderd.

23 De baby verstoort mijn eigen slaap zeer.

24 Het is fijn dat ik de baby heb. 


\section{Social support list}

Wilt u op een zespunt schaal aangeven in hoeverre $u$ het eens bent met de volgende uitspraken:

1. Sinds de geboorte van de baby is het gedrag van mijn man ten opzichte van mij erg veranderd.

2. Ik kan met mijn man goed praten over vragen of zorgen die ik heb over het kind.

3. Ik krijg veel steun van iemand buiten ons gezin.

4. Mijn echtgenoot neemt mij veel zorg voor de baby uit handen.

5. Ik wordt goed gesteund door anderen in de manier waarop ik met de baby om ga.

6. Ik heb vaak het gevoel dat ik er helemaal alleen voor sta.

7. Ik heb vaak het gevoel dat mijn partner niet van mij houdt.

8. Er bestaan op dit moment geen relatieproblemen.

9. Ik ervaar de bemoeienissen van mijn ouders nu als steun.

10. Er zijn nu zorgen die mij erg bezig houden.

11. Ik ben bang dat de baby door zijn aanwezigheid de relatie met mijn partner kan verstoren.

uitspraken over partner.

12. Als hij mij iets vraagt verplaatst hij zich niet in mijn positie.

13. Als hij en ik het niet eens zijn over wat er gebeuren moet, dan heeft ieder van ons even grote kans dat zijn idee wordt uitgevoerd.

14. Als wij het oneens zijn met elkaar zal hij zijn zin niet doordrijven maar ook naar mij luisteren.

15. Hij onderneemt veel nieuwe dingen.

16. Hij heeft veel invloed op mij.

17. Ik heb veel invloed op hem.

18. Hij geeft mij het gevoel dat ik een waardevol iemand ben.

19. Hebt $u$ wel eens ruzie of onenigheid met hem.

Als wij ruzie of onenigheid hebben:

20 ga ik hem uit de weg.

21 gaan we er voor zitten om het uit te praten.

23 proberen wij een oplossing te vinden die voor allebei redelijk is. 


\section{Edinburgh Postnatal Depression list}

De volgende vragen hebben betrekking op hoe u zich de afgelopen 7 dagen heeft gevoeld. Kruis dat antwoord aan dat het beste aangeeft hoe u zich voelde.

1. Ik heb kunnen lachen en de zonnige kant van de dingen kunnen inzien:

1. zoveel als ik altijd kon.

2. niet zo veel nu als anders.

3. zeker niet zo veel nu als anders

4. helemaal niet.

2. Ik heb met plezier naar dingen uitgekeken:

1. zoals altijd of meer.

2. wat minder dan ik gewend was

3. absoluut minder dan ik gewend was

4. nauwelijks

3. Ik heb mij zelf onnodig verwijten gemaakt als er iets fout ging:

1. ja,heel vaak

2. ja,soms

3. niet erg vaak

4. nee,nooit

4. Ik ben bang of bezorgd geweest zonder dat er een aanleiding was:

1. nee,helemaal niet

2. nauwelijks

3. ja,soms

4. ja,zeer vaak

5. Ik reageerde schrikachtig of paniekerig zonder echte goede reden:

1. ja,tamelijk vaak

2. ja,soms

3. nee,niet vaak

4. nooit 
6. De dingen groeiden me boven het hoofd:

1. ja,meestal was ik er niet tegen opgewassen

2. ja;soms was ik minder goed tegen dingen opgewassen dan anders.

3. nee, meestal kon ik de dingen erg goed aan.

4. nee, ik kon alles even goed aan als anders.

7. Ik voelde me zo ongelukkig dat ik er bijna niet van kon slapen:
1. ja,meestal
2. ja,soms
3. niet vaak
4. helemaal niet.

8. Ilk voelde me somber en beroerd:
1. ja,bijna steeds
2. ja,tamelijk vaak
3. niet erg vaak
4. nee,helemaal niet

9. Ik was zo ongelukkig dat ik heb zitten huilen:
1. ja,heel vaak
2. ja,tamelijk vaak
3. alleen af en toe
4. nee,nooit

10. Ik heb er aan gedacht om mezelf iets aan te doen:
1. ja,tamelijk vaak
2. soms
3. nauwelijks
4. nooit 


\section{Parental-mother list}

Wilt u op een zespunt schaal antwoord geven op de volgende vragen:

1. mijn moeder was verdraagzaam naar mij toe.

2. ik had een sterke band met mijn moeder.

3. ik heb mij vaak afgewezen gevoeld door mijn moeder.

4. mijn vader was verdraagzaam naar mij toe.

5. ik had een sterke band met mijn vader.

6. ik heb mij vaak afgewezen gevoeld door mijn vader.

7. ik heb soms het gevoel gehad dat ik slecht werd behandeld.

8. ik heb me vaak misdeeld gevoeld.

9. ik ben vaak gestraft.

10. mijn gedrag of mijn uiterlijk werd vaak afgekeurd.

11. ik werd overbeschermd door mijn moeder/vader. 
176 


\section{Curriculum vitae}

Victor Pop werd op 1 maart 1955 geboren te Bandung, Indonesie. Na voltooing van de gymnasium opleiding aan het R.K. Lyceum/ Boschveldcollege te Venray in 1973, werd een begin gemaakt met de studie geneeskunde aan de Universite Catholique te Leuven, Belgiè. Na het eerste kandidaatsjaar werd de studie voortgezet aan de Katholieke Universiteit Leuven, waar op 30 juni 1980 het artsexamen werd afgelegd. $\mathrm{Na}$ de studie was hij als assistent werkzaam aan de afdeling inwendige geneeskunde in het St. Elisabeth Ziekenhuis te Tilburg (hoofd: dr.J. Lockefeer), de afdeling verloskunde en gynaecologie van het Liduina Ziekenhuis te Boxtel (hoofd: F. Plantema) en aan The Boston University School of Medicine, Hypertension Section (chief: Prof. H.P. Gavras, MD).

Sedert tien jaar is hij als huisarts werkzaam te Riethoven. 
178 


\section{Publications}

Rooy de HA en Pop VJ .: Postpartale thyreoiditis, een overzicht. Ned Tdschr Geneesk 1989;133:810-4.

Pop VJ et al.: Postpartum thyroid dysfunction and depression in an unselected population. N Engl J Med 1991;324:1815-16.

Pop VJ et al.: Clinical relevance of increased risk for postpartum thyroid dysfunction in MsAb positive women. submitted

Pop VJ et al.: A follow-up study into the relationship between thyroid dysfunction and depression. submitted

Pop VJ, Son van MJ, Komproe I.: The Kempen study I. Postpartum depression or is it post-puerperium depression? submitted

Son van MJ, Komproe I, Pop VJ.: The Kempen study II. Characteristics of postpartum depressed women. submitted 